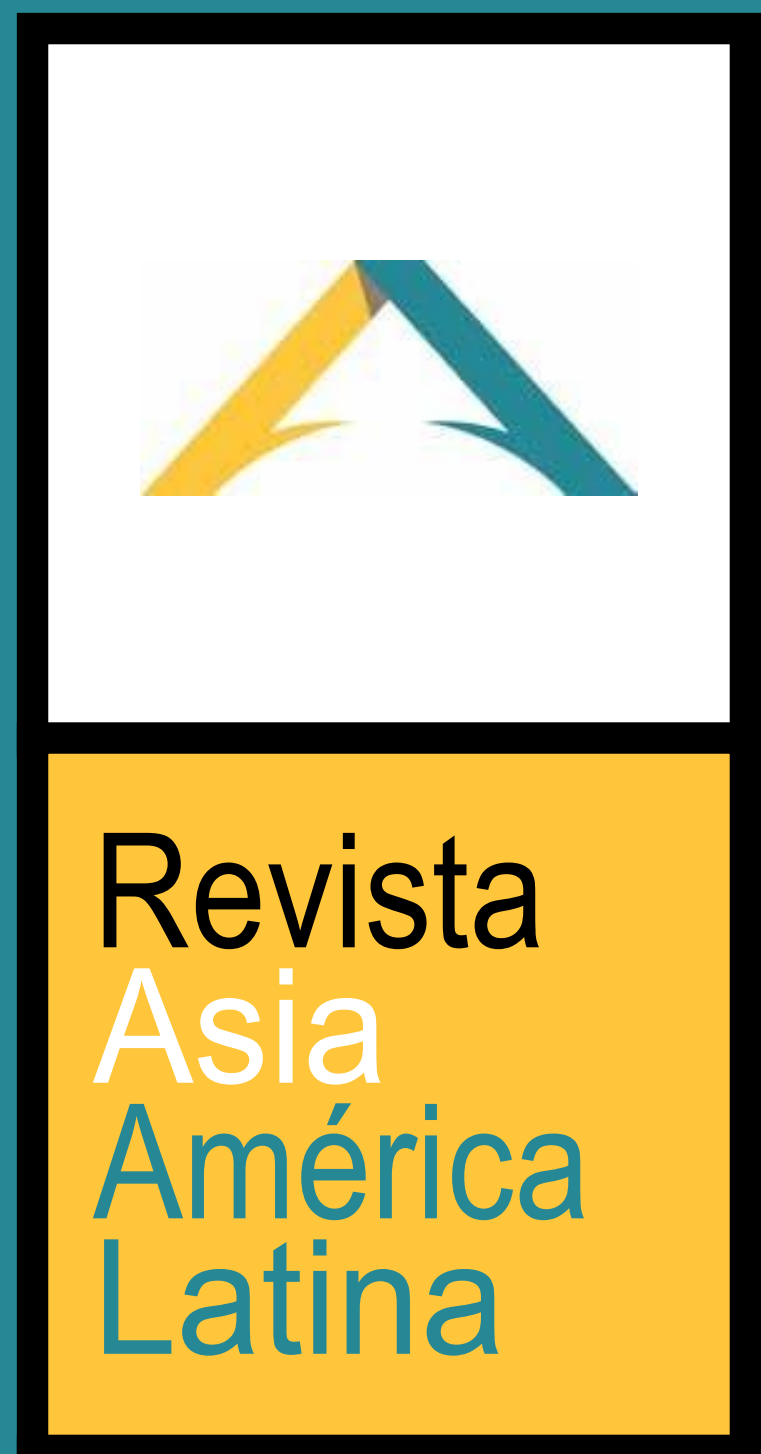

Año 6. Volumen 6. Número especial JUNIO 2021. Argentina

ISSN 2524-9347

Comité de ASEAN en Buenos Aires y

Grupo de Estudios sobre Asia y América Latina Instituto de Estudios de América Latina y el Caribe Universidad de Buenos Aires

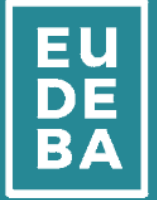

\section{Concurso de}

\section{Ensayos ASEAN}

FOREWORD / PRÓLOGO

S.E. Embajadora Niniek Kun Naryatie

INTRODUCCIÓN

Fernando Pedrosa y Ezequiel Ramoneda

\section{ENSAYOS}

THE ASEAN WAY ON THE INDO-PACIFIC

AMONG OTHER WAYS

Sebastián Sterzer

ANÁLISIS DE ASEAN COMO "COMUNIDAD DE

SEGURIDAD”. PERSPECTIVAS DESDE LA

CONSTRUCCIÓN INSTITUCIONAL

Bárbara Turner

REPENSAR LA GOBERNANZA FINANCIERA

GLOBAL DESDE LA ASEAN

Lola Ibáñez

UN CLIMA PARA EL CAMBIO.

OPORTUNIDADES Y DESAFIOOS PARA LA

ARTICULACIÓN INTERREGIONAL ASEAN-

MERCOSUR EN MATERIA DE CAMBIO

CLIMÁTICO

Diego Toledo

LAS DISPUTAS DEL MAR DE CHINA

MERIDIONAL: UNA OPORTUNIDAD PARA

FORTALECER A ASEAN

\section{Max Povse}

MERCOSUR-ASEAN: LAS RELACIONES

COMERCIALES ACTUALES Y LAS

OPORTUNIDADES DE NEGOCIO PARA EL

BLOQUE LATINOAMERICANO EN EL SECTOR

DE ALIMENTOS

\section{Soraia Danielle}

INTERVENIR O NO INTERVENIR: EL DESAFIOO DE CREAR UN SISTEMA REGIONAL DE DERECHOS HUMANOS EN LA ASEAN.

Alejandro Lamarque 
Grupo de Estudios sobre Asia y América Latina Instituto de Estudios de América Latina y el Caribe

\section{Director}

Dr. Fernando Pedrosa (Universidad de Buenos Aires)

\section{Secretario de Redacción}

Lic. Max Povse (Universidad de Buenos Aires)

\section{Editora de Reseñas}

Dra. Araceli Tinajero (The City College of New York)

\section{Equipo de edición}

Dr. Ariel Sribman (Universidad de Girona)

Lic. Alejandro Lamarque (Universidad de Buenos Aires)

Lic. Mariano Statello (Universidad de Buenos Aires)

Lic. Bárbara Turner (Facultad Latinoamericana de Ciencias Sociales)

\section{Comité Editorial}

Dr. Ignacio Bartesaghi (Universidad Católica de Uruguay)

Dr. Daniel Gomá (Universidad de Cantabria)

Dra. Nicole Jenne (Pontificia Universidad Católica de Chile)

Lic. Ezequiel Ramoneda (Universidad Nacional de La Plata)

\section{Consejo Académico}

Dr. David Doncel Abad (Universidad de Salamanca)

Dra. Mireya Sosa Abella (Universidad de Malasia)

Dra. Mercedes Botto (Facultad Latinoamericana de Ciencias Sociales)

Dr. Nicolás Comini (Universidad del Salvador)

Dra. Pasuree Luesakul (Universidad de Chulalongkorn)

Dr. Carlos Moneta (Universidad de Buenos Aires)

Dra. Zarina Othman (Universidad Nacional de Malasia)

Dra. Cristina Reigadas (Universidad de Buenos Aires)

Dra. Florencia Rubiolo (Universidad Nacional de Córdoba)

Dra. Leonor Seabra (Universidad de Macao)

Dr. Jaime Moreno Tejada (Universidad de Chulalongkorn)

Dr. Ignacio Tredici (Organización de las Naciones Unidas)

Dra. Wasana Wongsurawat (Universidad de Chulalongkorn)

Eudeba

Universidad de Buenos Aires

$1^{\circ}$ edición: junio 2016

(c) 2016

Editorial Universitaria de Buenos Aires

Sociedad de Economía Mixta

Av. Rivadavia 1571/73 (1033) Ciudad de Buenos Aires

Tel: 4383-8025 / Fax: 4383-2202

www.eudeba.com.ar 
Foreword / Prólogo

NINIEK KUN NARYATIE

\section{FOREWORD}

I am delighted to present the publication of selected essays from ASEAN Essay Contest held in 2019. The essay contest is one of the flagship programs of the ASEAN Committee in Buenos Aires (ACBA), aimed to engage students and academics on the issue of ASEAN. It has received high public enthusiasm, which can be seen from the number of essays submitted and variety of topics covered.

I observed that there are many interests on the political and security dimension of the ASEAN. Sebastian Sterzer, the winner in graduate category, wrote about the ASEAN Way on the Indo-Pacific. The runner up, Bárbara Turner, raised the issue of the Security Community of ASEAN, seen from the perspective of the institutional construction. While Max Povse discussed the South China Sea disputes as an opportunity to strengthen ASEAN.

Indeed, political and security dimension is one of the most discussed issues in ASEAN because the strategic geopolitical importance that it has in relation to the region.

We have witnessed shifts of geopolitical balance towards Asia in the last one or two decades. The economic growth of Asian countries brings about many opportunities and challenges. On one hand, economic growth opens many opportunities for cooperation to achieve greater prosperity, but on the other hand, we see the emergence of new economic and military might.

What is more, that ASEAN sits in the middle of the world's most important sea lines. It connects north and south, and east and west. Thus, a disunited region will bring crisis to the world.

Other topics which attract attention are economy and trade. Lusiana Ibañez, the winner of the student category, wrote about global financial governance from ASEAN, while Soraia Danielle discussed about ASEAN Mercosur trade and business opportunities in the food sector.

The discussion also very timely as the ASEAN has grown to become the fifth-largest economy in the world with a combined GDP of USD 2,9 trillion. ASEAN has also stepped further to integrate its economy with the region by adopting the Regional Comprehensive Economic Partnership (RCEP). Signed last year by 15 Asia-Pacific countries, it shows the commitment of ASEAN towards global economic recovery. It opens market access to around one third of global economy and two billion consumers, including 600 million population in ASEAN.

Furthermore, I also see discussion on the challenge of creating ASEAN system of human rights in Alejandro Lamarque's essay, and about ASEAN Mercosur climate change interregional articulation in Diego Toledo's essay. These will surely bring diversity on the topics covered in this publication. 
In this opportunity, I would like to commend all the writers for their intellectual contributions, and to the juries - Prof. Ezequiel Ramoneda, Prof. Fernando Pedrosa and Prof. Ignacio Bartesaghi - for the excellent work in assessing and evaluating all the essays submitted.

Finally, I want to extend my appreciation to my colleagues, other Ambassadors of ASEAN in Buenos Aires - Malaysia, Philippines, Thailand, Vietnam - for making the essay contest and its publication materialized. The essays will help readers understand more about ASEAN, but with unique South American perspective.

\section{Niniek Kun Naryatie}

Ambassador of the Republic of Indonesia

for Argentina, Paraguay, and Uruguay /

Chair of the ASEAN Committee in Buenos Aires (2021) 
Foreword / Prólogo

NINIEK KUN NARYATIE

\section{PRÓLOGO}

Tengo el agrado de presentar la publicación de los ensayos seleccionados en el Concurso de Ensayos ASEAN de 2019. El concurso de ensayos es uno de los programas insignia del Comité de la ASEAN en Buenos Aires (ACBA por sus siglas en inglés), orientado a involucrar a estudiantes y académicos en la temática de la ASEAN. Este ha recibido una importante respuesta pública, como puede observarse en los múltiples ensayos presentados y en la variedad de los temas abordados.

Pude ver que hay mucho interés en la dimensión política y securitaria de la ASEAN. Sebastián Sterzer, ganador en la categoría graduados, escribió sobre el $A S E A N W$ ay en el Indo-pacífico. En el segundo lugar, Bárbara Turner planteó la cuestión de la Comunidad de Seguridad de la ASEAN visto desde la perspectiva de la construcción institucional. Mientras que Max Povse evaluó las disputas sobre el Mar de China Meridional como una oportunidad para fortalecer a la ASEAN.

Efectivamente, la dimensión política y securitaria es una de las cuestiones más discutidas de la ASEAN dada su importancia geopolítica estratégica en relación con la región.

Hemos presenciado movimientos en el equilibrio geopolítico hacia Asia en las últimas dos décadas. El crecimiento económico de los países asiáticos conlleva muchas oportunidades y desafíos. Por una parte, el crecimiento económico habilita oportunidades de cooperación para alcanzar mayor prosperidad, pero, por otra parte, observamos el surgimiento de nuevo poderío económico y militar. Es más, la ASEAN se encuentra en el medio de las vías marítimas más importantes del mundo. Conecta al norte con el sur y al este con el oeste. En consecuencia, una región desunida traerá crisis al mundo.

Otros temas que demandan atención son la economía y el comercio. Lusiana Ibañez, ganadora de la categoría estudiantes, escribió sobre gobernanza financiera global desde la ASEAN, mientras que Soraia Danielle analizó oportunidades de comercio y negocios ASEAN-Mercosur en el sector alimenticio.

La discusión es también muy oportuna en tanto la ASEAN se ha convertido en la quinta economía más grande del mundo con un PIB de USD 2,9 trillones. La ASEAN también ha avanzado en integrar su economía con la región al aceptar la Asociación Económica Regional Integral (RCEP por sus siglas en inglés). Firmada el año anterior por 15 países del Asia-Pacífico, esta demuestra el compromiso de la ASEAN con la recuperación económica global. Esta abre acceso a los mercados de un tercio de la economía global y a dos mil millones de consumidores, incluyendo la población de 600 millones de la ASEAN. 
Asimismo, también veo debates sobre los desafíos de crear un sistema ASEAN de derechos humanos en el ensayo de Alejandro Lamarque, y sobre la articulación interregional ASEAN-Mercosur en materia de cambio climático en el ensayo de Diego Toledo. Estos sin duda brindarán diversidad a los temas abordados en esta publicación.

En esta oportunidad, quisiera felicitar a todos los ganadores por sus contribuciones intelectuales y también a los jurados —Prof. Ezequiel Ramoneda, Prof. Fernando Pedrosa y el Prof. Ignacio Bartesaghi- por el excelente trabajo al analizar y evaluar todos los ensayos presentados.

Finalmente, quiero expresar mi gratitud hacia mis colegas embajadores de la ASEAN en Buenos Aires - Malasia, Filipinas, Tailandia, Vietnam- por hacer del concurso de ensayos y su publicación una realidad. Los ensayos ayudarán a los lectores a entender más sobre la ASEAN, pero con una perspectiva sudamericana única.

\section{Niniek Kun Naryatie}

Embajadora de la República de Indonesia en Argentina, Paraguay y Uruguay /

Presidente del Comité de la ASEAN en Buenos Aires (2021) 


\section{INTRODUCCIÓN}

\section{Fernando Pedrosa}

Universidad de Buenos Aires

\section{Ezequiel Ramoneda}

Universidad Nacional de la Plata

Esta edición especial de la Revista Asia/AméricaLatina está dirigida a ofrecer una serie de artículos que versan sobre la Asociación de Naciones del Sudeste Asiático, conocida en inglés como Association of Southeast Asian Nations, o por sus siglas: ASEAN. La ASEAN es una organización regional integrada por diez países del llamado Sudeste Asiático: Brunéi, Camboya, Filipinas, Indonesia, Laos, Malasia, Myanmar, Singapur, Tailandia y Vietnam.

Este número especial tiene varias motivaciones. En primer lugar, porque el proceso de integración regional que inauguró ASEAN, de algún modo, parece colocarse como modelo en momentos en que otros intentos, algunos menos exitosos que otros, no parecen mostrar signos de vitalidad o de renovación en la actualidad. En segundo lugar, porque los artículos que se presentan son productos de una actividad impulsada por las representaciones diplomáticas de ASEAN en Argentina, concurrente con Uruguay y Paraguay, con el apoyo de instituciones académicas de renombre de los mencionados países sudamericanos. Y, por último, porque darle esta forma es uno de los objetivos por los cuales nació la Revista Asia/ América Latina.

\section{La importancia del modelo ASEAN}

La temática de la integración regional es un aspecto clave de la política del Sudeste Asiático, pero, además, también lo es para América Latina, aunque por motivos diferentes. Pensar, evaluar, mostrar y comparar la ASEAN con ojos del Mercosur y de América Latina -y en esa tarea unir a Asia y a América Latinaes el motivo que da vida a esta revista.

En este punto hay experiencias y cuestiones que abordar con interés especial. Hay experiencias en común de los países de ambos bloques que se pueden identificar en las últimas décadas, como: pertenecer al otrora llamado Tercer Mundo (hoy Sur Global); los procesos de democratización a mediados de la década de 1980; los intereses compartidos en cierto grado por ser economías exportadoras de agroalimentos; las crisis socioeconómicas a partir de la implementación de políticas neoliberales a fines de la década de 1990; las 
reacciones antioccidentales en pos de una mayor autonomía regional; entre otros aspectos. Pero también se pueden destacar diferencias.

El Mercosur, pesar de sus aspectos en común, como sus idiomas de raíz latina, su creencia cristiana de tradición católica y sus formas de gobierno republicanas presidencialistas, luego de transitar caminos irregulares con sucesivos momentos de entusiasmo -y también de abatimiento-, parece enfrentarse en la actualidad con los límites que le imponen los pobres resultados obtenidos. Hay una serie de causas diversas que explican esto, pero entre ellas, podemos mencionar la falta de una estrategia compartida y un proyecto común que justifique $-\mathrm{y}$ sostenga- su existencia en el largo plazo.

Por su parte, la ASEAN recorrió otro camino y, aunque parezca de Perogrullo, por eso también obtuvo otros resultados. Es preciso mencionar que no estuvo movido por un nacionalismo supranacional producto de un pasado colonial común, y tampoco se puso objetivos que no pudiera alcanzar. El pragmatismo y el consenso fueron la norma, lo cual resultó casi una estrategia de supervivencia, tomando en cuenta que la heterogeneidad es la característica principal entre los diez países que integran la Asociación; una heterogeneidad no solo social y lingüística, sino también política y religiosa.

La estrategia de la ASEAN no pudo ser más diferente a la del Mercosur, y también a otros modelos, sobre todo al que durante mucho tiempo fue el caso canónico: la Unión Europea. La ASEAN eludió las grandes burocracias, los parlamentos, las normas legales de estricto cumplimiento y las monedas comunes. Por el contrario, se planificó un proceso en el que sus componentes pudieran viajar ligeros, y el paso del tiempo y el cumplimiento sistemático de pequeños compromisos políticos fueran asfaltando con confianza un espacio de integración que, a diferencia del Mercosur, en sus inicios, tenía todas las posibilidades de fracasar.

Pero la ASEAN no fracasó. No solo eso, sino que además los países que lo integran lograron convertirse en los impulsores del tratado de libre comercio más grande del mundo, el Acuerdo de Asociación Económica Integral Regional (en inglés Regional Comprehensive Economic Partnership, conocido por sus siglas RCEP), que además de los diez miembros de la Asociación, agrupó nada menos que a China, Japón, Corea del Sur, Australia y Nueva Zelanda. Todos ellos juntos representan casi el 30\% del Producto Interno Bruto mundial, y suman aproximadamente casi un tercio del total de la población mundial.

La ASEAN no solo marcó un camino poco estudiado por los estudios de la integración que siguieron viendo en la Unión Europa el ejemplo modélico, sino que además influyó para que la RCEP adoptara algunas de sus señas de identidad, aquellas que permiten integrar países tan disímiles apostando al largo plazo, a la paciencia, y al mismo tiempo que se pone en claro que el futuro económico, comercial y financiero del mundo pasará por la región. El motor del 
crecimiento económico mundial no se encuentra más en el Atlántico, sino que se ha trasladado al Pacífico, con un pujante núcleo asiático.

Por ello nos pareció importante acercar estas reflexiones que, con ojos latinoamericanos, se acercaron al fenómeno de la ASEAN desde diversas perspectivas, y nos ofrecen hoy la posibilidad de pensarlo tanto en su propio devenir, como para repensar con una perspectiva fresca nuestro propio lugar en el mundo en tanto América Latina.

\section{E1 Concurso de Ensayos}

El Concurso de Ensayos sobre ASEAN es una iniciativa de las Embajadas que son miembros del Comité de la ASEAN en Buenos Aires (en inglés, ASEAN Committee in Buenos Aires, conocido por sus siglas ACBA), a saber, la República de Filipinas, la República de Indonesia, Malasia, el Reino de Tailandia, y la República Socialista de Vietnam.

La primera edición se organizó en 2013, seguida por una nueva edición el año siguiente. Finalmente, la tercera y última edición se organizó entre los años 2019 y 2020. Las embajadas del ACBA fueron acompañadas por instituciones académicas colaboradoras de Argentina y Uruguay: entre muchas otras, el Grupo de Estudios sobre Asia y América Latina (GESAAL) del Instituto de Estudios de América Latina y el Caribe (IELAC) de la Facultad de Ciencias Sociales de la Universidad de Buenos Aires (UBA), el Centro de Estudios del Sudeste Asiático (CESEA) del Departamento de Asia y el Pacífico (DAYP) del Instituto de Relaciones Internacionales (IRI) de la Universidad Nacional de la Plata (UNLP), y la Cátedra Mercosur-ASEAN del Departamento de Negocios Internacionales e Integración (DNII) de la Facultad Ciencias Empresariales de la Universidad Católica de Uruguay (UCU), cuyos representantes Fernando Pedrosa, Ezequiel Ramoneda e Ignacio Bartesaghi respectivamente, oficiaron de jurados en el Concurso. La actividad contó además con el apoyo de la Sección Argentina de la Asociación Latinoamericana de Estudios de Asia y África (ALADAA).

La convocatoria estuvo destinada a estudiantes de grado y académicos graduados, a fin de incentivar el desarrollo de análisis e investigaciones académicas para profundizar el conocimiento sobre la ASEAN. Los temas de los ensayos debían enfocarse en los países de la ASEAN como un bloque, las dinámicas y desarrollos políticos, económicos, socioculturales y religiosos como parte del bloque, o sus relaciones con el Mercosur y sus países miembros, especialmente la República Argentina, la República Oriental del Uruguay, y la República del Paraguay. El ensayo debía ser inédito y original, habría diversas categorías según el desarrollo de las carreras profesionales de los participantes, desde los estudios en relaciones internacionales hasta los análisis de comercio 
exterior, pasando por cuestiones de cooperación técnica, y la situación de los derechos humanos.

Se recibieron alrededor de quince trabajos, provenientes de diversas ciudades de Argentina y Uruguay, como Buenos Aires, Rosario, Córdoba, Tucumán, Montevideo, por mencionar las principales. Luego de la evaluación del jurado, se eligieron a los ganadores, quienes fueron, en la categoría de graduados, Sebastián Sterzer (primer premio) y Bárbara Turner (segundo premio). En la categoría de estudiantes, fueron Lola Ibañez (primer premio) y Diego Toledo (segundo premio). Además, hubo tres menciones especiales del jurado otorgadas a Max Povse, Soraia Danielle, y Alejandro Lamarque. Todos sus ensayos se encuentran en este número especial.

\section{El número especial de Asia/América Latina}

Para la Revista Asia/América Latina resulta muy importante este número, no solo porque se suma a los otros diez que ya regularmente llevamos editados en los últimos cinco años. Tampoco solo por lo dicho en los párrafos anteriores, es decir, la trascendencia del objeto al que se dedica, la ASEAN, que ya de por sí misma amerita especial atención. Sino más bien porque es el resultado de un continuo trabajo interinstitucional que permite fomentar el diálogo con colegas argentinos y de otros países, lo que es la base para la existencia y la continuidad de una comunidad académica sólida. La formación de estas redes ha sido el motivo primero por el cual se creó la Revista.

Pero, en esta ocasión, sobre todo, debe mencionarse un aspecto crucial de esta edición especial de Asia/América Latina: es fruto de una constante y productiva relación con las embajadas de los países de la ASEAN que están representados en Argentina. Las redes y la formación de una comunidad de interés y de producción académica latinoamericana sobre Asia no estarían completa si no lograra incluirse a contactos, nodos y recursos provenientes de la región que pretendemos estudiar.

En este punto, la Revista se ha vuelto una plataforma para relacionar investigadores de sendas regiones, y para avanzar en el conocimiento mutuo con instituciones del Sudeste Asiático. La tarea de las embajadas asiáticas en esta cuestión ha sido muy importante para nosotros, y aprovechamos este espacio para agradecerles.

La convocatoria para escribir (y pensar) sobre ASEAN desde nuestra región no puede ser más oportuna, más cuando se ha planteado el interés de avanzar en negociaciones de acuerdos comerciales para mejorar los flujos de intercambio de bienes y servicios entre el Mercosur y varios países de la región, y cuando se están explorando nuevas iniciativas para profundizar la cooperación producto de la adhesión de países sudamericanos al Tratado de Amistad y Cooperación de la ASEAN. Todavía más, esto último se produce en el marco 
de ausencias llamativas de debates y de espacios institucionales que apunten y estimulen a estudiar sistemáticamente otras experiencias de organización social, en este caso de integración regional. La falta de interés en otros espacios del planeta -y de la importancia de Asia- también ocurre a causa de una repetida carencia a la hora de pensar y explorar otros caminos, diferentes a los que nos llevaron a andar en círculos una y otra vez.

Los trabajos seleccionados en el concurso han pasado por una nueva etapa de conversión en artículos académicos, para lo cual han sido evaluados en su contenido y editados en las formalidades. Esa tarea le suma un mayor valor a textos que ya venían revisados y premiados. Por esta tarea es que también queremos agradecer a los evaluadores y a los autores.

Los artículos que aquí se presentan, realizados por investigadores jóvenes, pero con trayectoria en el trabajo académico, ofrecen una serie de enfoques diversos que, en su conjunto, comienzan a mostrar una intención de trabajo sistemático sobre el tema, que se extiende crecientemente entre investigadores y docentes conscientes de su importancia, y de todo lo que ignoramos todavía al respecto.

Este interés que el Grupo de Estudios sobre Asia y América Latina viene estimulando y reuniendo en la Universidad de Buenos Aires, abriendo las puertas a que las instituciones de educación superior retomen este creciente interés, y a que los estudios asiáticos superen la predominante sinología que los caracteriza actualmente.

El Sudeste Asiático es una zona de alta trascendencia para el mundo en que vivimos, no solo por su cercanía con China e India o por ser el escenario marítimo de una de las disputas geopolíticas más calientes de la actualidad. También es el corazón de la RCEP, sus economías son parte de los eslabonamientos industriales de más avanzada, es una zona con países megadiversos, con un pluralismo étnico asombroso, y con estrategias de desarrollo que deben llamarnos la atención. Aún más para nuestro país y otros de la región, cuyas economías están fuertemente vinculadas con el comercio con esta región, y por lo tanto debería ser lógico que estén interesados en los acontecimientos que allí suceden.

Estamos viviendo el siglo de Asia, y nuestra tarea desde una América Latina hoy en crisis hoy -y casi siempre marginal en la política mundial-, es saber más sobre ella, sobre las personas que allí viven, sus ideas, sus distintas tradiciones, y sus formas de organización y producción. Este es un nuevo aporte a esa tarea. 
ENSAYOS 


\section{THE ASEAN WAY ON THE INDO-PACIFIC AMONG OTHER WAYS}

\section{Sebastián Sterzer}

sterzersebastian@gmail.com

Universidad Nacional de Luján

\section{Introduction}

The Association of Southeast Asian Nations (ASEAN) has been one of the successful cases in terms of regional integration. Since its establishment in 1967, it has had numerous issues to address, from the threat of Communism in the region, regional incidents among member countries, the problem with China regarding the claims of Vietnam, Philippines for the sovereignty of the islands, among others.

ASEAN, likewise, is not alone in its regional integration, since it has signed or is in the process of negotiation, several agreements of an economic nature, especially. From the Free Trade Agreements with China to ASEAN + 6 (ASEAN, China, Japan, South Korea, India, Australia, and New Zealand), as well as the current Regional Comprehensive Economic Partnership (RCEP). Then, the ten countries that makeup ASEAN (Indonesia, Malaysia, Thailand, Singapore, Philippines, Brunei Darussalam, Vietnam, Cambodia, Laos, and Myanmar) have been involved in an attractive international relations dynamic to analyze.

However, a few years ago, a concept has emerged that falls within a broader framework, which confronts large countries. That concept is called Indo-Pacific. Meanwhile, the big countries that are currently confronted in a dispute that hangs over various aspects (geopolitics, military strategy, technology, bilateral trade) are the United States and China.

So, both the United States (and its allies) and China have developed major strategies to have greater competitiveness in the region. ASEAN, being involved in the area from a geographical issue, has not been able to avoid being left out, as it was necessary to have a position, mainly, as a regional bloc. Of course, not all its members have had the same interests, nor have they demonstrated the same dynamic. However, this year ASEAN has ruled on the Indo-Pacific, as it is on this concept that alliances between countries are drawing up as well as political-economic strategies that, whatever their degree, impact on the population. For this reason, this monograph tries to address the position of ASEAN for the other actors, concerning the Indo-Pacific, trying to elucidate what may happen in the future. 
II. ASEAN outlook on the Indo-Pacific: why was that necessary?

Currently, we are witnessing geopolitical challenges and related to this, and there is a concept generating controversy: "Indo-Pacific". When we think about Indo-Pacific, then we realize that is another concept -quite differentfrom the Asia-Pacific. Like the Asia Pacific, or Asia itself, the Indo-Pacific is a tactic for governments to set up the international situation to match their policy goals conditions. But the number of countries that find it a valuable way of understanding the world is increasing. And why is this happening? Because of the importance of this region: it includes the energy supplies, production chains, infrastructure and security networks that connect the Middle East, West Asia, and East Asia. It additionally contains US security and economic relationships throughout the Pacific. Even for Australia, the idea of the IndoPacific works well. Looking to the past, Australia's security, trade, and communications all rolled back through the Indian Ocean to Britain via the British Empire's own 'string of pearls' in Singapore, Colombo, Bombay, Aden and the Suez Canal.

In this context, more countries are participating in the Indo-Pacific, such as India. Historically, the US has been looking for any reason to be present in the Asian scenario. So, with Indo-Pacific in trend, they can be active in their purposes. Let us say it is another reason to fight with China. The IndoPacific region is fascinating if we consider which countries are involved in: it contains significant powers in world politics such as China, US, Japan, India, Russia, Australia, and the ASEAN member states. For ASEAN itself, except Laos, the other nine ASEAN members have maritime resources.

Subsequently, as ASEAN states are in the Indo-Pacific neighbourhood, they can take part in the discussion.

Indo-Pacific, which implies to the region across the Indian as well as Pacific Oceans, has had its initial progress from a long time ago. But Gurpreet Singh Khurana claimed that he was the first one presenting the vocabulary on academic dissertations through his work entitled "Security of Sealines: Prospects for India-Japan Cooperation" in 2007. By the other way, Japanese Prime Minister Shinzo Abe is considering as the first world leader who took up the notion as a cooperative context when he was talking to the Indian parliament in 2007, referring to countries around Asia, Africa, Pacific, as well as Indian Oceans. Those proposals of using the word of 'Indo-Pacific' get more interest with the increase of China through One Belt One Road (OBOR), and then colliding with the US and its allies' interests around the region (Yunanto y Samhudi, 2019). So, the concept of the Indo-Pacific as a regional one is not new to link the Indian and Pacific Oceans, even recognizing at the same time the role of India and Indonesia in any strategic geographical 
interpretation. But the Indo-Pacific concept was "alive" with the US Trump administration's acceptance of it.

Considering this, what is the situation with ASEAN countries? These countries, while belonging to the Association of Southeast Asian Nations (ASEAN), they do not act with the same energy. For example, for Indonesia, this concept of Indo-Pacific has been imported from some time ago. In other words, they were leading and sharing their vision about it.

After some meetings and summits (more than a year of deliberation), ASEAN issued its 'Outlook on the Indo-Pacific' in 34 ASEAN Summit on 23 June 2019 in Bangkok, Thailand. The critical fact is ASEAN members tried to react against the US, India, Japan, and Australia, with its interest in the Indian and the Pacific Ocean. Because they are locating between them, they cannot be out of the game. Now, is the moment to act and react. However, for these Southeast Asian countries, the role in this game is not about a zero-sum game basis, but win-to-win cooperation. So, the confrontation between US' view with China's one is not the way ASEAN want to follow. What is important, anyway, all ASEAN members are committing with this ASEAN view? Or maybe some of them would like to support the significant powers' vision? Think about, for example, historical ties of the Philippines and Thailand with the US, and Cambodia with China. Because of that, there could be such coordination problems if members of this bloc cannot reach agreement on what is the best way or option, even when it is affecting their interest to do so. Before the ASEAN Outlook was released, some Filipino analysts supported the US, because it "presents an opportunity for the Philippines to be part of a loose coalition of states that are willing and able to counter unilateral Chinese behaviour in the SCS [South China Sea] (...)" (Vicedo, 2018, parr. 4). Among other things, because during the 2017 Philippine-US Bilateral Strategic Dialogue, both countries announced their commitment to 'support freedom of navigation and overflight' in the South China Sea. However, the Philippines understands that, while their alliance with the US continue unbroken, at the same time, they foster closer economic ties with Beijing. In the case of Vietnam, they are exploring stronger maritime security and defence industry cooperation with the United States as well as the Vietnam-Japan Joint Vision Statement on Defence Relations and the promotion of Vietnam-Australia security relations into a strategic partnership. For the US, it is essential to note that Vietnam will lead the Chairman at ASEAN from 2020. During the "Meridian Diplomacy Forum: Countries of the Mekong" held in Washington last June, prominent US diplomats had highlighted the importance of Ha Noi for their country. The five states in the Greater Mekong Subregion (GMS), namely Cambodia, Laos, Myanmar, Thailand, and Vietnam are also in the Lower Mekong Initiative (LMI), an Association promoted with the US in 2009 to create integral subregional cooperation. Even that, US diplomats recognize and understand 
ASEAN state members do not want to choose either US or China.

Anyway, the 'Outlook on the Indo-Pacific' focus on 1) maritime cooperation, 2) connectivity, 3) meeting UN sustainable development goals, and 4) economic and technical cooperation. These areas are modern thinking paths to reach peace and prosperity. And this is important to realize, because "ASEAN is no longer the small collection of conservatives, developing, anti-communist, authoritarian states of the Cold War that made consensus easier to forge. Its current members have a range of economic needs, political systems, and strategic considerations" (Ja Ian Chong, 2019, parr. 8). ASEAN identifies the security-economic connections in the current regional contestation. At the same time, they focus on practical economic-development cooperation.

The problems arise when there are different understandings about what Indo-Pacific means for all countries involved. Let us take the example for the United States: two years ago, in its annual National Security Paper, they emphasized that Indo-Pacific region covers from the west coast of India to the western shores of the US. It is broader than Asia-Pacific meaning. Along with Australia, Japan, and India -the "Quad"- they talk about the idea of a "free and open Indo-Pacific". But that is a direct message against China because they see it as a treat to the "rules-based international order" as promoted by the US. The strategy is balancing as China is like the directed revisionist state to the status quo. ASEAN needed to issue about this. In this year, France revealed its Indo-Pacific policy in May 2019, followed by the United States with its updated 'Indo-Pacific Strategy Report' agreeing with US Acting Defense Secretary Patrick Shanahan's speech at the 2019 Shangri-La Dialogue in June.

What is the point for ASEAN? Even though they accept the term "Indo-Pacific", it does not mean that they share the US' vision at all. They do not want to play for any of the major powers. ASEAN also do not want to play for China's game. But ASEAN cannot deny the importance of China for them: for example, considering China is a member of existing regional infrastructure such as the East Asian Summit and the ASEAN Regional Forum (ARF). Apart from these, it is also noting that exist others ASEAN-led mechanisms like the ASEAN Defense Ministers Meeting Plus (ADMM-Plus), the Expanded ASEAN Maritime Forum (EAMF) and the relevant ASEAN Plus One mechanisms.

One point of differentiation between the US and ASEAN views are about the concept of 'freedom'. If one reads the ASEAN Outlook, there is no such explanation about what freedom means. Anyway, one could understand it as linked with the principle of non- intervention, respect for sovereignty, and equality. Looking at the US' view, 'freedom' means freedom to exercise independence as well as freedom from coercion. But, after that, for ASEAN 'freedom' is more about the inter-state relations, based on the international treaties. For the US, it is related to international relations too, but also the 
domestic governance, including the Human Rights.

Now, even is true that there are some worries about China and its ambitious plan in the region, and more concerns when we refer to the South China Sea tensions, even that the relationship between China and Southeast Asia has continued solid. Among other reasons, because China is the ASEAN's top trading partner, the geographical closeness and, significant, the historical/cultural links. So, it is doubtful that ASEAN would decline its cooperation with China (Kamaruddin, 2019). The stable economic development and international trade in China are two fascinating reasons for ASEAN to maintain good relations with them.

Within this context, regional analysts have enthusiastically supported the ASEAN Outlook on the Indo-Pacific. Notwithstanding, they see this as an ASEAN's "act of diplomatic and political assertion" and a "stand against great power rivalry" (Laksmana, 2019, parr. 3). For others, the ASEAN Outlook "is in many aspects the same old wine in a newly packaged bottle." (Hoang Thi Ha, 2019, p. 2).

Issuing a document is not an easy task for ASEAN when we think about China and the US as the big players and confronting with each other. For one side, and under Xi Jinping's rule, China will continue its hegemonic performance as its Belt and Road Initiative (BRI) pursues to offer an alternative regional order. Even Beijing has not been working with the IndoPacific terminology, and one could consider the maritime part of 'Belt and Road Initiative' as "Indo-Pacific with Chinese traits". The engagement of China by introducing BRI, has provoked several different reactions, notably from ASEAN and the US, which is manifesting variations of the Indo-Pacific cooperative agenda. For the other side, the incredible volatility of the Trump administration, including its destructive trade war, has deteriorated the scepticism over Washington's and its plan in the region. So, there is a question ASEAN analyst could do: with this panorama, and if ASEAN is looking for keeping its centrality, are existing mechanisms like the East Asia Summit and the ASEAN Regional Forum enough to contain it?

ASEAN is not looking to replace its existing mechanisms. Still, it is proposing to reestablish ASEAN's agenda of priorities for regional multilateral cooperation.

As the ASEAN Outlook emphasizes on ASEAN community-building and centrality, ASEAN member states decide to stay on ASEAN's view, and not to choose any significant power. So, its member states do not go towards one significant power's plan more than another. Then, by confirming ASEAN's "open door" policy with all partners and countries, they sustain their energies to promote the multi-polarity in the region.

Improving the regional connectivity with institutions like the Indian Ocean Rim Association (IORA), the Bay of Bengal Initiative for Multi-Sectoral 
Technical and Economic Cooperation (BIMSTEC), the Mekong subregional cooperation with ASEAN-led mechanisms could offer a clearer vision for better strategies for ASEAN.

Also, institutionalizing the East Asia Summit (for example, as being renamed the "Indo- Pacific Summit", with a permanent secretariat to reach institutional backing and weight) (Laksmana, 2019). Some authors say that ASEAN should propose the creation of the Master Plan on Indo-Pacific Connectivity (MPIC) - an extension of the Master Plan on ASEAN Connectivity (MPAC). Thus, promoting complementarity, synergy and prevention of overlap and contest in the region (Thepchatree, 2019).

What could happen if ASEAN could also try to help in the region in ways like the former Indonesian Foreign Minister Marty Natalegawa's idea of an "Indo-Pacific Treaty" as well? According to with some analysts, the ASEAN Outlook on the Indo- Pacific is the first step in endorsing "ASEAN centrality'; however, critics appear because the document lays out general principles but not concrete measures for cooperation. Referring to Indonesia, why is it worried about Indo-Pacific? Because it does not like the US' vision of isolating China. Even, they see US' allies as outside powers without ASEAN's participation. So, Indonesia was developing a new, different strategy coherent with ASEAN's principles such as consensus-building, diplomatic and political approach -not to focus so much on military strategy-. Indonesia has been leading the push for ASEAN to declare its vision for the Indo-Pacific: its proposal was being public at a gathering of ASEAN foreign ministers in January 2018. It wants an Indo-Pacific "regional architecture" similar to ASEAN's "ecosystem of peace, stability, and prosperity", which would draw on ASEAN-led mechanisms and based on the principles of inclusion, confidence building and international law. It outlooks the Asia- Pacific and the Indian Ocean regions as tightly integrated and interconnected, describing them as a single geostrategic place. When Indonesia fixes its relations with excellent power relations, it chooses "pragmatic equidistance", that means maintaining strategic autonomy by engaging one high power in cooperation without losing its relationship with another. But, outside of ASEAN, Indonesia does not have enough capacity for geopolitics (Laksmana, 2018).

Some Western analysts critic ASEAN's Outlook because it does not mention China as the target to fight. I agree with someone who can say what happens because it is the way how ASEAN has been doing its business since its establishment in 1967. Therefore, ASEAN destined to disappoint those who would like to find it behave like a high-power fighting with others (Acharya, 2019).

So, ASEAN as a bloc is looking for cooperation, but not competition. The Bangkok Summit underscored improvement in upgrading ASEAN infrastructure projects and highlighted the significance of boosting the 
integration of these infrastructure projects with other countries' ones under the slogan 'connecting the connectivities'. As mentioned before, there are several areas of possible collaboration, but issues like maritime security and connectivity are vital. There are many infrastructure projects in the IndoPacific: ASEAN has the Master Plan on ASEAN Connectivity (MPAC), China has the Belt and Road Initiative (BRI), while Japan, India and the United States are developing their regional infrastructure projects. Regionally, ASEAN could use active mechanisms within the Mekong subregional cooperation structures at a time when China and Japan are contesting with each other to influence in the Mekong. In terms of maritime cooperation in the Indian Ocean region, ASEAN and IORA could work together in exchanging their own experiences in regional collaboration (Hussain, 2019).

The ASEAN Outlook does not want to see the Asia-Pacific and the Indian Ocean as a single geographic structure. Why? Because of the vast diversity in the territories, peoples and their histories, the socio-cultural patterns and international relations are circulating throughout the two oceans. As an Alternative, the ASEAN Outlook views the conjunction between the Asia-Pacific and the Indian Ocean regions from two viewpoints: 1) an area of vibrant economic integration and connectivity, and 2) a unified maritime space. The emphasis on Indo-Pacific concept as an economic and connectivity-linked one (and not related to the military-security one) supports to introduce a neutral and inoffensive ASEAN Indo-Pacific outlook - one that not intended to confront or contain any other country or bloc-. Project performed by ASEAN is believed a hedging tactic to the contestation of power in the region between China and the US. This idea is meant mainly for China because Beijing considers that the Indo-Pacific strategy targeted to limit China's rise.

The ASEAN Outlook development-focused concept has something of the influence of Indonesia's pragmatist foreign policy under the Jokowi administration. Hoang Thi Ha brings refer to this as follow:

A good metaphor of this pragmatism is the coconut deal that sells Indonesian coconuts in Aceh to India's Andaman and Nicobar Islands at low costs thanks to geographic proximity between the islands. Dr Siswo Pramono from the Indonesian Ministry of Foreign Affairs saw this deal as a concrete manifestation of the ASEAN Indo-Pacific outlook: 'This is the Indo-Pacific concept that we mean. It is directly felt by the people. It is not about who wants to contain whom'. (Hoang Thi Ha, 2019)

ASEAN Outlook on the Indo-Pacific is looking to provide the preservation of peace, freedom, and prosperity. ASEAN Outlook on the IndoPacific follows these principles: ASEAN Centrality, openness, transparency, 
and inclusivity. Also, a rules-based framework, good governance, respect for sovereignty, non-intervention, and respect for international law. These laws are coming from UN Charter, the 1982 UN Convention on the Law of the Sea, and other relevant UN treaties and conventions, the ASEAN Charter and various ASEAN treaties (like the ASEAN Economic Community Blueprint, ASEAN Political-Security Community Blueprint, and ASEAN Socio-Cultural Blueprint) and agreements and the EAS Principles for Mutually Beneficial Relations (2011) (Association of Southeast Asian Nations, 2019). In the long run, the ASEAN's vision is the most inclusive yet and signifies an effective option that can stabilize the regional balance of power. For example, if ASEAN could institutionalize the EAS (Laksmana, 2018). So far, there is a substantial agreement that the East Asia Summit is the best stage to talk about the Indo-Pacific. Since 2005, the EAS has been the only site for ASEAN leaders to discuss strategic affairs with their partners from the US, China, Russia, Japan, South Korea, India, Australia, and New Zealand (Chongkittavorn, 2018).

If analyzing the ASEAN Outlook by itself is not good enough, then it is more interesting to compare it with those coming from China, India, and the United States. For example, China's New Security Concept (from 2002), which is a call for the diversification of security to make it inclusive and equitable for all, and it seeks settlement of disputes with its neighbours through peaceful negotiation. However, some analysts say that China's approach for regional architectures in Asia is limited, dictatorial, and unfair. Beijing has seen as seeking the upper hand during talks with smaller parties (for instance, presenting the Belt and Road Initiative (BRI) as a win-win venture but pushing countries into a debt-for-equity swap).

In the case of India, there is a push for an Open and Inclusive IndoPacific. It is clear from a few official Indian declarations that New Delhi wants a free, open, and inclusive maritime agenda in the region. India has stressed the position of ASEAN centrality in any regional architecture in the Indo-Pacific. Both ASEAN and India gave significance to existing norms and internationally accepted rules of law when it linked to freedom of navigation, for example. About US., the Trump administration sees Asia as a military and economic partner against "strategic competitor" China and its policies in the IndoPacific are related to that. And this is no less important: the renaming of the Pacific Command to the Indo-Pacific Command emphasizes that the United States sees the waters of the Indian and Pacific Oceans as only one zone of influence (Bhatt, 2019). In its new Indo- Pacific strategy, the United States places a strong significance in working with India to preserve a free and open Asian region. While India's economic potential and democratic principles are essential to the strategy, it is the potential of defence cooperation that is vital to attaining this vision (Abercrombie, 2018). So, the US put more emphasis on 
security and defence. And for India, is about the protection of its territorial interests in its maritime surrounds.

The significant protagonists behind the 'free and open Indo-Pacific' (FOIP) concept are continuing diplomatic attempts to crystallize a plan for its fulfilment. But there is no agreement on what the idea will involve nor is sure what kind of structures are necessary for its execution. The United States, Japan, and India held their first trilateral meeting on the sidelines of the December 2018 G20 summit in Buenos Aires. They arranged that a 'free, open, inclusive and rules-based' order is vital for peace and prosperity in the Indo-Pacific. To Japan, the FOIP is open to all countries that adhere to the rule of law, freedom of navigation and appropriate principles of transparency and sustainable development. For Japanese Prime Minister Shinzo Abe, his target is to make sure that China and its 'Chinese standards' do not control the infrastructure networks through Asia to Africa. Japan and India have already decided to strengthen naval and maritime security cooperation and join forces on infrastructure projects in third countries, including Myanmar, Bangladesh, and Sri Lanka, to boost strategic connectivity in the Indo-Pacific (Hussain, 2019).

One interesting topic related to the Indo-Pacific arena and its impact on ASEAN bloc in general, and ASEAN member states, could be the monthlong, two-yearly Rim of the Pacific (RIMPAC) exercise, not so far from the Hawaiian Islands. RIMPAC has been a constant since 1971, but the training has evolved, showing fluctuating times and tensions. In many ways, modern RIMPACs are soft power events intended to showcase the attraction of the US as a collaborator and partner. The US emphasizes that many navies would like to train with them. By the other side, significant nations like China and Russia don't offer any invitation to others to their most critical naval exercises. In 2018, Vietnam was joining the activity for the first time. In the case of Malaysia, already participating last time, it was sending a warship for the first time. Something similar was happening with the Philippines (Layton, 2018).

About countries like India and Indonesia, the authors asked if it could be a chance for both countries to reach a common understanding of IndoPacific. But they usually say that this is doubtful, due to a misalignment between the two countries' political and economic targets. India's integration with the Pacific region was to be driven by the 'Look East' policy and then the 'Act East' policy, with focus on regional and sub- regional ideas for trade, economic cooperation, and connectivity. For example, free trade agreements have been signed or negotiated between India and the Association of Southeast Asian Nations (ASEAN), Thailand, Malaysia, and Australia. However, in general, the results of these initiatives have been limited. Now, India has declined to pull out of the Regional Comprehensive Economic Partnership (RCEP). Deep-rooted structural local problems, weak global demand and 
increasing protectionist sentiment amongst potential trading partners could explain why that happened. India's stances on agriculture and services have also impeded RCEP negotiations.

About Indonesia, its integration with the Indian Ocean region stretches back to the founding of the Indian Ocean Rim Association (IORA) in 1997 and has been boosted by its commitment with the Indo-Pacific concept since 2013. The current government of Joko Widodo foresees Indonesia as a maritime pivot. Indonesia is interested with the Indian Ocean because of the Middle Eastern energy, and India's possibility as both an investor and a market for Indonesian goods. During Indonesia's 2016-18 leadership of IORA, there was a calling for more significant intra-regional trade and investment.

Nevertheless, Indonesia's commitment to Indian Ocean markets continues limited. And we refer bilaterally to Indonesia and India, protectionist attitudes remain to hinder a developing of India-Indonesia trade. Under Widodo administration, Indonesia's international agenda influenced by the requirement for foreign investment. For Widodo, now the Indian Ocean region and the broader Indo-Pacific are only of significance for his economic plan. Anyway, Indo-Pacific is a concept being progressively utilized by both policymakers and analysts under the theory that commercial links between Asia's two oceanic regions will go on to expand as much as economies of countries like India and Indonesia will continue growing (Chacko, 2018).

Following Gyngell, sometimes the Indo-Pacific bodies will be created to cooperate (the East Asia Summit), and at times they will be intended to compete (the evolving infrastructure options to the Belt and Road Initiative). Finally, he says "Only a strategic and economic ecosystem as varied as this will be able to accommodate the Indo-Pacific's diverse faces" (Gyngell, 2018, párr. 20).

\section{Conclusion}

ASEAN has taken part in the development of the INDO-PACIFIC concept. After several meetings, where it was necessary to find a point of a joint agreement, they finally arrived at what is known as ASEAN OUTLOOK ON THE INDO-PACIFIC. This Outlook also understood as a stance against those of the great powers (mainly, the United States and China).

ASEAN does not want to favour the positions of the great powers but has chosen its vision: ASEAN WAY. In it, the focus is on non-interference in internal state affairs, the principle of sovereignty, economic cooperation, among other issues.

Even so, it is not clear how the links between the different parties will develop, that is, how the different positions can find an echo in the same place. Therefore, it is necessary establishing an Institution that deals specifically with 
Indo-Pacific, in which all the actors in the region are part. Or institutionalize or formalize much more the East Asia Summit, recognizing its progress achieved so far.

ASEAN, with its mechanisms and Treaties, cannot in itself address the issue. It needs the approach and cooperation with everyone else. That will not be easy considering the current regional and international context, characterized by the tension between the United States and China. Among them, ASEAN is in the middle.

\section{Bibliographical references}

Abercrombie, C. (20 May 2018). Translating defence trade into cooperation in the Indo-Pacific. East Asian Forum.

https://www.eastasiaforum.org/2018/05/20/translating-defence-

trade-into-cooperation-in-the-indo-pacific/

ACHARYA, A. (11 August 2019). Why ASEAN's Indo-Pacific outlook matters. East Asian Forum.

https://www.eastasiaforum.org/?p=198717?utm_source=newsletter\& utm_medium=email\&utm_campaign=newsletter2019-08-11

BнAтт, P. (31 July 2019). ASEAN's Outlook for the Indo-Pacific: An attempt to set rules of the game. South Asian Voices.

https://southasianvoices.org/aseans- outlook-for-the-indo-pacific-anattempt-to-set-rules-of-the-game/

CHAckO, P. (30 August 2018). Far from all-in on the Indo-Pacific. East Asian Forum. https://www.eastasiaforum.org/2018/08/30/far-from-all-inon-the-indo-

pacific/?utm_source=newsletter\&utm_medium=email\&utm_campaign

=new sletter2018-09-02

Chongkittavorn, K. (4 December 2018). Watch out for Asean's new IndoPacific. Bangkok Post.

https://www.bangkokpost.com/opinion/opinion/1587206/watch-

out-for- aseans-new-indo-pacific

GyNGELL., A. (23 May 2018). To each their own 'Indo-Pacific'. East Asian

Forum. https://www.eastasiaforum.org/2018/05/23/to-each-theirown-indo-pacific/

HoANG THI HA (2019). ASEAN Outlook on the Indo-Pacific: Old Wine in New Bottle? Perspective, ISEAS Yusof Ishak Institute, Issue 2019, N 51, ISSN 2335-6677, 2-7. https://www.iseas.edu.sg/images/pdf/ISEAS_Perspective_2019_51.p df

Hussain, N. (16 August 2019). ASEAN joins the Indo-Pacific conversation. East Asian Forum. https://www.eastasiaforum.org/2019/08/16/asean- 
joins-the-indo-pacific-conversation/

Hussain., N. (9 February 2019). Regional consensus needed for a 'free and open Indo-Pacific'. East Asian Forum.

https://www.eastasiaforum.org/2019/02/09/regional-consensusneeded-for-a-free-and-open-indo-pacific/

JA IAN CHONG (3 September 2019). ASEAN needs more than an 'outlook' on the Indo- Pacific. East Asian Forum. https://www.eastasiaforum.org/2019/09/03/asean-needs-more-thanan-outlook-on-the-indo-pacific/

KAMARUdDin, N. (5 August 2019). ASEAN's strategic engagement in the unwieldy Indo-Pacific. Lowy Institute. https://www.lowyinstitute.org/the-interpreter/asean-s-strategicengagement-unwieldy-indo-pacific

LAKSMANA, E. (27 November 2018). Buck-passing from behind: Indonesia's foreign policy and the Indo-Pacific. Brooking. https://www.brookings.edu/blog/order-fromchaos/2018/11/27/buck-passing-from-behind-indonesias-foreignpolicy-and-the-indo-pacific/

LaKsmana, E. (19 September 2019). Flawed Assumptions: Why the ASEAN Outlook on the Indo-Pacific is Defective. Asia Global Online. https://www.asiaglobalonline.hku.hk/flawed-assumptions-why-theasean-outlook-on-the-indo-pacific-is-defective

LAKSMANA, E. (20 November 2018). Indonesia's Indo-Pacific vision is a call for Asean to stick together instead of picking sides. South China Morning Post.https://www.scmp.com/weekasia/geopolitics/article/2173934/in donesias-indo-pacific-vision-call-asean-stick-together

LAYTON, P. (2 July 2018). Mai Tai diplomacy in the Indo-Pacific. Lony Institute. https://www.lowyinstitute.org/the-interpreter/mai-tai-diplomacy-inthe-indo-pacific

ThePChAtree, P. (15 August 2019) Expanding ASEAN's Indo-Pacific role. East Asian

Forum. https://www.eastasiaforum.org/2019/08/15/expanding-aseans-indopacific-role/

Vicedo, C. (2 August 2018), The Philippines stays free and open in its position on the Indo-Pacific. East Asian Forum. https://www.eastasiaforum.org/2018/08/02/the-philippines-staysfree-and-open-in-its-position-on-the-indo-pacific/

YunANTO, S. y SAMHUdi, G. R. (2019). Different interests explain different proposals: The contestation of Indo-Pacific cooperation framework between ASEAN and the US, E-Journal GLOBAL STRATEGIS, Vol 13, $\mathrm{N}^{\circ}$ 2, 2019, UNIVERSITAS AIRLANGGA. https://ejournal.unair.ac.id/JGS/article/view/12299/8674 
Análisis de ASEAN como “comunidad de seguridad”. Perspectivas desde la

construcción institucional

BÁRBARA TURNER

\title{
ANÁLISIS DE ASEAN COMO “COMUNIDAD DE SEGURIDAD”. PERSPECTIVAS DESDE LA CONSTRUCCIÓN INSTITUCIONAL
}

\author{
Bárbara Turner \\ Universidad de Buenos Aires-FLACSO \\ bturner@flacso.org.ar
}

\section{Introducción}

La Asociación de Naciones del Sudeste Asiático (ASEAN por sus siglas en inglés) fue fundada en el año 1967, reuniendo a cinco miembros de características diversas: Indonesia, Malasia, Tailandia, Singapur y Filipinas. Estos Estados eran divergentes, tanto en tamaño como composición étnica y también respecto a su experiencia colonial y postcolonial. Sin embargo, poseían dos similitudes. Por un lado, vivían involucrados en una serie de serias disputas entre ellos y, por lo tanto, necesitaban un mecanismo para la prevención de la guerra y la gestión de conflictos. Por otro lado, carecían de experiencia previa significativa en términos de cooperación multilateral.

Este artículo argumentará que ASEAN fue concebida desde sus inicios como una organización que permitiera prevenir, gestionar y resolver conflictos en la región, basada en la creación de una Comunidad de Seguridad en el Sudeste Asiático. A partir de sostener esa construcción en el tiempo se logró la consolidación de un sistema más proactivo destinado a la seguridad y modificando cualitativamente la situación que existía al momento de formación de la asociación.

\section{Comunidad de Seguridad}

El concepto de Comunidad de Seguridad fue acuñado por Karl Deutsch en 1957 para definir a "un grupo de Estados cuyos miembros comparten expectativas de cambio pacífico en sus relaciones mutuas y descartan el uso de la fuerza como medio de resolución de problemas" (Acharya, 1991: 159). Dichas comunidades pueden ser representadas, según Acharya (1991), como la fusión política formal de las unidades participantes, o establecerse como pluralistas, en cuyo caso los miembros conservan su independencia y soberanía, como en el caso de ASEAN. A su vez, el autor describe que la ausencia de guerra o violencia organizada no implica una ausencia de diferencias, disputas o conflictos de intereses entre los actores, sino que es la habilidad para manejar conflictos entre los participantes de manera pacífica lo que distingue a una Comunidad de Seguridad. 
Análisis de ASEAN como “comunidad de seguridad”. Perspectivas desde la construcción institucional

BÁRBARA TURNER

Este tipo de comunidades también están marcadas por la ausencia de competencia militar o carreras armamentistas, de modo que superan el dilema de seguridad planteado por los realistas. Collins (2006) puntualiza que el dilema de seguridad está representado en la incertidumbre acerca de las intenciones de otros Estados que causa la acumulación de armas. La reducción o desaparición de este elemento en las Comunidades de Seguridad se realiza a partir de una convergencia de intereses fundamental, inequívoca y de largo plazo sobre las expectativas de resolución pacífica de conflictos. En este sentido, estas comunidades reúnen a grupos de actores que a menudo desarrollan criterios e identidades comunes.

Es posible afirmar que ASEAN desde su gestación fue imaginada como una Comunidad de Seguridad, si bien su formalización ocurrió en el 2003 en la Segunda Conferencia de Bali. La constante práctica de reducción de la probabilidad de luchas armadas y la mediación en los conflictos intrarregionales, aunque con obstáculos y dificultades, permite observar a ASEAN desde sus inicios como una Comunidad de Seguridad en construcción, que ha ido perfeccionándose con el tiempo.

\section{Formación y consolidación institucional}

Las relaciones entre los miembros fundadores de ASEAN en la década de 1960 estuvieron marcadas por rivalidades interestatales, como el reclamo de territorio, la asistencia a grupos secesionistas o la falta de reconocimiento de la legitimidad de otro Estado. Aquello, se agregó a vulnerabilidades existentes en todos los gobiernos nacionales por administrar sociedades divididas a nivel nacional y no controlar partes periféricas de sus Estados. En 1967, los gobiernos en Indonesia, Malasia, Tailandia, Singapur y Filipinas observaron que tales formas de comportamiento eran decididamente improductivas para sus sistemas, y la realidad de una amenaza común -incluida la posible insurgencia comunista solventada por otros países y los esfuerzos de China y Rusia por entrometerse en el Sureste de Asia- generó un incentivo para la creación de la ASEAN.

Su evolución es descrita por Foong Kong y Nesadurai (2007) como marcada por un acercamiento regional que preveía que la participación en la asociación ayudaría a moderar la dinámica competitiva desenfrenada entre sus vecinos y que permitiría a los gobiernos centrar su atención y recursos en abordar desafíos políticos, económicos y sociales sin tener que preocuparse por el comportamiento de los otros Estados cercanos. A su vez, Archaya (2009) analizó que el regionalismo tuvo la utilidad de potenciar la mejora del poder de negociación de los Estados pequeños en sus relaciones con las grandes potencias. 
Análisis de ASEAN como "comunidad de seguridad”. Perspectivas desde la construcción institucional

BÁRBARA TURNER

En definitiva, ASEAN no se constituyó como una alianza o como un pacto de defensa mutua dirigido hacia otro Estado específico, sino que se gestó como un proceso diplomático de acomodación mutua entre sus miembros, con un mandato decididamente deliberativo, con consultas regulares y diálogo entre sus miembros sobre una gran cantidad de problemas intrarregionales. La más notable de estas consultas fue la reunión anual de ministros de Relaciones Exteriores, en la cual en el año 1971 se creó la Zona de Paz, Libertad y Neutralidad (ZOPFAN, por sus siglas en inglés).

Dicha Zona es explicitada por Acharya (2009) como fundada para preservar y mantener la identidad nacional, independencia e integridad de los Estados en pos de alcanzar el desarrollo nacional y promover la cooperación regional, de acuerdo con ideales y aspiraciones propias, y en relación con los principios de la Carta de las Naciones Unidas, libre de interferencias por parte de los poderes centrales. Sin embargo, Narine (2008) profundiza en que, dado el alcance limitado de la asociación en ese momento, la creación de reglas formales y cronogramas eran considerados innecesarios mientras se mantuvieran la soberanía, estabilidad e integridad territorial de los miembros, lo que impidió el mayor perfeccionamiento de la ZOPFAN.

Sólo después de cinco años, en 1976, se estableció el primer acuerdo formal de la asociación: el Tratado de Amistad y Cooperación del Sudeste Asiático (TAC) en el cual se instituyó que la conducta interestatal de ASEAN se regiría, según Foong Kong y Nesadurai (2007), por dos conjuntos de principios: las normas reguladoras básicas sobre cómo deberían comportarse los Estados entre sí, y las normas de procedimiento que guiarían la toma de decisiones colectivas. Esta última es llamada "ASEAN Way" (Foong Kong; Nesadurai, 2007: 34) y prescribe la informalidad sobre las instituciones formales, la flexibilidad, la práctica del consenso y, principalmente, la doctrina de no interferencia, propuesta por Acharya (2009). Esto se traduce en evitar críticas a un gobierno miembro por acciones tomadas hacia sus propios ciudadanos y sobre el rumbo que adopte sistema político nacional. Al mismo tiempo implica negar reconocimiento o apoyo a cualquier grupo rebelde que buscara desestabilizar a un Estado vecino.

De esta forma, el TAC se convirtió en uno de los símbolos más fuertes de la ASEAN, incluso ejerciendo influencia en el resto de Asia. Sin embargo, Narine (2008) explicita que Vietnam rechazó el Tratado por considerarlo demasiado occidentalista y vinculado a los Estados Unidos, lo cual desembocaría en una de las mayores amenazas de seguridad que enfrentó la ASEAN en el período de Guerra Fría.

\section{La Invasión de Camboya}


Análisis de ASEAN como “comunidad de seguridad”. Perspectivas desde la construcción institucional

BÁRBARA TURNER

La invasión y la ocupación de Camboya por décadas por parte de las fuerzas vietnamitas desde diciembre de 1978 planteó el desafío de seguridad más serio para ASEAN desde sus inicios, ya que la acción de Vietnam no sólo se consideró una violación flagrante de sus normas, sino que amenazaba la cultura emergente de unidad y consenso. Las diferencias entre los miembros de ASEAN en cuanto a cómo abordar el conflicto se extendieron por un largo período, desafiando el papel de la asociación en el arreglo pacífico de disputas regionales, alejada de la interferencia de los poderes centrales.

Si bien, en sentido estricto, la invasión y crisis estaban fuera del marco de búsqueda de soluciones pacíficas de los conflictos regionales, ya que ni Vietnam ni Camboya pertenecían como miembros a ASEAN, Acharya (2009) representa a la acción de Vietnam como un conflicto para la asociación que involucraba mucho más que rivalidades locales, sino que podían observarse antagonismos relacionados entre una serie de actores centrales como China, Japón, la Unión Soviética y los Estados Unidos. Aquello, impedía la ejecución de la premisa "regional solutions for regional problems" (Acharya, 2009: 101), es decir, la reducción del papel de los grandes poderes en el Sudeste Asiático.

La participación de la ASEAN durante una década en el establecimiento de la paz en Camboya estaría marcada, según el autor, por una tensión entre dos enfoques. Por un lado, una diplomacia que buscaba abordar el conflicto en un marco esencialmente regional, con una intervención mínima por parte de las potencias extranjeras, al cual adherían Indonesia y Malasia. Por otro lado, una estrategia de confrontación, cuyo objetivo consistía en lograr el aislamiento de Vietnam de la comunidad internacional y aumentar los costos diplomáticos y militares por su ocupación de Camboya. De esta forma, Tailandia y Singapur resolvieron organizar un frente de resistencia contra Vietnam, realizando propuestas de cooperación militar dentro de ASEAN y en la búsqueda de respaldo directo por parte de las potencias.

Finalmente, la posibilidad de renuncia a la asociación por parte de Tailandia y su posible acercamiento a China, se tradujo en una aceptación del segundo tipo de política exterior, que convirtió a ASEAN en la principal oposición internacional de Vietnam. En consecuencia, Acharya (2009) demuestra que la respuesta a la crisis incluyó objetivos como la negación de la legitimidad al gobierno instalado por Vietnam en Camboya, el aislamiento internacional de Vietnam, la retirada incondicional de las fuerzas vietnamitas y evitar una nueva invasión en Tailandia. Velozmente, en 1980, la política de ASEAN hacia Camboya cosechó algunos éxitos, como el aislamiento efectivo de Vietnam y la incorporación del conflicto a la agenda de las Naciones Unidas. En parte gracias a los esfuerzos de la asociación, los costos de la disputa para Vietnam se hicieron cada vez más pronunciados en términos políticos, económicos y sociales.

Asia/AméricaLatina, vol. 6, no especial, pp. 25-36. DOI: 10.33177/ASEAN.3 
Análisis de ASEAN como "comunidad de seguridad”. Perspectivas desde la construcción institucional

BÁRBARA TURNER

Sin embargo, los progresos a nivel internacional fueron factores importantes en la conducción del proceso de paz. Narine (1997) detalla que el final de la Guerra Fría permitió un acercamiento entre las potencias que generó condiciones favorables para avanzar en el proceso de paz. En última instancia, los poderes permanentes del Consejo de Seguridad de la ONU se hicieron cargo de la situación en Camboya, confluyendo en el Tratado de Paz de París en 1991, que puso fin al conflicto entre Vietnam y Camboya.

En conclusión, la invasión de Camboya ilustra el crecimiento y desarrollo de la ASEAN, al haber mantenido el conflicto en la agenda internacional en un momento en que la comunidad internacional tenía poco interés en los sucesos en el Sudeste Asiático y en el perfeccionamiento de una identidad regional de la asociación, presentando la invasión vietnamita como una grave violación del principio de no intervención en los asuntos internos de los Estados y a la prohibición del uso de la fuerza en las relaciones interestatales.

Aunque la agresión de Vietnam demostró los límites en la acción de los pequeños Estados frente a los poderes centrales, motivó a los miembros de la ASEAN a superar sus conflictivos intereses y disputas territoriales para avanzar en el camino hacia una Comunidad de Seguridad. En este sentido, los objetivos de ASEAN respecto a Indochina cambiaron de manera fundamental, avanzando en la construcción de un nuevo sistema regional.

\section{ASEAN en la Post Guerra Fría}

El fin de la Guerra Fría obligó a ASEAN a rediseñarse y a encontrar un nuevo propósito unificador entre sus miembros. La acción colectiva sobre Camboya había permitido desviar la atención de las diferencias dentro del bloque y, en consecuencia, ASEAN consideró que existían grandes ventajas políticas internacionales de operar como grupo, dadas las disputas territoriales y tensiones políticas aun presentes en la región. Asimismo, el fin de la bipolaridad implicó para la región de Asia Pacífico la necesidad de crear nuevas estructuras de seguridad para gestionar las más recientes intenciones de China, particularmente en la contienda por las Islas Spratly, y el repliegue de Estados Unidos en la zona.

En este sentido, la construcción de una Comunidad de Seguridad requirió una nueva evaluación. Si bien ASEAN se había desplegado como una entidad subregional dinámica en el pasado, con el fin de la Guerra Fría buscó establecer un nuevo orden regional de paz y prosperidad, que abarcara a todas las naciones del Sudeste Asiático. De esta manera, en los años noventa surgió el "ASEAN-10" (Cuyvers et al, 2005: 5) o "One Southeast Asia" (Acharya, 2009: 122), con la inclusión en la asociación de Brunéi, Camboya, Laos, Myanmar y Vietnam. 
Análisis de ASEAN como “comunidad de seguridad". Perspectivas desde la construcción institucional

BÁRBARA TURNER

La expansión de ASEAN introdujo una mayor diversidad en cuestiones de política y de seguridad sobre los miembros de la agrupación. En principio, promovió nuevos contactos transnacionales entre las distintas sociedades, promoviendo un mayor sentido de regionalismo. A su vez, la nueva membresía fue especialmente beneficiosa para los Estados pequeños, que ahora podrían ser tratados como socios iguales con sus vecinos más poderosos, y con aquellos Estados aislados de la política internacional, marcando el fin de su retraimiento. Sin embargo, Acharya (2009) demuestra que las interacciones entre ellos se volvieron más complejas y se generaron nuevas tensiones al interior de la asociación. En particular, era incierto si los nuevos miembros respetarían las normas de la ASEAN sobre la prohibición del uso de la fuerza y la solución pacífica de controversias, mientras que también se observaba la introducción de una mayor diversidad de perspectivas políticas dentro de la agrupación, especialmente sobre cuestiones de derechos humanos y democracia, volviendo más difícil la tarea de mantener una posición común frente a las potencias externas.

En el caso de China, Foot (1998), Rowan (2005) y Whiting (1997) coinciden en que el conflicto por las Islas Spratly fue considerado el punto más álgido de conflicto en el Sudeste Asiático después de la Guerra Fría. El conjunto de las Islas Spratly se encuentra ubicado en el Mar de la China Meridional y cubre aproximadamente 250 mil kilómetros cuadrados. Su importancia se debe a la existencia de importantes recursos naturales en la zona, así como por su ubicación estratégica entre algunas de las rutas marítimas más importantes del mundo. Las más de doscientas islas pequeñas y arrecifes son reclamadas, en parte o en su totalidad, por seis naciones asiáticas: China y Taiwán lo hacen sobre todo el archipiélago de las Spratly, mientras que Vietnam, Filipinas, Malasia y Brunéi con reclamos parciales.

La estrategia de ASEAN para hallar una solución al conflicto fue descrita por los autores mencionados como basada en un impulso de cuestiones de desarrollo conjunto y cooperación funcional, que produjeran acuerdos sobre proyectos específicos y que establecieran medidas de confianza mutua. Una vez más, los esfuerzos de la asociación llevaron la disputa al centro de atención internacional, estableciendo un costo diplomático alto para China. Finalmente, las negociaciones condujeron a una declaración sobre lo que Acharya (2009) llama un Código de conducta en el Mar del Sur de China.

Esta declaración reflejó los altos costos que la disputa mantuvo sobre China, resultando perjudicial para sus propios intereses. Igualmente, el acuerdo avanzó debido a la exclusión de Taiwán, y el deseo de Beijing de evitar una posible intervención de terceros países en el conflicto, especialmente los Estados Unidos. Pero, sobre todo, la declaración representó una confirmación del reconocimiento de China a tratar multilateralmente con ASEAN sobre un tema que anteriormente habría insistido en resolver bilateralmente. Aquello, 
Análisis de ASEAN como "comunidad de seguridad”. Perspectivas desde la construcción institucional

BÁRBARA TURNER

permitió luego la construcción de otra estructura institucional crucial: el "ASEAN+3" (Foong Kong; Nesadurai, 2007: 60), donde el "tres" representa a China, Japón y Corea del Sur. Según Narine (1997) este nuevo órgano tuvo como objetivo coordinar reuniones en representación de Asia frente a Europa, al mismo tiempo que identificar áreas de cooperación económica regional. En el año 2000 esto se intensificó con la llamada Iniciativa Chang Mai, una serie de acuerdos de intercambio de divisas que permitió una mayor estabilidad financiera en la región.

\section{ASEAN como Foro de Seguridad Regional}

En este contexto, el intento más ambicioso por gestionar la seguridad de Asia Pacífico, en el período posterior a la Guerra Fría, fue a través del Foro Regional de ASEAN (ARF, por sus siglas en inglés), un grupo con veintisiete miembros incluyendo a los diez de ASEAN más Australia, Bangladesh, Canadá, China, Corea del Sur, la Unión Europea, India, Japón, Mongolia, Nueva Zelanda, Pakistán, Rusia y Estados Unidos, entre otros. Una parte considerable del atractivo de ARF para los Estados no pertenecientes a ASEAN se debió a la reputación de esta como una entidad diplomática cohesiva frente a la exigencia de una nueva organización de seguridad. Es por eso por lo que los enfoques bilaterales o subregionales fueron desestimados frente a un marco regional que resultaba más necesario que nunca.

El entorno desafiante a la seguridad común de los Estados en la región y los niveles de interdependencia, tanto económicos como de seguridad, actuaron como desencadenantes para la creación del Foro. El ARF se convirtió en el primer Foro de seguridad multilateral de la región, con el propósito de forjar una zona de seguridad cooperativa, en lo que Acharya (2009) denomina 'con otros' en lugar de 'contra otros'. En este sentido, la seguridad regional se garantizaría mejor mediante el equilibrio entre los diversos Estados pequeños y las grandes potencias, involucrando a todos los actores regionales, pese a que ASEAN trató de preservar su papel central en el regionalismo asiático estableciéndose como centro institucional.

En consecuencia, desde el comienzo los miembros de ASEAN buscaron dominar y marcar el ritmo del ARF, desempeñando un papel significativo en su lanzamiento, la creación de sus normas y construcción institucional, demandando un grado de influencia sobre asuntos regionales que de otro modo no hubiera podido alcanzar. Así, según Narine (1997), la asociación delineó tres categorías de cooperación de seguridad: medidas que fomentaran la confianza mutua, diplomacia preventiva y resolución de conflictos. Cada una de estas categorías contenía medidas respectivas con un cronograma de implementación en dos etapas. La primera incluía medidas de corto plazo, como diálogos sobre percepciones de la seguridad, intercambio de 
Análisis de ASEAN como “comunidad de seguridad”. Perspectivas desde la construcción institucional

BÁRBARA TURNER

información sobre políticas de defensa y publicación de documentos. La segunda categoría incluía enfoques de largo plazo, incluyendo medidas de transparencia y notificación de despliegues militares trascendentales para la región.

No obstante, Acharya (2009) analiza que los ataques del 11 de septiembre en los Estados Unidos llevaron al ARF a cambiar su enfoque de asuntos convencionales de cooperación a cuestiones no tradicionales de seguridad o transnacionales. En términos funcionales, el Foro se expandió, agregando temáticas como delincuencia transnacional, piratería, migración ilegal, tráficos de armas y drogas, delitos informáticos, lavado de dinero y, especialmente, terrorismo.

En conclusión, la contribución del ARF al orden regional reside en su novedoso impacto relacionado al multilateralismo y en la construcción de equilibrios entre las principales potencias de Asia Pacífico. A su vez, el liderazgo de ASEAN no sólo permitió mejorar las perspectivas del relacionamiento entre Estados, sino que también diluyó parte de la influencia de los grandes poderes en el Sudeste Asiático, utilizando como elemento esencial el balance de poder a partir de la participación de actores con intereses divergentes como China, Estados Unidos, India, Japón y Rusia en el mismo Foro.

\section{ASEAN como Comunidad de Seguridad}

Durante la Guerra Fría, los desafíos de seguridad para los miembros de ASEAN provinieron principalmente del ámbito interno, por la inestabilidad de la región y por la rivalidad entre las potencias. A pesar del cambio en el equilibrio de poder, impulsado por el fin de la bipolaridad, los retos a la seguridad se mantuvieron como conflictos interestatales. Algunos de estos desafíos no desaparecerían. Sin embargo, los peligros a los que se enfrentaría ASEAN a fines de la década de 1990, y en el comienzo del nuevo siglo, eran de naturaleza diferente. Aquello estimuló y permitió un cambio de enfoque, analizado previamente, hacia una cooperación sobre cuestiones no tradicionales de seguridad y transnacionales.

Estos nuevos peligros se manifestaron de diversas maneras, entre ellas amenazas terroristas, epidemias y desastres naturales (Asia News, 2018; Agencia EFE, 2018; DW, 2018; La Voz de Vietnam, 2013; Vietnam Plus, 2015). La inclusión de estas amenazas como nuevos objetivos de seguridad incluyeron, algunas características similares, como el surgimiento repentino e inesperado en un contexto de globalización, excediendo las fronteras nacionales (Acharya, 2009).

En este contexto, la Declaración de la ASEAN Corncord II, adoptada por la novena cumbre de la ASEAN en Bali en el año 2003, conformó formalmente la Comunidad de Política y Seguridad de ASEAN (APSC), junto 
Análisis de ASEAN como "comunidad de seguridad”. Perspectivas desde la construcción institucional

BÁRBARA TURNER

con la Comunidad Económica y la Comunidad Sociocultural de la asociación. A partir de lo establecido en el Plan de Acción para APSC (2009), la Comunidad tenía como objetivo llevar la cooperación de ASEAN en política y seguridad a un plano superior, aunque afirmando los principios tradicionales de la asociación: toma de decisiones a través del consenso, renuncia a la amenaza o uso de la fuerza y solución pacífica de controversias. La nueva Comunidad también reconocía los instrumentos ya existentes de la ASEAN, como la Declaración sobre ZOPFAN y el TAC, que continuarían desempeñando un papel fundamental en el fomento de la confianza mutua, la diplomacia preventiva y en la resolución de conflictos. Por último, se incluyeron medidas para promover el desarrollo político a través de la democracia, el reconocimiento de derechos humanos, la buena gobernanza y la asistencia legal mutua.

La creación del APSC fue claramente influenciada por la literatura académica sobre las Comunidades de Seguridad. En este sentido, el Plan de Acción (2009) definió a su Comunidad como un conjunto de países que habían logrado alcanzar expectativas de paz, como resultado de los flujos de comunicación y el hábito de cooperación, desechando la posibilidad del uso de la fuerza entre los miembros. En consecuencia, los Estados han considerado que su seguridad está fundamentalmente ligada a la de los demás, generando estabilidad y previsibilidad en la región.

Concluyentemente, es posible considerar al APSC como un cambio normativo en el marco regional de cooperación en seguridad, ya que implica la creación de un orden regional con fundamento normativo y capacidad institucional, capaz de abordar la amplia gama de conflictos presentes en la región. Así, Mely Caballero (2010) expone que a partir de tal construcción se espera proporcionar la voluntad política para la consolidación de un sistema más proactivo que reactivo en el bloque, para garantizar la seguridad en el Sudeste Asiático.

\section{Conclusión}

A partir del análisis esgrimido anteriormente, es posible afirmar que la ASEAN ha propiciado, desde sus inicios, los valores de una Comunidad de Seguridad, entendida como una entidad ligada a la paz, consciente de sus lazos históricos, herencia cultural e identidad común, que propicia la estabilidad en sus relaciones y la incorporación de mecanismos de confianza mutua. Este sentido de Comunidad es captado en los propósitos de ASEAN, donde se enfatiza que la prosperidad de los miembros está intrínsecamente ligada a un acrecentamiento de las relaciones mutuas y a su perfeccionamiento, manifestado, por ejemplo, en su Plan ASEAN Vision para el año 2020. 
Análisis de ASEAN como “comunidad de seguridad”. Perspectivas desde la construcción institucional

BÁRBARA TURNER

Es necesario advertir que han persistido una serie de disputas que han desafiado las soluciones políticas y diplomáticas más recientes, junto con nuevos obstáculos delicados y difíciles de resolver para la región. Sin embargo, la definición de Comunidad de Seguridad no implica necesariamente, como hemos expuesto anteriormente, la ausencia de conflictos o desacuerdos, sino la manifestación de destreza para remediarlos en forma conjunta y en paz, como bien ha demostrado la asociación en el caso de la Invasión a Camboya o en la formación del ARF y APSC.

En definitiva, la evolución de la ASEAN demuestra que el estado actual de sus relaciones entre Estados es cualitativamente diferente de la que existía en el momento de la formación de la agrupación, evidenciando su imagen de Comunidad de Seguridad en el sentido de que sus miembros no prevén la posibilidad de recurrir a la confrontación armada para resolver las disputas existentes. ASEAN puede reclamar un éxito en su objetivo, aunque aún frágil, en la construcción de una Comunidad de Seguridad que debe ser fortalecida y asegurada para su buen funcionamiento en el futuro.

\section{Bibliografía}

ACHarya, A. (2009) Constructing a Security Community in Southeast Asia. ASEAN and the problem of regional order, New York, Routledge

ACHarya, A. (1991) "The Association of Southeast Asian Nations: 'Security Community' or 'Defence Community'?”, Pacific Affairs, Vol. 64, Num. 2, pp. 159- 178

ASEAN SECTRETARIAAT (2009) ASEAN Political-Security Community Blueprint, Jakarta

Collins, A. (2006) "Forming a Security Community: lessons from ASEAN", International Relations of the Asia-Pacific, Vol. 7, Num. 2, pp. 203-225

ASIA NEWs (2018) "Acuerdo entre seis países de la ASEAN sobre la lucha contra el terrorismo islámico", 25/01, link: http:/ /www.asianews.it/noticias-es/Acuerdo-entre- seis-países-de-laASEAN-sobre-la-lucha-contra-el-terrorismo-islámico-42926.html

AGENCIA EFE (2018) “Australia y ASEAN estrechan la cooperación en terrorismo y violencia radical", 17/03, link: https://www.efe.com/efe/usa/mundo/australia-y- asean-estrechanla-cooperacion-en-terrorismo-violencia-radical/50000108-3556017

Cuyvers, L.; De Lombaerde, P.; Veherstraeten, S. (2005) "From AFTA towards an ASEAN economic community and beyond", Centre for ASEAN Studies, Num. 46, pp. 3-22

DW (2018) "ASEAN host warns of threats to Southeast Asia from Islamic State", 28/04, link: https://www.dw.com/en/asean-host-warns-ofthreats-to-southeast-asia- from-islamic-state/a-43580323 
Análisis de ASEAN como “comunidad de seguridad”. Perspectivas desde la construcción institucional

BÁRBARA TURNER

Emmers, R. (2003) Cooperative Security and the Balance of Power in ASEAN and the $A R F$, New York, Routledge

Emmerson, D. K. (2005) "Security, Community, and Democracy in Southeast Asia: Analyzing ASEAN", Japanese Journal of Political Science, Vol. 6, Num. 2, pp. 165- 185

FoOng KhOng, Y.; Nesadurai, H. E. S. (2007) "Hanging together, institutional design, and cooperation in Southeast Asia: AFTA and the ARF”, en Acharya A.; Johnston, I. Crafting Cooperation. Regional International Institutions in Comparative Perspective, pp. 32-82

FOоT, R. (1998) "China in the ASEAN Regional Forum: Organizational Processes and Domestic Modes of Thought", Asian Survey, Vol. 38, Num. 5, pp. 425-440

GANESAN, N. (1994) "Rethinking ASEAN as a Security Community in Southeast Asia", Asian Affairs: An American Review, Vol. 21, Num. 4, pp. 210-226

Garofano, J. (2002) "Power, Institutions, and the ASEAN Regional Forum: A Security Community for Asia?", Asian Survey, Vol. 42, Num. 3, pp. $502-521$

KHoO, N. (2010) "Constructing Southeast Asian security: the pitfalls of imagining a security community and the temptations of orthodoxy", Cambridge Review of International Affairs, Vol. 17, Num. 1, pp. 137153

Kupchan, C. A.; Kupchan, C. A. (1995) “The Promise of Collective Security”, International Security, Vol. 20, Num. 1, pp. 52-61

LA VOZ DE VIETNAM (2013) “ASEAN prioriza en la gestión de desastres naturales”, 30/05, link: http://vovworld.vn/es-ES/noticias/aseanprioriza-en-la-gestion-de- desastres-naturales-157616.vov

LEIFER, M. (2013) ASEAN and the Security of South-East Asia, New York, Routledge

LONG, A. G.; LeEDS, B. A. (2006) "Trading for Security: Military Alliances and Economic Agreements", Journal of Peace Research, Vol. 43, Num. 4, pp. $433-451$

Mely Caballero, A. (2010) "Non-Traditional Security Challenges, Regional Governance and the ASEAN Political-Security Community (APSC)", Asia Security Initiative Policy Series, Num. 7, pp. 1-14

NARINE, S. (1997) "ASEAN and the ARF", Asian Survey, Vol. 37, Num. 10, pp. $961-978$

NARINE, S. (2008) "Forty years of ASEAN: a historical review", The Pacific Review, Vol. 21, Num. 4, pp. 411-429

RowAN, J. P. (2005) "The US-Japan Security Alliance, ASEAN, and theSouth

China Sea Dispute", Asian Survey, Vol. 45, Num. 3, pp. 414-436

TARDIF, E. (2011) “Teoría y práctica del uso legítimo de la fuerza en la 
Análisis de ASEAN como "comunidad de seguridad”. Perspectivas desde la construcción institucional

BÁRBARA TURNER

Asia

Anérica

Latina

36

comunidad internacional: evolución durante el útlimo siglo y tendencias recientes", Estudios Internacionales, Vol. 170, pp. 81-103

VIETNAM PLUS (2015) "ASEAN avanza en gestión de desastres naturales", 04/11, link: https://es.vietnamplus.vn/asean-avanza-en-gestion-dedesastres-naturales/57169.vnp

Whiting, A. S. (1997) "ASEAN eyes China: The security dimension", Asian Survey, Vol. 37, Num. 4 pp. 299-322 


\section{REPENSAR LA GOBERNANZA FINANCIERA GLOBAL DESDE} LA ASEAN

Lola Ibáñez

lolaibanez16@gmail.com

Universidad Nacional de Rosario

\section{Introducción}

El debate sobre la configuración de una gobernanza financiera global cobró renovado vigor luego de la profunda crisis de 2008. Una vez más, la cuestión de la regulación financiera recuperó relevancia en medio de una grave debacle económica, de la cual prácticamente ningún país quedó exento. El mercado hipotecario estadounidense se transformó en el epicentro de esta crisis, que se trasladó principalmente a los demás países desarrollados, pero también alcanzó al mundo en desarrollo bajo la forma de una pronunciada caída en la actividad económica (comercio, inversiones y flujos de capital).

Más precisamente, su origen tuvo lugar en un sector minoritario en el mercado de las hipotecas, como lo fueron las hipotecas subprime o de alto riesgo, que representaban poco más del $20 \%$ del total de hipotecas generadas. ${ }^{1}$ Cuando la tasa de impago de estas hipotecas sobrepasó el 30\%, ${ }^{2}$ grandes bancos de importancia sistémica, como Lehman Brothers, e instituciones respaldadas por el gobierno, como Fannie Mae y Freddie Mac, se declararon en bancarrota. Aquellas instituciones que no quebraron reportaron grandes problemas de solvencia debido a los altos niveles de endeudamiento que manejaban.

Claramente, el hecho de que un segmento minoritario del mercado hipotecario diera origen a una crisis de tal magnitud indicó que los actores financieros se habían conducido tan irresponsablemente, que el sistema no resistía la más mínima perturbación. Esto puso nuevamente sobre la mesa la problemática de cómo controlar el accionar imprudente de las grandes instituciones financieras, que adoptaban prácticas cuestionables independientemente del grado de riesgo en el que incurrían, y devolvió el foco a la figura del Estado como actor necesario e irrenunciable en la regulación y prevención de nuevas crisis.

\footnotetext{
${ }^{1}$ https://www.wsj.com/articles/lenders-step-up-financing-to-subprime-borrowers1424296649

2https://www.richmondfed.org/ /media/richmondfedorg/banking/markets_trends_and _statistics/trends/pdf/delinquency_and_foreclosure_rates.pdf
} 
Las características del sistema financiero actual vuelven ineludible la tarea de construir un nuevo modelo de gobernanza global, capaz de poner un coto a esta clase de comportamientos desmesurados que amenazan la estabilidad económica global. Su complejidad, opacidad y aparente homogeneidad lo tornan un sistema robusto pero frágil e incierto, que se está volviendo más propenso a crisis y donde la liquidez es una preocupación cada vez mayor (León et al., 2011).

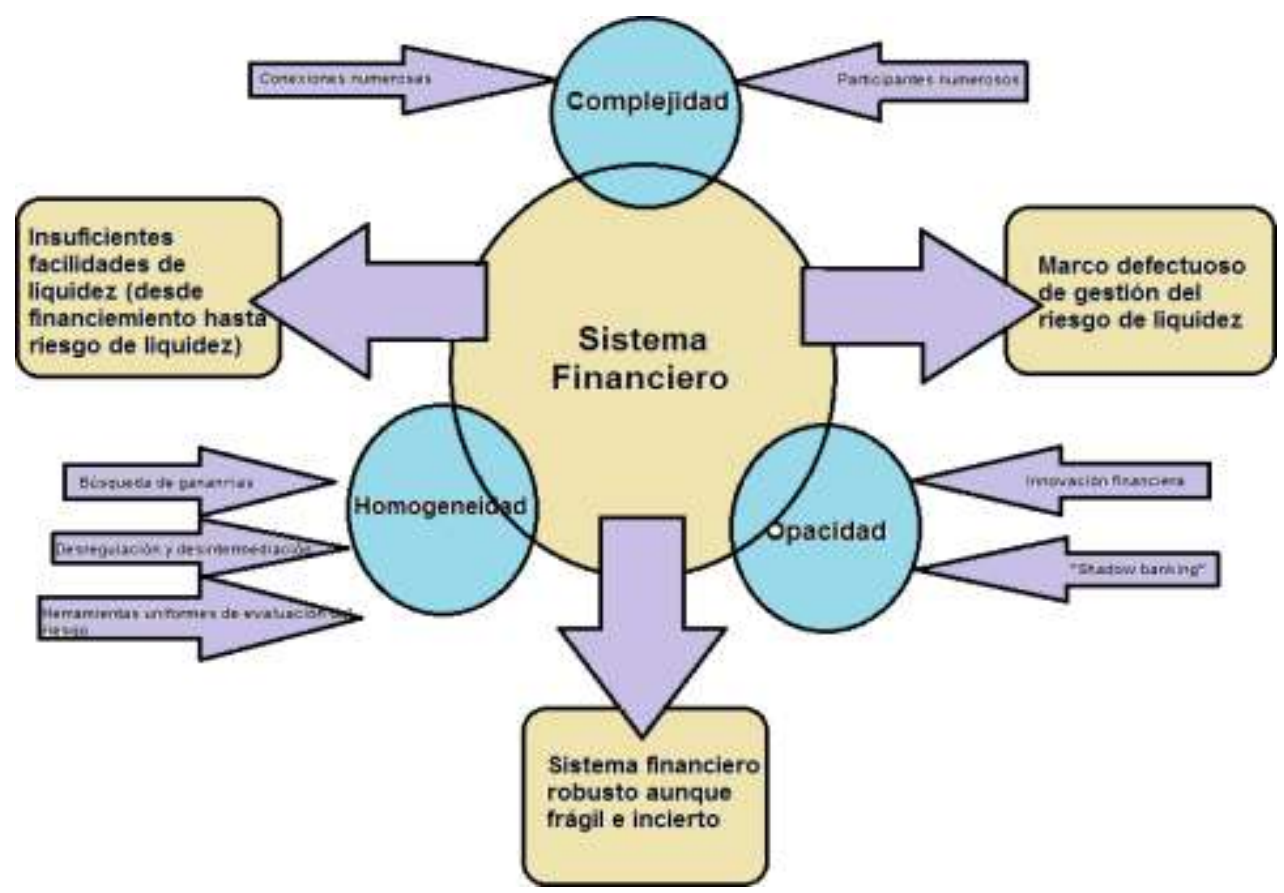

Gráfico 1: Esquema de sistema financiero propenso a crisis, problemas y desafíos. Fuente: León et al., 2011. Traducción propia.

De esta compleja interacción de características y debilidades, surge la noción de Too connected to fail (TCTF), similar al ya conocido Too big to fail, pero con énfasis en el fenómeno de la interconexión más que en el volumen de capital. Las instituciones too connected to fail se definen como aquellas cuyo nivel de conectividad, directa o indirecta, es tal que su incapacidad para cumplir con sus obligaciones resulta en la incapacidad de otros participantes o instituciones del sistema para cumplir con las suyas propias.

Con estas consideraciones en mente, es imperativo procurar construir un nuevo modelo global de gobernanza financiera que prevenga la repetición de crisis como la del 2008 y postule un paradigma regulatorio eficiente y 
efectivo. Para esto, es esencial que los países en desarrollo participen activamente y capitalicen de su presencia en los foros de los que forman parte. Los procesos de integración regional, por ejemplo, son una excelente herramienta para alcanzar acuerdos y concertar posiciones que luego puedan ser proyectadas y sostenidas a mayor escala.

Actualmente, presenciamos un período que se replantea seriamente los aspectos más controversiales de la integración global real, como la inmigración y los conflictos comerciales. Sin embargo, los actores internacionales parecen relegar una tarea no menos urgente y aún más desafiante, como lo es el abordaje de las repercusiones de la integración global financiera, en un contexto con un altísimo grado de interconexión y una complejidad que se eleva progresivamente. Si pensamos en la gobernanza global como aquel sistema generalizado que regula las cuestiones humanas a nivel mundial (O’Brien y Williams, 2004), podemos detectar la importancia que posee la formulación de las normas que regulan estas cuestiones. Importancia aún mayor si tenemos en cuenta que se refiere a mercados internacionales en los que se intercambian altísimos niveles de activos, y cuyo accionar en las últimas décadas se ha caracterizado por ser volátil y altamente reversible, viéndose al mismo tiempo afectado por comportamientos grupales y de contagio. Estas particularidades guardan en sí mecanismos de repetición de las crisis que ya hemos experimentado, y factores amplificadores de su gravedad.

De esta forma, es de suma importancia la participación de los países en desarrollo se aboque a la construcción de una nueva gobernanza financiera global, que les permita consolidar sus logros, proteger la estabilidad económica y promover un paradigma más equitativo. Se trata, en definitiva, de abogar por una verdadera alternativa al actual modelo de privatización de las ganancias y socialización del riesgo que termina siempre operando en detrimento del desarrollo.

En consonancia con esto, es indispensable que el peso de los países asiáticos en los organismos multilaterales se condiga de una vez con su lugar estratégico en la economía mundial. Richard Stubbs (2014) señala cómo las contribuciones de la Asociación de Naciones del Sudeste Asiático (ASEAN) a las cuestiones globales son generalmente vistas como marginales. Esto se debe, en gran parte, a la limitada influencia que posee sobre las mayores organizaciones mundiales, como ONU, el FMI, la Organización Mundial del Comercio y el Banco Mundial. Estas organizaciones ya estaban bien establecidas mucho antes de que la ASEAN pudiera comenzar a ejercer cualquier influencia, sin mencionar que sus prácticas y procedimientos son difíciles de cambiar. Sin embargo, prosigue el autor, por sí solo esto constituye una visión simplista que no reconoce la influencia internacional que ha alcanzado la Asociación, y la interesante alternativa paradigmática que ofrece ante el modelo occidental liberal de gobernanza global. 
En los siguientes apartados, relevaremos las particularidades económicas de la ASEAN como proceso de integración regional en el contexto global y el proceso de integración monetaria que tiene lugar al interior de esta región, para destacar las potencialidades de esta organización en la construcción de un nuevo paradigma de gobernanza financiera.

\section{La ASEAN a contracorriente de las tendencias actuales}

Como señalamos en la introducción, la crisis financiera de 2008 produjo cambios en los marcos regulatorios y compromiso por parte de actores políticos para promover la innovación institucional, aunque no así en el statu quo prevalente. El lugar central del que gozaban las economías del G20 y la Unión Europea en la gobernanza económica no fue alterado a raíz de la crisis; sin embargo, en la cumbre del G20 en Pittsburgh en septiembre de 2009 se operó un cambio en la orientación de las iniciativas de los organismos financieros internacionales.

La crisis pareció promover un espíritu organizacional tendiente, en mayor o menor medida, a operar proceso de pluralización de las instancias decisionales. En la Cumbre de Pittsburgh se propuso una revisión de cuotas del FMI y del Banco mundial, en menor medida, que reflejaran la importancia de los países en desarrollo (Kalher, 2010). De la misma forma, el Foro de Estabilidad Financiera (Financial Stability Forum o FSF) pasó a ser el Consejo de Estabilidad Financiera (Financial Stability Council o FSC), entidad sucesoria que sumó cinco países miembros. De estos países, tres no pertenecían al G20 (Singapur, Hong Kong y Suiza), uno pertenecía agregado dentro de la Unión Europea (Países Bajos) y el último pertenecía al G20, pero no al que otrora era el FSF (China)

Es interesante notar que la incorporación de economías asiáticas emergentes como Singapur y Hong Kong, además de la adhesión de China a un organismo de gobernanza como es el FSC, constituye un reconocimiento al traslado hacia continente asiático de una significativa porción del peso económico global. No obstante, la influencia de Asia en la gobernanza financiera global sigue sin ser consistente con su peso en la economía global (Henning y Khan, 2011). Asimismo, la presencia de países como India, China, Corea del Sur e Indonesia en el seno del G20 representa una ventana de oportunidad para influir en las altas esferas de decisión del escenario internacional.

Hoy en día, podemos afirmar que es pertinente hablar de un escenario económico internacional complejo y altamente volátil. La guerra comercial entre Estados Unidos y China ha venido a consolidar el pesimismo originado en las escasas perspectivas de crecimiento previstas para este 2019. Ya a fin del primer semestre de este año el Banco Mundial calificó al 2019 como un año 
con tensiones agudizadas e inversiones disminuidas, ${ }^{3}$ durante el cual se espera una alarmante caída del crecimiento económico mundial que lo pondría a nivel de un año conflictivo como fue 2016

Sin embargo, a más de cincuenta años de su creación, la ASEAN es uno de los procesos de integración regional de larga data que en la actualidad conserva un dinamismo económico y político activo, en comparación a otros procesos de integración que se encuentran atravesando diversas dificultades al interior de sus estructuras. Basta mirar hacia Europa para ver los desafíos que ha planteado el Brexit en términos de unidad y costos políticos, y las implicancias regionales y extrarregionales que conllevan el abandono de Gran Bretaña de su lugar en el foro europeo.

Del mismo modo, la realidad regional del Cono Sur se presenta se presenta compleja y plagada de desafíos para un proceso de integración que siempre ha estado altamente expuesto a los cambios de signo político de los gobiernos de la región, y que ahora debe lidiar además con miembros que experimentan importantes crisis económicas, rupturas del orden constitucional y una relación espinosa entre los dos mayores países integrantes.

De esta forma, la distintiva situación macroeconómica de la que gozan las economías del Sudeste Asiático no es solo una particularidad favorable, sino que, a la vez, que se configura en una plataforma desde la cual estos países pueden construir las bases de una política exterior más proactiva desde la cual poder proyectarse más asertivamente. En este caso, uno de los hechos más notables que se da en el marco de la ASEAN es el progresivo y sostenido crecimiento económico que han alcanzado los países miembros, situando el promedio regional en un elevado 5,1\%.

\begin{tabular}{|c|c|c|c|c|c|c|c|c|c|c|c|}
\hline Etonomy & $\begin{array}{l}\text { Brand } \\
\text { Oansulam }\end{array}$ & Cambodal & Fidsanesia & Las PBR & Malapia & Myminar & Pillppine & Sngupsen & EThailund & Vist Wan & ASEAN \\
\hline COF at aurart proce (US56) & 13.6 & 245 & $104: 6$ & 18.1 & 354.2 & 71.5 & 342.6 & 3618 & 5051 & 209.7 & 29729 \\
\hline GOP per capta (USS) & $31,695,1$ & 1,5355 & 3,507 & 2,6278 & 10.907 .7 & 1.328 .2 & $3,213,3$ & 64.2739 & $7,43.5$ & 25026 & $4.57 \pi .1$ \\
\hline hea GOP grouth (\$)] & 0.1 & 70 & 52 & 67 & 4.6 & 64 & 62 & 33 & 41 & 7.1 & 51 \\
\hline Hatinn ate surrago fis & 0.2 & na & 32 & 20 & 0.9 & 69 & 53 & 04 & 1.1 & 35 & 0.2 .69 \\
\hline
\end{tabular}

Tabla 1: PBI por país integrante de la ASEAN.

Fuente: ASEAN Economic Integration Brief, 2019

Las economías emergentes asiáticas comenzaron su recuperación de la crisis financiera antes y más robustamente que sus contrapartes en otras regiones en desarrollo (Goldstein y Xie, 2009). Incluso podemos observar que

${ }^{3}$ https://www.bancomundial.org/es/publication/global-economic-prospects 
el dinámico desempeño económico de los países miembros de la ASEAN se presenta como una excepción que contrasta el crecimiento ralentizado generalizado entre sus pares occidentales y de algunas economías vecinas, como Japón.

\begin{tabular}{|l|r|r|r|r|r|r|r|}
\hline & 2015 & 2016 & 2017 & 2018 & 2019 & 2020 & 2021 \\
\hline Mundo & $\mathbf{2 , 9}$ & $\mathbf{2 , 6}$ & $\mathbf{3 , 1}$ & $\mathbf{3 , 0}$ & $\mathbf{2 , 6}$ & $\mathbf{2 , 7}$ & $\mathbf{2 , 8}$ \\
\hline Economías avanzadas & $\mathbf{2 , 3}$ & $\mathbf{1 , 7}$ & $\mathbf{2 , 3}$ & $\mathbf{2 , 1}$ & $\mathbf{1 , 7}$ & $\mathbf{1 , 5}$ & $\mathbf{1 , 5}$ \\
\hline Estados Unidos & 2,9 & 1,6 & 2,2 & 2,9 & 2,5 & 1,7 & 1,6 \\
\hline Zona euro & 2,1 & 2,0 & 2,4 & 1,8 & 1,2 & 1,4 & 1,3 \\
\hline Japón & 1,2 & 0,6 & 1,9 & 0,8 & 0,8 & 0,7 & 0,6 \\
\hline
\end{tabular}

Tabla 2: Perspectivas de crecimiento para 2019, 2020 y 2021.

Fuente: Banco Mundial

Vietnam es el país de la ASEAN con la mayor tasa de crecimiento y cuyo PBI ha experimentado una impresionante expansión en la última década, superando incluso las expectativas del Banco Mundial para 2018 que preveían un $6,8 \%{ }^{4}$ para ubicarse casi en el $7,1 \%$. Los sectores de la economía vietnamita que más dinamismo mostraron durante el primer cuarto del 2019 fueron la industria $(2,68 \%)$, los servicios $(6,5 \%)$, la construcción $(8,63 \%)$ y la manufactura y procesamiento $(12,35 \%) .^{5}$

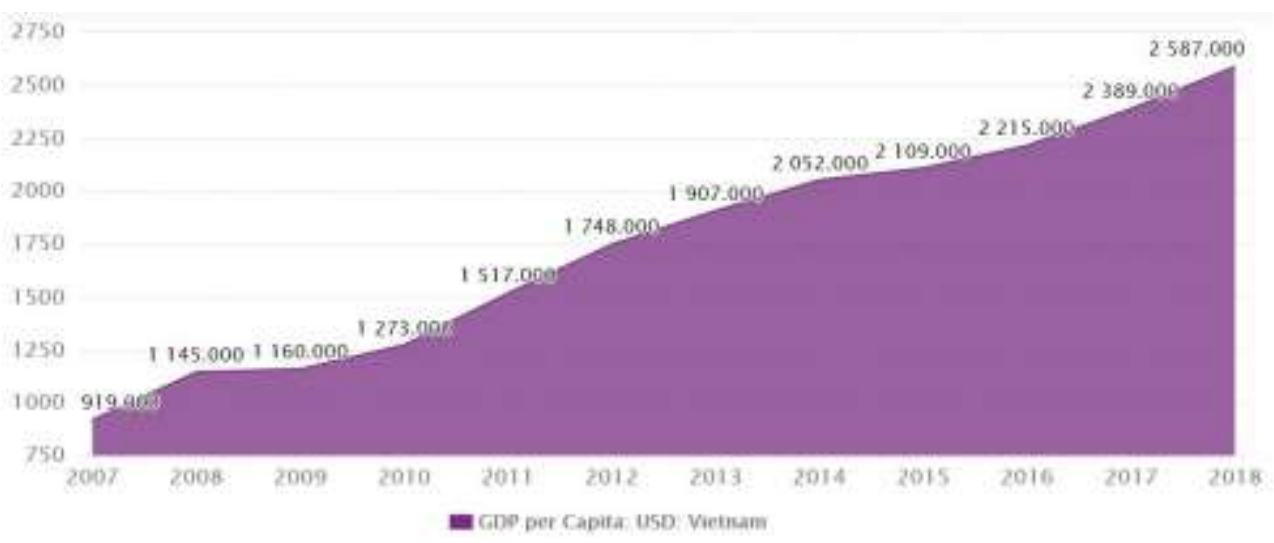

Gráfico 2: Crecimiento del PBI de Vietnam en millones de dólares (2007-2018) Fuente: www.ceicdata.com

\footnotetext{
${ }^{4}$ https://www.worldbank.org/en/news/press-release/2018/06/14/vietnams-economicprospect- improves-further-with-gdp-projected-to-expand-by-68-percent-in-2018 ${ }^{5}$ https://vietnamnews.vn/economy/518041/viet-nams-economic-growth-impressivein- q1.html\#3K8eXXM7iEgWFwwx.97
} 


\begin{tabular}{r|r|}
\hline \multicolumn{2}{|c|}{ Evolución PBI de Vietnam } \\
\hline Año & \multicolumn{1}{c|}{ Crecimiento $\%$} \\
\hline 2007 & 7,13 \\
\hline 2008 & 5,66 \\
\hline 2009 & 5,4 \\
\hline 2010 & 6,42 \\
\hline 2011 & 6,24 \\
\hline 2012 & 5,24 \\
\hline 2013 & 5,42 \\
\hline 2014 & 5,98 \\
\hline 2015 & 6,68 \\
\hline 2016 & 6,21 \\
\hline 2017 & 6,81 \\
\hline 2018 & 7,08 \\
\hline Promedio & 6,19 \\
\hline
\end{tabular}

Tabla 2: Crecimiento del PBI de Vietnam en porcentajes (2007-2018)

Fuente: elaboración propia con datos del Banco Mundial

Una característica que vale la pena destacar de la experiencia vietnamita es el énfasis en el incremento de la productividad que le han dado los actores políticos de ese país. En el Vietnam Development Forum, el primer ministro, Nguyen Xuan Phuc, enfatizó el rol de la productividad en la conformación de bases sólidas que permitan mejorar la competitividad del país. ${ }^{6}$ El Premier, además, enfatizó la importancia de llevar a cabo reformas financieras y bancarias para orientar los flujos de capital hacia industrias de alta productividad, así como proveer acceso al financiamiento a pequeñas y medianas empresas.

El sector manufacturero juega un rol destacado en la estructura económica de los países de la ASEAN. A pesar de una pequeña caída en el índice de compras de los gerentes (índice que mide especialmente el desempeño del sector manufacturero), que ralentizó o redujo levemente el crecimiento de esta variable en algunos de los países miembros, ${ }^{7}$ podemos ver en el siguiente gráfico que la ASEAN mantiene un promedio saludable de casi 50 puntos. Esto lo coloca actualmente por encima del promedio de la Zona euro (46,9), y otras economías emergentes, como Rusia $(45,6)$ y Sudáfrica $(48,6) .^{8}$

${ }^{6}$ https://www.vir.com.vn/in-record-2017-vietnam-living-up-to-its-potential55244.html

7 https://www.nationthailand.com/noname/30374026

${ }^{8}$ https://www.markiteconomics.com/public?language $=\mathrm{es}$ 


\section{LOLA IBÁÑEZ}

\begin{tabular}{|c|}
\hline Asia \\
America \\
Latina
\end{tabular}

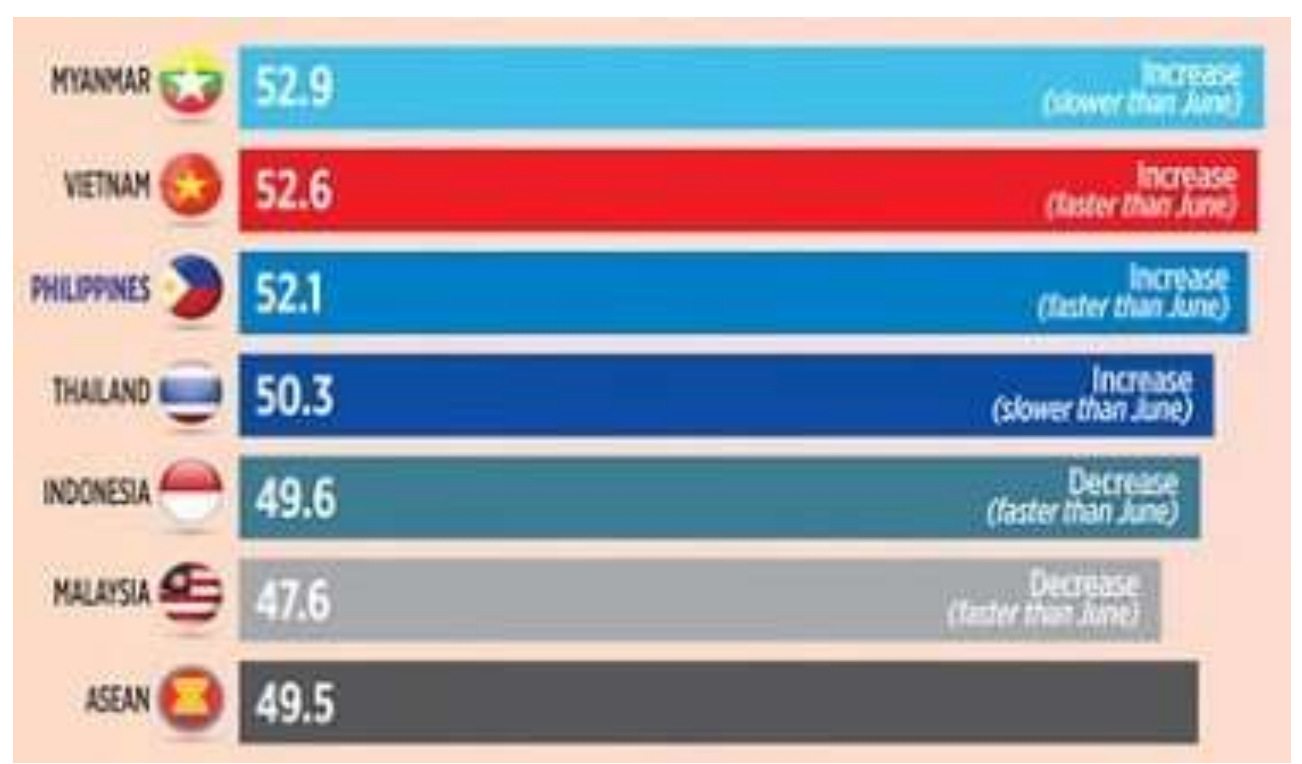

Gráfico 5: Purchasing Managers' Index por país y promedio regional Fuente: www.bworldonline.com

Si bien la ASEAN tiene un lugar estratégico en la cadena de valor global, el consumo doméstico y las inversiones jugaron un rol primordial para que el crecimiento en 2018 se mantuviera por encima del 5\%. ${ }^{9}$ En algunos países miembros como Filipinas el consumo doméstico contribuye a alrededor del $70 \%$ de la producción nacional, por lo que, muchas veces, estos incrementos en el PMI responden a incrementos de la demanda interna, que reflejan el aumento del poder de compra de los ciudadanos y medidas impositivas expansivas, como la reducción de impuestos sobre los ingresos personales, como los implementados por el gobierno filipino en enero de $2018 .^{10}$

Por otro lado, los flujos de inversión externa directa (IED) son otro aspecto de relevancia a tener en cuenta. En las últimas décadas, la ASEAN se ha transformado en un destino atractivo para los flujos de capitales. Solamente entre 2016 y 2017, el total de flujos de IED hacia la ASEAN se elevó de 123.000 millones de dólares a 137.000 millones; en paralelo, el flujo de IED desde la ASEAN hacia economías en desarrollo aumentó de 18\% en 2016 a $20 \%$ en 2017 , y los flujos hacia sur y este de Asia subieron del $31 \%$ al $34 \%$ en los mismos años. ${ }^{11}$

\footnotetext{
${ }^{9}$ https://asean.org/storage/2019/06/AEIB_5th_Issue_Released.pdf

10 https://www.bworldonline.com/phl-factory-gain-strongest-in-6-months /

${ }^{11}$ https://asean.org/storage/2018/11/ASEAN-Investment-Report-2018-for-
} 


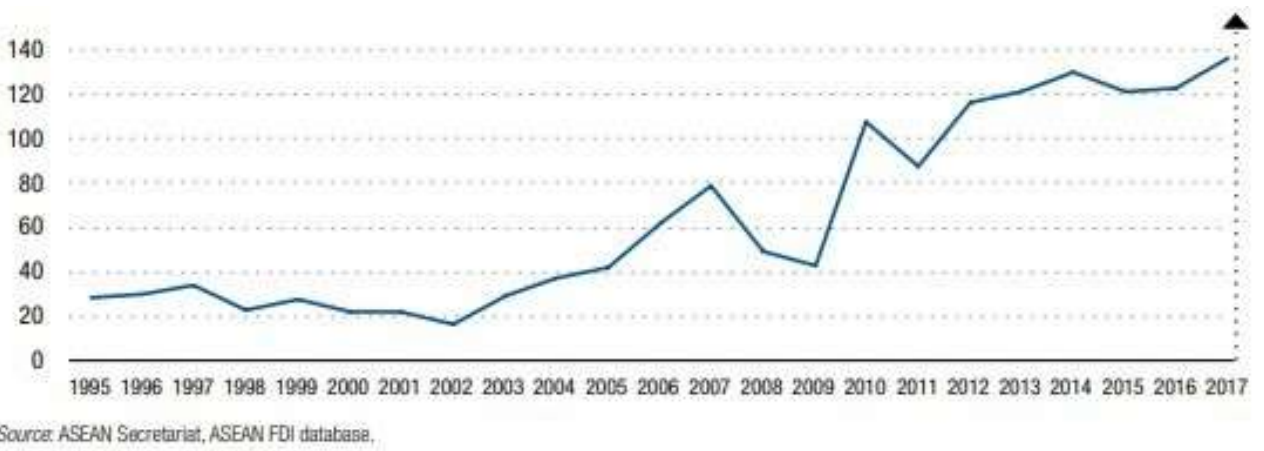

Gráfico 6: Evolución del volumen de inversión externa directa en la ASEAN Fuente: ASEAN Investment Report 2018

En 2017, solamente tres Estados (Singapur, Indonesia y Vietnam) daban cuenta del $72 \%$ de los flujos de IED hacia la ASEAN, lo cual muestra un alto nivel de concentración en su distribución. No obstante, esto representa una menor proporción en comparación con el 79\% que regía entre 2012 y 2016. Por su parte, Singapur se mantuvo como como el mayor recipiente de IED, concentrando el 45\% de los flujos destinados a la ASEAN incluso con la caída experimentada de 77.000 a 62.000 millones de dólares de inversiones.

Es sumamente interesante rastrear la evolución que han tenido no solo los indicadores macroeconómicos en los países de la ASEAN, sino también los indicadores sociales y de desarrollo. Si bien crecimiento económico no equivale a desarrollo, los países miembros han procurado un esquema de liberalización comercial con desarrollo de su estructura productiva, lo que les provee una mejor base desde la cual incrementar su productividad y competir a nivel global.

Con una mirada previsora, los países de la ASEAN supieron traducir el sostenido crecimiento económico del que goza esta región en un aumento del bienestar de la población, reduciendo el desempleo y aumentando el poder de compra, aumentando la proporción invertida del PBI en educación y reduciendo drásticamente (y en algunos caso prácticamente extinguiendo) el índice de analfabetismo, al mismo tiempo que incrementaron los índices de ingreso a la educación superior, ${ }^{12}$ esto en cuestión de pocas décadas. Asimismo, el cambio climático ${ }^{13}$ y el bienestar y la incorporación más activa de la juventud

\footnotetext{
Website.pdf

12 https://ched.gov.ph/wp-content/uploads/2017/09/2016-ASEAN-Indicators-asof-8-August-2017.pdf

13 https:/ / environment.asean.org/wp-content/uploads/2018/01/SOER5.pdf
} 
asiática, ${ }^{14}$ la infraestructura y la urbanización ${ }^{15}$ se han transformado también en temas de agenda que actualmente ocupan los foros regionales para incrementar el desarrollo social del Sudeste Asiático.

\section{Integración monetaria y financiera en la ASEAN}

Desde inicios del 2000, los países del este y sudeste de Asia se han inclinado por la cooperación regional en asuntos financieros y la integración monetaria. La introducción del euro y las repercusiones de la crisis asiática fueron importantes catalizadores de estas inclinaciones. Esto demostró que es posible implementar una divisa propia y dio origen a cuestionamientos en torno a la alta dependencia de estas economías con respecto al dólar (Dieter, 2008).

De esta manera, monetarismo regional y acuerdos de libre comercio han cobrado particular importancia en el continente asiático. El establecimiento de la Comunidad Económica de la ASEAN (AEC) en 2015, significó un hito mayor en términos de la constitución de un mercado regional de más de 622 millones de personas y equivalente a 2.6 billones de dólares, esto lo posicionó como el tercer mercado más grande de Asia y el séptimo nivel mundial. ${ }^{16}$ Más economías integradas significa un mercado más grande, lo que representa también más recursos disponibles para hacer frente a los problemas que se presenten.

Coincidimos con Heribert Dieter (2008) cuando afirma que la integración monetaria y financiera de la ASEAN se concentra en metas determinadas: 1) facilitamiento del comercio de bienes y servicios mediante la provisión de condiciones de estabilidad monetaria, 2) aseguramiento de mercados financieros eficientes y de buen funcionamiento, 3) prevención de crisis financieras y 4) dirección regional de crisis de crédito y divisas.

Así, el emergente monetarismo regional apunta a conservar la estabilidad financiera regional, incluso en un contexto de inestabilidad financiera global, prevenir ataques especulativos sobre las monedas nacionales y posibilitar a los países miembros un margen de maniobra con respecto al tipo de cambio, para formular políticas sostenibles y estables en un escenario de crisis y contagio (Dayaratna-Banda y Whalley, 2007).

Para amplificar el alcance de las capacidades y estrategias nacionales, los gobiernos tienden a crear coaliciones con otros gobiernos con los que poseen afinidades de distinta índole y así, aumentar su poder de negociación. Una región con peso en términos económicos, como lo es el Sudeste Asiático,

\footnotetext{
14 https://asean.org/storage/2017/10/ASEAN-UNFPA_report_web-final-05sep.pdf 15 https://asean.org/storage/2019/10/Investing_in_ASEAN_2019_2020.pdf

16 https://asean.org/asean-economic-community/
} 
representaría un potencial incremento en la influencia sobre la dirección de la gobernanza global. Esto, aunado a una coalición política coherente, otorgaría un considerable poder de negociación para posicionarse frente a las economías centrales (Kahler, 2010).

Más allá de las potencialidades de la ASEAN para influir en la gobernanza global, y más específicamente en la gobernanza financiera, primero es necesario que sus países miembros se planteen una estrategia coalicional viable con respecto a la potencia más cercana, China. Además, un desafío no menor se presenta al intentar alcanzar un consenso en relación con qué modelo de gobernanza promover como región, teniendo en cuenta la gran diversidad presente entre los países de la ASEAN.

Por lo pronto, los países del Sudeste parecen estar concentrando esfuerzos colectivos en la creación de mecanismos de cooperación financiera. Los primeros rastros de regionalismo financiero pueden rastrearse hacia 1977, cuando las autoridades monetarias de los cinco países originales de la ASEAN (Indonesia, Malasia, Filipinas, Singapur y Tailandia) implementaron acuerdos recíprocos de swaps, conocidos como ASEAN Swap Arrangements (ASA). ${ }^{17}$ Sin embargo, estos arreglos eran demasiado modestos como para amortiguar el impacto de la crisis financiera.

La Iniciativa Chiang Mai (CMI) fue creada en el año 2000, expandiendo el monto de los swaps bilaterales de ASA y extendiéndose a todos los nuevos miembros de la ASEAN, Corea del Sur, Japón y China (lo que comúnmente se conoce como la ASEAN+3). Además de una red de seguridad, la iniciativa fue pensada como una alternativa al Fondo Monetario, organismo que despertaba profundo recelo y reparos luego de la crisis de los noventa, las políticas de ajuste que había requerido como condición por sus préstamos y las consecuencias de éstas. Aunque frente a la crisis de 2008, economías como Corea del Sur y Singapur prefirieron recurrir a la Reserva Federal.

En 2009, la Iniciativa Chiang Mai se multilateralizó, transformándose en la CMIM (Chiang Mai Initiative Multilateralization). Un acuerdo de pooling de reservas donde los países de la ASEAN contribuirían con el $20 \%$ de los fondos, y los +3 con el 80\%, lo que en 2010 representaba 120.000 millones de dólares, accesibles a los países miembros como alternativa a otras fuentes de divisas estadounidenses. En 2011, se creó una unidad de vigilancia conocida como la Oficina de Investigación Macroeconómica de la ASEAN+3 (AMRO); y en 2012, se implementó el Encuentro de ministros de Hacienda y directores de los Bancos Centrales de la ASEAN +3, un foro común donde los responsables de la política económica y fiscal se reunían periódicamente.

En mayo de 2019, en una reunión del Encuentro de ministros decidió que la CMIM también contemplaría swaps en moneda local, no solo dólares

17 https://asiancenturyinstitute.com/economy/248-chiang-mai-initiative-an-asian-imf 
estadounidenses. ${ }^{18}$ Esta decisión refleja no solo la importancia progresiva del yuan en los intercambios regionales, sino también un producto de la incertidumbre global generada por la guerra comercial entre China y Estados Unidos. Esto responde a las metas regionales que Heribert Dieter (2008) detecta, especialmente aquellas referidas a la facilitación de los intercambios regionales y la conservación del buen funcionamiento y eficiencia del mercado financiero.

A pesar de los avances realizados en materia de integración monetaria para la estabilidad financiera, aún existen barreras que impiden que los mecanismos de Chiang Mai, aunque potencialmente beneficiosos, se desempeñen con efectividad. Un primer problema, lo presenta el nivel de los fondos disponibles a través de la CMIM, que continúan siendo demasiado modestos como para ser efectivos y resultar una alternativa plausible al FMI. ${ }^{19}$ Además, las marcadas diferencias en el tamaño de las economías al interior de la ASEAN pone en cuestión el tema del porcentaje de las reservas que deberá y podrá aportar cada miembro. Teniendo en cuenta que la protección de los socios más vulnerables y menos pudientes del esquema regional es esencial para la credibilidad y el funcionamiento de cualquier iniciativa.

Por otro lado, aunque la implementación de la Oficina de Investigación Macroeconómica sea una excelente herramienta para el monitoreo de las finanzas regionales, todavía carece de la fuerza necesaria para imponer sistemas de vigilancia y requerimientos a los actores que participan del circuito financiero. Si nos remitimos al acuerdo de creación de este órgano, podemos observar carece de la capacidad de acceder a cierta información empresarial que le resultaría vital en caso de grandes movimientos especulativos. ${ }^{20}$

Como podemos ver, la CMIM aún tiene camino que recorrer si quiere transformarse en una alternativa regional viable a los organismos de crédito de las economías centrales, pero no podemos dejar de reconocer los progresos que se han realizado en materia de integración monetaria para el mantenimiento de la estabilidad financiera. Asegurar un crecimiento sostenible y la consolidar los logros obtenidos son aspectos que los países en desarrollo no pueden darse el lujo de relegar en el orden de prioridades.

\section{Conclusiones}

No parece que las tendencias económicas favorables vayan a alterarse en un futuro cercano, aunque mantenimiento de la trayectoria de éxito económico y social dependerá (más allá del contexto global) de cómo los países

\footnotetext{
18 https://thediplomat.com/2019/05/reforming-the-chiang-mai-initiative/

${ }^{19}$ https://asiancenturyinstitute.com/economy/248-chiang-mai-initiative-an-asian-imf

${ }^{20}$ https://amro-asia.org/wp-content/uploads/2016/09/amro-agreement.pdf
} 
de la ASEAN enfrenten los desafíos que se plantean a mediano y corto plazo. Las perspectivas de crecimiento podrían verse afectadas si la región no puede alcanzar algún grado de coordinación política que le permita consolidar y expandir sus logros, y asegurar una prosperidad económica sostenible por medio del esquema regional.

Asia es una región sumamente heterogénea en todos los aspectos, comparada con Europa o América. La brecha entre países de renta baja y alta es mucho mayor que en cualquiera de las otras regiones a pesar de los avances obtenidos en las últimas décadas y, por ende, las diferencias de poder entre los países se hacen sentir constantemente.

Miles Kahler (2010) señala que otro desafío fundamental al que deberá hacer frente la ASEAN es la dependencia externa de la región, que constituye una característica estructural de su esquema económico. La organización de la cadena de valor global en la que se insertó la región continúa teniendo a las economías desarrolladas como destinos de exportación principales, lo cual genera una situación de fuerte dependencia con esas economías y vulnerabilidad ante las disrupciones que en ellas se produzcan. La apertura económica es una buena herramienta de desarrollo y una forma de proyectar presencia en el escenario internacional, pero esa apertura puede convertirse en una barrera al momento de construir un posicionamiento político coherente y cohesionado.

Además, la preferencia por un bajo grado de institucionalización al interior del esquema regional puede dificultar la consecución de un posicionamiento cohesionado. Las prácticas conocidas como la "manera ASEAN" de hacer las cosas (the ASEAN way) pueden resultar un arma de doble filo. Existe en la región un entendimiento en torno a los principios de no interferencia, que descansa en la creencia de que los problemas domésticos deben tener soluciones domésticas, ya que los Estados miembros son capaces de dar respuestas propias a sus propios problemas (Suzuki, 2019). Si bien este principio resulta razonable en algunos aspectos, las problemáticas que se generan en el ámbito financiero no responden a esta lógica. Como expusimos en la introducción, las características del sistema financiero actual son perfectamente capaces de trivializar los esfuerzos domésticos, si éstos no vienen acompañados de respuestas conjuntas.

En los últimos años, hemos presenciado la afluencia de fuerzas disruptivas del orden internacional establecido, lo cual no solo implica la emergencia y disputa del poder por parte de nuevas potencias, como China. Las tendencias proteccionistas y las oleadas nacionalistas que surgen en diferentes latitudes son un indicador preocupante de la preferencia por soluciones domésticas a problemáticas claramente globales.

Es de vital importancia promover soluciones conjuntas a cuestiones complejas, como aquellas relacionadas con el sistema financiero, y los procesos 
de integración regional establecidos conforman un espacio político propicio para alcanzar consensos básicos y dar visibilidad a discusiones fundamentales en el escenario internacional. Los países de la ASEAN pueden capitalizar sus logros socioeconómicos y aprovechar la coyuntura internacional para abogar por un nuevo paradigma de gobernanza, el cual sea capaz de proveer seguridad y estabilidad para que las economías en desarrollo se mantengan en la senda del crecimiento y el bienestar social.

\section{Referencias bibliográficas}

DIETER, H. (2014). ASEAN and the emerging monetary regionalism: a case of limited contribution. The Pacific Review. https:/ / doi.org/10.1080/09512740802294531

GARCÍA-ARIAS, J. (2008) Finanzas internacionales y desarrollo: ¿oportunidad o amenaza? Revista de la CEPAL https://repositorio.cepal.org//handle/11362/11285

GoldsteIN, M Y XIE, D. (2009). The impact of the financial crisis on emerging Asia. Peterson Institute for International Economics, 9-11.

https://www.piie.com/publications/wp/wp09-11.pdf

HenNing, R y KHAN, M (2011). Asia and Global Financial Governance.

Peterson Institute for International Economics, 11-16

https://www.piie.com/sites/default/files/publications/wp/wp1116.pdf

KAHLER, M (2010). Asia and the reform of Global Governance. Asian Economic Policy Review. https://doi.org/10.1111/j.1748-3131.2010.01160.x

León, C., Machado, C., Cepeda, F. y SARmiento, M. (2011). Too connected to fail Institutions and Payment System's stability: Assessing Challenges for Financial Authorities. Borradores de Economia (644) https:/ /dx.doi.org/10.2139/ssrn.2101221

Nesadurai, H (2008). The Association of Southeast Asian Nations (ASEAN). New Political Economy https://doi.org/10.1080/13563460802018588

O’Brien, R y Williams, M. (2004). Global Political Economy, evolution and dynamics. Macmillan.

STUBBS, R. (2014). The ASEAN alternative? Ideas, institutions and the challenge to global governance. The Pacific Review. https://doi.org/10.1080/09512740802294713

SUZUKI, S. (2019). Why is ASEAN not intrusive? Non-interference meets state strength. Journal of Contemporary East Asia Studies. https://doi.org/10.1080/24761028.2019.1681652 
Un clima para el cambio. Oportunidades y desafíos para la articulación interregional ASEAN-MERCOSUR en materia de cambio climático

DiEgo TOLEDO

\section{UN CLIMA PARA EL CAMBIO. OPORTUNIDADES Y DESAFÍOS PARA LA ARTICULACIÓN INTERREGIONAL ASEAN- MERCOSUR EN MATERIA DE CAMBIO CLIMÁTICO}

\section{Diego Toledo}

Universidad Católica de Córdoba

toledo_bugarini@hotmail.com

\section{Introducción}

El cambio climático se ha convertido en uno de los principales temas de la agenda política global. En la medida en que los plazos para afrontar el problema son cada vez más reducidos y sus consecuencias se hacen más notorias, se vuelven más relevantes los estudios sobre el tema. Para el caso de los países del Sur Global, los incrementos de los impactos conllevan una profundización de los problemas ya existentes en nuestras sociedades como son las desigualdades multidimensionales, la forma de vinculación con el ambiente y el engranaje productivo-comercial.

El presente trabajo pretende abordar las relaciones ASEANMERCOSUR desde una perspectiva interregional y un nivel macro de análisis, enfatizando en la temática del cambio climático y exponiendo un marco general de posibilidades que se abren para la cooperación sur-sur entre ambos bloques o entre sus Estados parte. Esto debido a que se entiende que, hasta el momento, las iniciativas interregionales entre ambos bloques funcionan como un complemento al bilateralismo entre Estados de América del Sur y del Sudeste Asiático (SEA en adelante) (Rubiolo, 2016).

La elección del tema responde no solo a la relevancia política de la agenda del cambio climático y su integración con la agenda social y gubernamental de los países mencionados, sino que además espera resultar innovadora en tanto se constata que la mayoría de los estudios que abordan las relaciones SEA-América del Sur se dirigen al análisis de las transformaciones, desafíos y potencialidades del flujo e intercambio comercial entre países de ambas regiones (Ramoneda, 2013).

El diseño metodológico es de tipo cualitativo. Se emplean técnicas de recolección de datos provenientes de fuentes primarias (documentos oficiales de ASEAN, MERCOSUR) y secundarias (artículos publicados en revistas científicas, policy briefs de organismos especializados en la temática, etc.). El análisis documental, tanto estadístico como cualitativo, es la principal técnica de análisis de información. No existe un recorte temporal explícito dado que entiende la construcción institucional y de agenda de ambos bloques como un 
Un clima para el cambio. Oportunidades y desafíos para la articulación interregional ASEAN-MERCOSUR en materia de cambio climático

DiEgo TOLEDO

proceso abierto. Sin embargo, el lector encontrará que los principales desarrollos parten desde inicios de este siglo hasta el presente (2000-2019).

El texto, entonces, se estructura en torno a cuatro apartados. El primero, plantea algunas notas sobre el contexto global en el cual se despliegan las relaciones interregionales. El segundo, expone algunos apuntes en torno a la gobernanza global del cambio climático y explora el posicionamiento y la situación de los países ASEAN-MERCOSUR en relación con la temática. Luego, se presentan las trayectorias que los países de ASEAN y del MERCOSUR han seguido para responder a las problemáticas del cambio climático, se analizan sus dificultades y se explora la posibilidad de articulaciones, transferencias y formatos de cooperación sursur entre ambos bloques. Finalmente, se presentan algunas conclusiones a modo de síntesis.

\section{Declive de Occidente, ¿̇ascenso del resto ${ }^{1}$ La relevancia de la articulación ASEAN-MERCOSUR en el actual escenario global}

El escenario internacional actual está atravesando un momento crítico, de transformación. El mundo multipolar en el que vivimos está surcado por una globalización en crisis y por una disputa por el liderazgo mundial. Hasta el momento, la crisis de la globalización conlleva movimientos paradójicos. Mientras siguen intentándose algunos avances en mega acuerdos o iniciativas de "regionalismo del siglo XXI" (Baldwin, 2011; Zelicovich, 2016), se percibe el "retorno" al proteccionismo y un inquietante ascenso de nacionalistas de derecha en diversas partes del globo (Sanahuja, 2019). Estos cambios vienen acompañados de una revitalización de los acuerdos bilaterales de libre comercio y de virajes en las formas del multilateralismo, que transita desde "lo abierto e incluyente" -influido por el fracaso de las negociaciones en las rondas de la Organización Mundial del Comercio (OMC) - hacia los "Foros G" (Sanahuja 2019) o alternativas de multilateralismo corporativo (Tussie, 2019).

En paralelo, se experimenta el desarrollo y convergencia de nuevos actores emergentes -como los denominados BRICS (Brasil, Rusia, India, China y Suráfrica) - y el desenvolvimiento de diversos polos de poder frente a las hegemonías "tradicionales" o históricas de Estados Unidos y Europa.

\footnotetext{
${ }^{1}$ El título del apartado pone en clave interrogativa una afirmación del analista Barry Buzan. Considero que el tono cuestionador resulta una forma más propicia para el análisis que, además, evita caer en interpretaciones proclive al "choque de civilizaciones" o la "Trampa de Tucídides", que nos lleva a creer que las respuestas o disuasión armada son la solución a un contexto de crisis o transición hegemónica (bloque histórico hegemónico).
} 
Un clima para el cambio. Oportunidades y desafíos para la articulación interregional ASEAN-MERCOSUR en materia de cambio climático

Diego Toledo

Particularmente, el actual enfrentamiento entre China y Estados Unidos -que excede lo comercial ${ }^{2}$ - juega un rol fundamental en el reordenamiento geoeconómico y político a nivel mundial.

Para el caso latinoamericano, la presencia de China era algo prácticamente insignificante hasta el inicio del nuevo milenio. Con el ingreso de China a la OMC en 2001, el cambio comenzó a gestarse (Ramón Berjano, 2019, p. 37). Desde entonces, China se ha vuelto el primer o segundo socio comercial de los países latinoamericanos y se ha convertido en la principal fuente de financiamiento de proyectos de desarrollo regional, por encima de los organismos tradicionales como el BID o el BM (Tussie, 2019, p. 110). Hasta tal punto llega la interconexión que, en 2017, durante el Foro de la Iniciativa de la Ruta de la Seda en Beijing el presidente Xi Jinping llegó a referirse a la región como "la extensión natural" de la Iniciativa (Ramón Berjano, 2019, p. 43).

El aumento de esta interdependencia latinoamericana hacia China (Piccone, 2016), y el hecho de que los países latinoamericanos definitivamente no pueden dejar de colocar sus materias primas en el mercado chino (Tussie, 2019, p. 113) genera, como contraparte, una presión más fuerte hacia América Latina por parte de los Estados Unidos, que siente amenazada no solo su economía sino también la hegemonía en lo que históricamente ha considerado su "patio trasero". Por ello, apoyado en la doctrina del "American First" -que no es más que una reactualización histórica de la idea del Destino Manifiesto y de un sentido auto adjudicado de excepcionalidad-, Estados Unidos (con Trump a la cabeza) está reforzando su "ofensiva" hacia lo que hoy explícitamente nombra como "países de mierda". Es importante anotar aquí algunos antecedentes que juegan un rol en este aspecto. El rechazo al ALCA (2005) y el desarrollo de iniciativas regionales como ALBA-TCP y la UNASUR (particularmente su Consejo de Defensa) supusieron trabas concretas al ejercicio de influencia estadounidense en la región. Sin embargo, con el actual declive del proyecto post-liberal de integración y el desplazamiento de la gran mayoría de gobiernos progresistas que le dieron sustento durante la década del 2000, Estados Unidos encuentra una nueva correlación de fuerzas en la que puede recuperar su influencia.

\footnotetext{
2 De acuerdo con Tussie (2019, p. 108-109) "China hoy representa el centro de una histórica transformación del sistema contemporáneo”. Además del exponencial crecimiento de su PIB, se convirtió en uno de los principales consumidores de energía eléctrica del planeta, sacó a 740 millones de personas de la pobreza, y se está posicionando como un gran acreedor mundial con la acumulación de U\$S3 trillones de reservas internacionales, diplomacia financiera que utiliza para generar simpatías y para reducir la eficacia del "castigo financiero" de Estados Unidos como medida de presión internacional.
} 
Un clima para el cambio. Oportunidades y desafíos para la articulación interregional ASEAN-MERCOSUR en materia de cambio climático

DIEGO TOLEDO

$\mathrm{Al}$ mismo tiempo, y con ayuda de think tanks conservadores, Estados Unidos intenta expandir la interpretación de la presencia china en la región como una nueva forma de colonialismo (Tussie, 2019). Pero, la permanencia de un modelo extractivista no puede adjudicarse únicamente a la profundización de las relaciones comerciales con China. La acusación de colonialismo no encuentra demasiado sustento porque China no muestra interés en "exportar" su propio modelo político, económico o social. De hecho, para la diplomacia china una asociación estratégica se basa en la complementariedad y la cooperación, y no se dirige contra un tercer Estado y tiene eje en la economía (Tussie, 2019, p. 111). Esa es su principal diferencia con Estados Unidos.

Asimismo, en el Sudeste Asiático se perciben tensiones similares en torno al enfrentamiento China-Estados Unidos. La vecindad con China y su rol hegemónico en la región implica para ASEAN una alianza ineludible que convive con el surgimiento de contrapesos políticos dentro y fuera de la región, principalmente de India, Rusia, y Estados Unidos (Buzan, 2012). La presencia de Estados Unidos en el SEA sigue replicando la lógica de la Guerra Fría y, en tanto el Acuerdo Trans Atlántico de Comercio e Inversión (TTIP) que marcó el "pivote a Asia" en 2008 hoy se encuentra en pausa, el mantenimiento de las "áreas de influencia" corre por la vía de las relaciones bilaterales.

Cabe mencionar que, si bien la integración latinoamericana eventualmente "responde" a los mencionados enfrentamientos hegemónicos globales con iniciativas más favorables o menos hacia Asia o hacia Estados Unidos-Europa; el estado heterogéneo, complejo y lleno de altibajos de la integración regional nos habla de un panorama que excede la "fractura Atlántico-Pacifico" (Sanahuja, 2016). En este sentido, se observa la coexistencia de proyectos como CAN (año), MERCOSUR (1991), ALBATCP (2004), UNASUR (2008), Alianza del Pacífico y CELAC (2011), PROSUR (2019).

Por su parte, el SEA transita transformaciones profundas relacionadas con la profundización de ASEAN como bloque, el despliegue de una nueva etapa de desarrollo económico en China, y los avances en las mega negociaciones -como el Trans-Pacific Partnership (TPP) suscrito, pero no vigente, el mencionado TTIP, y el Regional Comprehensive Economic Partnership (RCEP) impulsado por China que vincula toda la región de Asia Pacífico (ASEAN +6) (Bartesaghi, 2015).

En este contexto, las relaciones entre ambos bloques pueden contribuir a fortalecer los respectivos regionalismos "por medio del interregionalismo" (Hanggi, 2003), generando diálogos, debates e informaciones "de nivel medio" que luego pueden nutrir los procesos multilaterales mundiales, o bien producir agendas compartidas y combinadas 
Un clima para el cambio. Oportunidades y desafíos para la articulación interregional ASEAN-MERCOSUR en materia de cambio climático

DiEgo TOLEDO

con mayor o nivel de consenso que pueden también expresarse en instancias y negociaciones globales (Rubiolo, 2016).

Pese a que existen diferencias significativas en torno al modo de cooperar ${ }^{3}$, las potencialidades tampoco pueden negarse. En este sentido, aunque -por el momento- se trate de desenvolver un "interregionalismo flexible", en el que ninguna de las dos partes actúa con la otra "como si fuera un todo unificado", el desarrollo de la cooperación sur-sur puede resultar beneficiosa para ambas partes frente a posibles "estrangulamientos" de los principales polos del poder mundial como China (Lo Brutto, 2015), Estados Unidos, Rusia, etc. De acuerdo con Rubiolo (2016), el interregionalismo flexible se diferencia de los casos de interregionalismo puro o bilateral (por ejemplo. UE-ASEAN) por acoger relaciones de distinto nivel de institucionalización regional, haciendo parte de relaciones bilaterales (EstadoEstado), región-Estado, o la formación de grupos interregionales, como el caso de FOCALAE. Por ello, se considera que este marco analítico resulta más útil que el interregionalismo puro para entender las relaciones Sur-Sur o no triádicas (aquellas que no refieren a América del Norte, Europa o Asia del Este).

En medio de un enfrentamiento por la hegemonía a nivel mundial, la asociación de este particular interregionalismo puede no solo poner un límite o contrapeso a dichas relaciones hegemónicas, sino además promover o facilitar la "legalización" de las relaciones internacionales y los compromisos estatales con las normas globales.

\section{El posicionamiento de ASEAN-MERCOSUR en el contexto de la gobernanza global del cambio climático. Situaciones y respuestas}

El cambio climático es, políticamente, un tema difícil por tres razones básicas (Keohane y Victor, 2010). En primer lugar, al ser un problema global no puede ser solucionado de manera unilateral o fragmentada, requiere necesariamente coordinación y acción colectiva. En segundo lugar, es un problema intergeneracional que implica un esfuerzo doble para los líderes interesados en impulsar una acción efectiva: deben persuadir a sus seguidores de que su acción marca una diferencia y de que los costos de hoy impactarán en el futuro. Por último, cambiar las prácticas de tantas personas, organizaciones, gobiernos y empresas supone para los Estados un interés y

\footnotetext{
3 Por ejemplo, Mercosur no contempla la firma de acuerdo de libre comercio individuales por parte de sus miembros mientras ASEAN sí. Además, mientras en el SEA se tiende a un regionalismo amplio, abierto y flexible, en América Latina subsiste una mayor fragmentación de mercados regionales por la competencia entre miembros del bloque (Rubiolo, 2016).
} 
Un clima para el cambio. Oportunidades y desafíos para la articulación interregional ASEAN-MERCOSUR en materia de cambio climático

DiEgo TOLEDO

una capacidad de ejercer influencia y otorgar incentivos para realizar esas transformaciones.

De acuerdo con Palacio (2013, p. 51), el cambio climático no debe ser confundido con la variabilidad climática, que refiere simplemente fenómenos naturales de variación climática, tales como El Niño, que se producen independientemente de la acción humana. Sin embargo, esto no quiere decir que estos fenómenos no estén afectando la vida en general un modo más grave a causa del cambio climático.

La Convención Marco de las Naciones Unidas sobre el Cambio Climático (CMNUCC), en su Artículo 1, define 'cambio climático' como 'un cambio de clima atribuido directa o indirectamente a la actividad bumana que altera la composición de la atmósfera mundial y que se suma a la variabilidad natural del clima observada durante períodos de tiempo comparables' (el subrayado es mío). El IPCC (2001), por su parte, define al cambio climático de una manera más amplia. Lo entiende como:

una importante variación estadística en el estado medio del clima o en su variabilidad, que persiste durante un período prolongado (normalmente decenios o incluso más). El cambio climático se puede deber a procesos naturales internos o a cambios del forzamiento externo, o bien a cambios persistentes antropogénicos en la composición de la atmósfera o en el uso de las tierras. (p. 175)

En tanto fenómeno de afectación global, la problemática del cambio climático viene siendo objeto de variados intentos de regulación y acción en la esfera internacional. Por ello, el cambio climático tiene una estructura de gobernanza global que le es propia. En términos de Ruland y Storz (2008) un sistema de gobernanza global es "una articulación de instituciones, por lo general pero no exclusivamente gubernamentales, que regulan el comportamiento de los Estados y otros actores en diferentes áreas de la política internacional" (p. 3). No obstante, dada la complejidad que le aporta su carácter multicausal, su expresión multidimensional y la variabilidad de los compromisos asumidos por los Estados, el estado de tal gobernanza es difuso y variado.

Difuso porque se percibe, en realidad, la coexistencia de un régimen internacional formal -que encabeza la CMNUCC- y de una serie de iniciativas de actores privados, ONG globales y actores estatales subnacionales, entre otros. No hay una arquitectura global completamente integrada que cohesione todo el conjunto de iniciativas y regulaciones. En otras palabras, coexiste un régimen internacional de cambio climático con iniciativas transnacionales de gobernanza climática (Hickmann, 2017). 
Un clima para el cambio. Oportunidades y desafíos para la articulación interregional ASEAN-MERCOSUR en materia de cambio climático

DiEgo TOLEDO

$\mathrm{Y}$ variado porque, dentro del régimen internacional de cambio climático, lo que existe es una amplia gama de regímenes regulativos específicos para las distintas problemáticas (como el uso de la tierra y forestación, o las emisiones de gases de efecto invernadero), que a su vez pueden reforzarse mutuamente o bien entrar en contradicción o conflicto. De acuerdo con Keohane y Victor (2010), pese a que estos arreglos formales en la materia necesitan forjar un mayor estándar de coherencia, efectividad, determinación, sustentabilidad, accountability y "calidad epistémica"; su carácter flexible, en alcance y contenido, los vuelve útiles y políticamente realistas dada la incertidumbre y los flujos políticos y económicos que influyen sobre la acción climática en sus distintos niveles.

Comprender este "complejo de régimen" (Keohane y Victor, 2010) resulta fundamental en un contexto de transformación de la política internacional del cambio climático (del Pilar Bueno, 2012), en el que la emergencia de un enfoque bottom-up se traduce en la formulación compromisos voluntarios de las partes o, como suelen llamarse, "Contribuciones Previstas y Nacionalmente Determinadas" (iNDCs, por sus siglas en inglés) (Kiessling, 2019). Para los países en desarrollo de ambas regiones (SEA y MERCOSUR), el desafío es singular ya que implica afrontar políticas de mitigación y de adaptación a la vez, con un presupuesto por lo general limitado; lo que muchas veces genera un trade-off entre las mismas.

Estudiar el condicionamiento mutuo entre política climática y política internacional del cambio climático en las potencias o países emergentes es importante porque, como afirma Kiessling (2019):

(...) son Estados que son objeto de flujos de socialización de normas internacionales que no necesariamente son generadas domésticamente, pero que, en su internalización, a través de la localización, producen procesos de contestación que transforman el significado, la interpretación y el sentido de la norma; lo que, a través de la capacidad de agencia de estos actores, termina impactando nuevamente sobre la gobernanza global del cambio climático. (p. 80)

\footnotetext{
${ }_{4}^{4}$ Aunque existe un acuerdo generalizado con los lineamientos generales del IPCC, es bueno mencionar que algunas visiones críticas apuntan que en los estudios del IPCC hay un "eslabón ausente" en la economía del carbono. No se evalúa la capacidad de los países para capturar y almacenar carbono en sus tierras. Esto generaría un sesgo distorsivo en las políticas, que solo tendrían en cuenta la medida de las emisiones de gases. Los números se ordenan de manera radicalmente distinta cuando esas emisiones son expresadas por hectárea de tierra y no por habitante. Por ejemplo, mientras los cuatro países del Mercosur registran menos del $3 \%$ de las emisiones globales de carbono; por ser grandes secuestradores de carbono, algunos indicadores le asignan una emisión per cápita mayor que las de China e India, dos de los mayores emisores mundiales (Viglizzo y Ricard, s/f; Viglizzo, 2018).
} 
Un clima para el cambio. Oportunidades y desafíos para la articulación interregional ASEAN-MERCOSUR en materia de cambio climático

DiEgo TOLEDO

Todos los Estado miembros de ASEAN y del MERCOSUR han ratificado el Protocolo de Kioto y han firmado el Acuerdo de París. Sin embargo (con la clara y notoria excepción de Brasil o de los vecinos del SEA, China e India), ninguno parece prefigurarse como generador de normas internacionales. En su lugar, todos se posicionan como tomadores de normas, se limitan a aceptar o contestar las normas que otros Estados generan. Por ello, la cooperación entre ambas partes resulta necesaria.

Fuera de la casuística y de la heterogeneidad y especificidad con la que el cambio climático se manifiesta en cada región, los países de ambas regiones enfrentan desafíos similares en relación a los impactos que el cambio climático produce en ambas regiones: incendios forestales (Indonesia, Malasia y Singapur en 2015; la Amazonía brasilera y la Chiquitanía boliviana en 2019); inundaciones (norte de Tailandia en 2017, Argentina y Uruguay en 2017), riesgo de perder poblaciones y entramados productivos en ciudades costeras por el aumento del nivel del mar-agravados por las migraciones del campo a la ciudad-, mayor dependencia de importación de bienes básicos (para el caso del SEA), y mayores riesgos de pérdidas y crisis económicas dada la dependencia a las exportaciones de dichas materias primas en América del Sur.

Frente a esto, ambas regiones se están haciendo preguntas similares en torno a problemáticas de seguridad alimentaria, la necesidad de una transición energética (de un modelo basado en lo fósil a un modelo de energía renovable) y de modelos de desarrollo más sustentables, que dejen de estar surcados por factores como las deforestaciones y el avance de la frontera agrícola, las prácticas extractivistas o la deficitaria regulación de empresas multinacionales, entre otras.

\section{Trayectorias regionales de ASEAN y MERCOSUR en materia de cambio climático. Límites, desafíos y posibilidades para la cooperación}

ASEAN es el segundo proyecto de integración regional más antiguo después de la Unión Europea (Ramoneda, 2013; Rubiolo, 2011). Ha cooperado en materias ambientales entre sus integrantes desde 1977, reconociendo así la importancia del tema para el desarrollo sustentable y la integración regional (Association of Southeast Asian Nations, 2019a). Desde el Foro realizado en Singapur en 2007, ASEAN ha promovido la cooperación e integración entre sus Estados parte en cambio climático y ha identificado constantemente al cambio climático como una temática prioritaria de la organización (ASEAN, 2019b).

Desde el 2015, el mismo año en que las Naciones Unidas formuló los nuevos Objetivos de Desarrollo Sustentables (ODS) para una Agenda 2030, 
Un clima para el cambio. Oportunidades y desafíos para la articulación interregional ASEAN-MERCOSUR en materia de cambio climático

DiEgo TOLEDO

ASEAN realizó su tránsito hacia la "Comunidad ASEAN" (ASEAN Community), según había sido fijado por los líderes de los países integrantes en 2003.

Bajo este nuevo formato institucional, se establecieron tres pilares fundamentales sobre los que se desarrollaría la región, creando tres Comunidades: Política (Seguridad), Económica, y Socio-Cultural (ASCC, en inglés) (Asean, 2015). Esta última, supervisa y contiene todos los programas de ASEAN relativos a la cooperación y actividades conjuntas en cambio climático.

Tailandia funciona como el coordinador de ASEAN en materia de ODS y procura su alineamiento y complementariedad con las áreas prioritarias del bloque (Letchumanan, 2010), siguiendo los lineamientos del plan "ASEAN 2025 Forging Ahead Together" (ASEAN, s/f) y de la ASCC Blueprint 2025, la cual guía la cooperación en temas ambientales de la ASEAN, proyectando el fortalecimiento de una comunidad que compromete y beneficia a sus pueblos, siendo "inclusiva, sustentable, resiliente y dinámica".

La actual estructura institucional de ASEAN para la cooperación en temas ambientales está compuesta por las Reuniones Ministeriales de Ambiente de ASEAN (AMME, en inglés), que ocurren una vez cada dos años; los Oficiales Senior de Ambiente de ASEAN (ASOEN, en inglés) y siete grupos de trabajo subsidiarios, que se reúnen una vez por año para revisar la implementación del Plan Estratégico de Ambiente de ASEAN (ASPEN, en inglés) y ASCC Blueprint 2025. (Letchumanan, 2010).

Mientras la "Sección D" del ASCC Blueprint 2025 establece específicamente medidas de acción dirigidas a mitigar los impactos del cambio climático, en tanto se persigue como objetivo general "asegurar la sustentabilidad medioambiental" (ASEAN, 2016), el ASPEN está integrado por siete áreas prioritarias, correspondientes a cada uno de los grupos de trabajo especializados subsidiarios de ASOEN. De estos, uno está dedicado exclusivamente a la problemática del cambio climático (AGWCC, en inglés), funcionando como el brazo operativo de la Iniciativa ASEAN para el Cambio Climático (ACCI, en inglés) a través de la Respuesta Conjunta de ASEAN para el Cambio Climático (ASEAN, 2012).

Este grupo de trabajo especializado, establecido en 2009, ha definido cinco prioridades como propias: (i) adaptación y resiliencia, (ii) mitigación, (iii) transferencia tecnológica, (iv) financiamiento del cambio climático, y (v) coordinación multisectorial (transversal) y alianzas globales.

ASEAN cuenta con diversas políticas transversales (en función del carácter multidimensional del cambio climático) y entre algunas de ellas podemos mencionar: el Programa de Trabajo para el Acuerdo en Manejo de Desastres y Respuestas a Emergencias de ASEAN (AADMER, en inglés) 
Un clima para el cambio. Oportunidades y desafíos para la articulación interregional ASEAN-MERCOSUR en materia de cambio climático

DiEgo TOLEDO

como parte de iniciativas de adaptación al cambio climático, El Acuerdo para controlar la Contaminación Transfronteriza de HASE (AATHP, en inglés) vigente desde 2003, la Estrategia ASEAN para el Manejo de Peatland (20062020), el Marco Multisectorial de ASEAN para el Cambio Climático en Agricultura, Forestry en pos del logro de los ODS, la seguridad alimentaria y la nutrición, el Plan de Acción ASEAN para la Cooperación Energética (APAEC) adoptado en 2009 por el período 2010-2015, la creación en 2005 del Centro ASEAN para la Biodiversidad y la Iniciativa ASEAN de Ciudades Ambientalmente Sustentables (AIESC) (ASEAN, 2018; Letchumanan, 2010).

Asimismo, ASEAN cuenta desde 2012 con un Plan de Acción de Respuestas Conjuntas al Cambio Climático, en que se detallan actividades, resultados a obtener y países líderes (del bloque) encargados de su ejecución o vigilancia (ASEAN, 2012).

Si bien los países de ASEAN formularon iNDCs bajo el Acuerdo de París, la región continúa expandiendo su capacidad de generar electricidad a base de energías fósiles, lo cual daña su reputación internacional, genera dependencia de las importaciones provenientes del Medio Oriente, y no mitiga los impactos agregados del cambio climático en la región (Øverland, 2017).

Pese a su posicionamiento favorable a las normas internacionales de cambio climático, la mayoría de los países de ASEAN no han tomado roles prominentes en este campo. Un estudio del Stockholm Environment Institute (2016), dividió a 8 de los países ASEAN en 3 categorías: los pioneros de la adaptación (Filipinas y Vietnam), que toman la adaptación como una necesidad urgente y han generado nuevos arreglos institucionales para abordarla, los campeones emergentes (Camboya, Indonesia y Myanmar), que siguen de cerca a los primeros, tomando nuevos abordajes de adaptación; y los de adaptación paulatina (Laos, Malasia y Tailandia), que por tener una menor exposición a desastres han tendido a ser complacientes ante la necesidad de adaptación, con políticas desintegradas, débiles o limitadas en su impacto.

Manteniéndose como tomadores de normas, ASEAN se enfrenta a una posible pérdida de estatus si limita únicamente a seguir lo que sus Estados miembros hacen por el cambio climático, ${ }^{5}$ más aún si estos Estados fallan en lograr sus iNDCs. Por ello, especialistas en la materia indican que ASEAN puede tener problemas de acción colectiva en materia de política climática internacional: sus Estados miembro esperan que ASEAN adopte un rol más fuerte, mientras la Secretaría de ASEAN espera que sean los Estado miembro los que lideren el proceso (Øverland, 2017).

\footnotetext{
5 Un mapeo de organismos de cambio climático para cada país de ASEAN puede verse en Salamanca, A., \& Nguyen, H. (2016).
} 
Un clima para el cambio. Oportunidades y desafíos para la articulación interregional ASEAN-MERCOSUR en materia de cambio climático

DiEgo TOLEDO

La Secretaría de ASEAN puede entonces promover un espíritu de equipo, formulando por ejemplo Contribuciones Regionalmente Determinadas (RDC) para sus Estados miembro. También puede reforzar y expandir su staff especializado en cambio climático (lo cual requiere capacitaciones y financiamiento), además de reconsiderar la manera en que conduce los negocios, enfatizando en la soberanía nacional, la no interferencia y el consenso en la toma de decisiones como principios básicos.

En el caso del MERCOSUR, parece que los objetivos ambientales se piensan de forma subordinada a una lógica comercial, ${ }^{6}$ en donde la problemática ambiental aparece relacionada con posibles distorsiones en los costos de producción (y por ende en competitividad) de los miembros de cada bloque. Es decir, existe una idea de que las medidas ambientales funcionan como una traba para el desarrollo comercial de la región, y no logra percibirse la interrelación existente entre política comercial, política ambiental/climática, y desarrollo socioeconómico (Stuhldreher, 2012).

Desde los años 90, con el avance de la globalización y el "regionalismo abierto" en la región -que implicaban una influencia creciente de las relaciones externas sobre el diseño de políticas internas- se hizo necesario explicitar una entidad regional unificada a partir de la cual la región pudiera proyectarse hacia el exterior. Esto contribuyó a que, en el ámbito medioambiental, MERCOSUR buscara la participación y posicionamiento conjuntos en negociaciones internacionales. El Preámbulo del Tratado de Asunción de 1991 ya contiene algunas notas al respecto, donde la preservación del medioambiente -supeditada a los principios de gradualidad, flexibilidad y equilibrio- aparece como un medio para ampliar los mercados mediante la integración (Fedorovsky y Niglia, 2010). Otros antecedentes fueron la Declaración de Canela (1992), que establecía el principio de complementariedad entre la protección ambiental y el desarrollo económico; y la Declaración de Taranco (1995) que, explícitamente, buscaba la consolidación de posicionamientos conjuntos hacia la arena internacional.

En 1992, se avanzó a partir de una resolución del Grupo del Mercado Común (GMC), órgano operativo del MERCOSUR, que creó la Reunión Especializada de Medio Ambiente (REMA). Esta redactó las Directrices Básicas en Materia Ambiental del MERCOSUR (1994) que, aunque sin carácter vinculante, procuraban la coordinación de criterios ambientales comunes para negociar como bloque (Fedorovsky y Niglia, 2010; Stuhldreher, 2012).

En 1995, tras la Declaración de Taranco, la REMA fue reemplazada por el Subgrupo de Trabajo 6 (SGT 6), dedicado a Medio Ambiente. El grupo

\footnotetext{
${ }^{6}$ Los debates en torno a la reciente firma del Tratado UE-Mercosur y la polémica Macron-Bolsonaro ejemplifican este punto.
} 
Un clima para el cambio. Oportunidades y desafíos para la articulación interregional ASEAN-MERCOSUR en materia de cambio climático

Diego Toledo

-que aún continua vigente- elaboró una lista de Tareas Prioritarias, entre las que se planteó la posibilidad de proyectar un Instrumento Jurídico de Medio Ambiente para el MERCOSUR, el diseño de un sistema de información ambiental (SIAM, hoy vigente) y la creación de un Sello Verde MERCOSUR (Fedorovsky y Niglia, 2010).

El Acuerdo Marco sobre Medio ambiente de 2001, adoptado por medio de una decisión del CMC, fue un hito para la región, ya que ratificó los principios de la Declaración de Río (principalmente el de responsabilidades comunes pero diferenciadas) y fijó el compromiso de los Estados a cumplimentar sus acuerdos internacionales, estableciendo así la complementariedad entre política comercial y medioambiental (Stuhldreher, 2012). Siendo el primer instrumento jurídico ambiental en dicho ámbito proyecto de integración, entró en vigor en 2004. Luego de ello, se dieron algunos otros acuerdos -como la aprobación del Protocolo Adicional en Materia de Cooperación y Asistencia ante Emergencias Ambientales-, pero fueron de menor importancia y no vinculantes (Fedorovsky y Niglia, 2010).

Sin embargo, en materia de cambio climático, las menciones son pocas. En 2009 se propusieron lineamientos para formular un proyecto de cooperación de adaptación al cambio climático en el marco de la X Reunión de ministros de Medio Ambiente; y en 2010, en la XI Reunión, se discutió sobre la formulación de una posición conjunta para la Cumbre de Cancún sobre Cambio Climático (Stuhldreher, 2012).

Vemos entonces que a diferencia de ASEAN, los países del MERCOSUR no tienen un acercamiento verdaderamente regional al fenómeno del cambio climático. Aunque se ha intentado, tampoco existen pronunciamientos ni posicionamientos conjuntos (como bloque) en las negociaciones internacionales de cambio climático (Fedorovsky y Niglia, 2010). De hecho, su participación en estas instancias suele ser desigual, donde países como Brasil tienen un rol destacado y se posicionan como creadores de normas globales para el cambio climático.

Los desafíos para construir una institucionalidad climática en Sudamérica son diversos. La transversalidad de la agenda climática es uno. La asimetría de poder de las áreas a cargo de los temas climáticos frente a otras áreas de gobierno es otro. Los déficits de implementación de las políticas climáticas (por planeamiento erróneo y un bajo nivel de law enforcement) también son destacables. Por último, también entran en juego factores políticos relativos a la voluntad política y las lógicas de poder en contextos electorales, dónde la necesidad de rédito político a corto plazo se enfrenta la temporalidad de largo plazo exigida por las (además inciertas) políticas climáticas (Manzano Franco, 2016; Ryan, 2017).

La configuración de una agenda medioambiental para el MERCOSUR constituye entonces un proceso fragmentario y no completamente coherente. 
Un clima para el cambio. Oportunidades y desafíos para la articulación interregional ASEAN-MERCOSUR en materia de cambio climático

DiEgo TOLEDO

Actualmente, el mecanismo más formal en torno a las decisiones en política climática para la región está constituido las Reuniones de Ministerios de Medio Ambiente de los Estados parte del bloque, de las cuales no hay demasiada información disponible. Si bien podemos reconocer el carácter transversal del cambio climático, la escasa evidencia documental del MERCOSUR indica que la problemática se aborda de manera secundaria o residual ante otras temáticas centrales del bloque ${ }^{7}$.

Aunque algunas tareas prioritarias del STG 6, especializado en Medio Ambiente. se relacionan al cambio climático -como las Emergencias Ambientales y el Acompañamiento de la Agenda Ambiental Internacional-, ninguno de sus órganos subsidiarios (ad hoc) aborda exclusivamente la temática (MERCOSUR, 2019a).

Sin embargo, el panorama no es tan desolador. Aunque quizás atrasado en comparación otras regiones del globo, es innegable los países de América del Sur también vienen buscando una mayor integración a los asuntos ambientales globales, en parte debido a la ya observada vulnerabilidad al cambio climático que tiene la región (CEPAL/ECLAC, 2016). En este sentido, los eventos mencionados anteriormente funcionan como antecedentes para un proceso más extenso de formación y adopción de agenda en torno al cambio climático en la región. En el año 2019, por ejemplo, se realizó el "Primer Encuentro de diálogo político y social sobre Cambio Climático del MERCOSUR" —organizado por su Parlamento Social en el marco de preparación para la COP 25-, además de una Declaración Conjunta de los presidentes del bloque sobre Desarrollo Sostenible (MERCOSUR, 2019b).

En Argentina en particular, se creó recientemente el Gabinete Nacional de Cambio Climático (Decreto 891/2016), el cual busca diseñar políticas públicas coherentes, consensuadas y estratégicas para reducir las emisiones de gases de efecto invernadero y atender el cambio climático. Agrupa ministerios y secretarías nacionales involucrados en políticas climáticas bajo la órbita de Jefatura de Gabinete de ministros. La Secretaría de Cambio Climático y Desarrollo Sustentable es su coordinadora. La participación de las provincias se articula a través del Consejo Federal de Medio Ambiente (COFEMA) y las mesas ampliadas son la instancia de articulación con la sociedad civil, académicos, sector privado y trabajadores.

\footnotetext{
${ }^{7}$ Por ejemplo, cuando uno visita el sitio oficial del bloque, en la sección "Temas" no figura ninguna directamente relacionada al Medioambiente o al cambio climático. Solo existen algunas menciones en torno a lo medioambiental (en general) en otras áreas temáticas como la "Cooperación intrarregional" (Mercosur, 2020) o la salud (Mercosur, 2018).
} 
Un clima para el cambio. Oportunidades y desafíos para la articulación interregional ASEAN-MERCOSUR en materia de cambio climático

DiEgo TOLEDO

Amalia Stuhldreher (2012) menciona diversos cambios producidos en Argentina en materia ambiental en diversos sectores sociales. A nivel público, el INTI y el INTA incorporaron líneas de desarrollo sustentable y energía renovable. También se crearon entidades privadas de investigación; e intereses corporativos como la Sociedad Rural o la Unión Industrial Argentina han creado espacios de "sustentabilidad ambiental". Siguiendo los análisis de María del Pilar Bueno (2017), estos avances se encuadran en una dimensión de "poder climático social" (proceso de institucionalización de ideas, creencias e identidades construidas intersubjetivamente), que junto a otras variables de "poder material climático" (el poder en tanto capacidad material de un Estado y su poder de negociación en un ámbito en particular) explican la capacidad de incidir de un Estado en las negociaciones multilaterales y su doble plexo, interno y externo.

En este marco se desarrolla el proceso de elaboración y validación de los Planes de Acción Sectoriales de Cambio Climático respecto a energía, bosques, transporte, industria, agricultura y ganadería e infraestructura y territorio, que son el piso sobre el cual se desarrolla el Plan Nacional de Mitigación y el Plan Nacional de Adaptación, ambos parte del Plan Nacional de Respuesta al Cambio Climático. En este contexto, los desarrollos tecnológicos y conocimientos científicos que producen las agencias de investigación argentinas pueden realizar importantes aportes a la cooperación sur-sur con los Estados miembros de ASEAN en materia de cambio climático, complementando y fortaleciendo las expectativas abiertas tras la firma del Tratado de Amistad y Cooperación (2017) entre Argentina-ASEAN.

De manera más general, pueden aprovecharse los dispositivos institucionales que existen en los países de varias regiones para potenciar el trabajo en áreas estratégicas para ambas partes. Puede avanzarse en la cooperación sur-sur en cambio climático a través fortalecer una agenda común en los encuentros interregionales, aprovechando espacios como las Reuniones Ministeriales MERCOSUR-ASEAN.

Para ello, podrían establecerse principios de acción (beneficio mutuo, horizontalidad, consulta y consenso) y áreas prioritarias comunes sobre las cuales actuar: educación ambiental (concientización pública), producción mejor adaptada al cambio climático (más limpia), construcción de capacidad de gestión en materia ambiental, cooperación en bienes y servicios ambientales, e intercambio y acuerdo en asuntos globales medioambientales.

Dado el mayor grado de consolidación institucional y de desarrollo de iniciativas que ASEAN tiene en temas de cambio climático, sus aportes podrían ser de gran valor para el bloque sudamericano. Podrían, por ejemplo, pensarse mecanismos de capacitación (foros, reuniones de alto nivel, etc.) para personal encargado de implementar y diseñar políticas ambientales y políticas económicas "más verdes". 
Un clima para el cambio. Oportunidades y desafíos para la articulación interregional ASEAN-MERCOSUR en materia de cambio climático

DiEgo TOLEDO

En relación con la promoción de ciudades sustentables, ambos bloques podrían aprovechar su pertenencia a redes transnacionales (como ICLEI) y la formación de proyectos intrarregionales (como Mercociudades y AIESC) para intercambiar experiencias y fortalecer su capacidad de vincularse entre sí, y nutrir las Iniciativas de ASEAN para el Aire Limpio, Agua Limpia y Tierra Limpia.

En materia de transición energética hacia un modelo bajo en carbón, los desarrollos de Malasia y Tailandia como manufactureros de paneles solares pueden ser objeto de transferencia tecnológica para países como los nuestros, que están comenzando a apostar por las energías renovables. A su vez Brasil, Argentina y Uruguay vienen haciendo fuertes esfuerzos en materia de cooperación energética, apoyándose en espacios como el FOCEM (Fondo de Convergencia Estructural) para el desarrollo de la infraestructura energética (Freier, 2016; Stuhldreher \& Olmos, 2019).

Por último, ambos bloques pueden fortalecer su conocimiento en el campo de la verificación de buenas prácticas agroecológicas y agropecuarias, la promoción de consumos y producciones sustentables, y certificación orgánica y ecológica de productos regionales. MERCOSUR puede aquí realizar un aporte, teniendo en cuenta que desde finales de la década de los 90 busca impulsar la Iniciativa del Sello Verde MERCOSUR (Consani y Servi, 1999; Gillet, 2014). También las Comisiones de Cambio Climático que existen en organismos argentinos como el INTA y el INTI pueden intercambiar conocimiento con agencias homólogas de países de la ASEAN, ejerciendo un rol prominente en desarrollos relativos la seguridad alimentaria interregional y la transformación productiva.

\section{Reflexiones finales}

El panorama político y económico global nos indica que es necesario contar con estrategias de desarrollo que permitan enfocarse en el avance de cada región. No se trata, entonces, de elegir entre Estados Unidos o China. El desafío para ambos bloques es poder mantenerse unidos e integrados frente a la fragmentación de un orden internacional, basado en reglas, que hoy está transitando una crisis. La articulación interregional ASEAN-MERCOSUR es una oportunidad para fortalecer los sistemas de gobernanza global y generar contrapesos alternativos a esos centros de poder hegemónicos, fortaleciendo otros contenidos y canales para la cooperación entre países emergentes. Siendo la ASEAN una de mayores economías del mundo, para el MERCOSUR podría ser un impulso necesario para posicionarse más fuertemente a nivel regional e internacional.

Sin embargo, en el contexto de la actual degradación ambiental global, la reactivación del comercio MERCOSUR-ASEAN no solo puede tratarse de 
Un clima para el cambio. Oportunidades y desafíos para la articulación interregional ASEAN-MERCOSUR en materia de cambio climático

DiEgo TOLEDO

diversificar y agregar valor a las exportaciones de cada región. Las negociaciones comerciales bilaterales e interregionales deben nutrirse del intercambio de conocimiento sobre políticas y formas de mitigar y adaptar las producciones regionales al cambio climático. En la revisión de las iNDCs, los gobiernos de MERCOSUR y ASEAN deben enfatizar el desarrollo tecnológico y medidas efectivas, especialmente en los campos de la energía, el transporte, la seguridad alimentaria y los enclaves urbanos.

La alianza interregional en materia de cambio climático puede ser útil para ejercer una mayor incidencia en las negociaciones multilaterales, especialmente en torno a los mecanismos de financiamiento del cambio climático y los esfuerzos para transformar las matrices productivas. Los países de ambas regiones pueden fortalecer su rol en los regímenes ambientales internacionales alineando sus prioridades nacionales con la agenda global, desarrollando estrategias y modelos de desarrollo económico sustentable más coherentes e integrados.

$\mathrm{Si}$ bien no debemos olvidar que es necesario un esfuerzo mancomunado de actores gubernamentales, privados y sociales para la acción frente al cambio climático, la integración y retroalimentación multinivel de los regímenes regulativos ambientales y su traducción en planes de desarrollo -y de adaptación al cambio climático- nacionales es esencial para generar un clima para el cambio. ASEAN y Mercosur deben recordar que la anarquía ambiental es lo que los Estados hacen de ella.

\section{Referencias bibliográficas}

Association of Southeast Asian Nations (s/f). ASEAN Community Vision 2025. https://www.asean.org/wpcontent/uploads/images/2015/November/aec-page/ASEANCommunity-Vision-2025.pdf

Association of Southeast Asian Nations (2012). ASEAN Action Plan on Joint Response to Climate Change. http://environment.asean.org/wpcontent/uploads/2015/06/ANNEX-8-Lead-Countries-for-ASEANAction-Plan-on-Joint-Response-to-Climate-Change-27-March-2013.pdf Association of SOUTHEAST Asian NATIONS (2015). Fact Sheet - ASEAN Community. https://asean.org/storage/2012/05/7.-Fact-Sheet- onASEAN-Community.pdf

Association Of SOUTHEAST Asian NATIONS (2016). ASEAN Socio-Cultural Community Blueprint 2025. https://asean.org/?static_post=aseansocio-cultural-community-blueprint-2025

Association OF SOUTHEAST Asian NATIONS (2018). ASEAN Multi-sectoral framework for climate change: agriculture and forestry towards food and nutrition seecurity and achievement of SDGs. 
Un clima para el cambio. Oportunidades y desafíos para la articulación interregional ASEAN-MERCOSUR en materia de cambio climático

DIEGO TOLEDO

https://asean.org/storage/2012/05/ASEAN-Multisectoral-

Framework-for-climate-change.pdf

Association Of SOUTHEAST AsIAN NATIONS (2019a). ASEAN Cooperation on Environment: At a glance. https://environment.asean.org/aseancooperation-on-environment-at-a-glance-brochure/

Association of Southeast Asian NATIOns (2019b). Fuelling ASEAN's energy security. Singapore: ISEAS Yusof Ishak Institute.

BALDWIN, R (2011). 21st century regionalism: Filling the gap between 21st century trade and 20th century trade rules. En World Trade Organization (WTO), Economic Research and Statistics Division. No. ERSD -2011 -08. Ginebra

BArtesaghi, I. (2015). La integración regional en Asia Pacífico: El caso de la ASEAN, la APEC y el RCEP. En Phillips Sñanchez, L. (comp), Ágora Latinoamericana. Logros, obstáculos y retos de la integración regional. Tomo I.

BuzAn, B. (2012). Asia: A geopolitical reconfiguration. Politique étrangère, 77(2), pp. 13.

CEPAL/ECLAC (2018). Economics of climate change in Latin America and the Caribean. A graphic view.

CONSANI, N. E., \& SERVI, A. (1999). MERCOSUR y medio ambiente. Relaciones Internacionales.

Del Pilar Bueno, M. (2012). La Anarquía Ambiental es lo que los Estados hacen de Esta. Las Conferencias Ambientales desde Estocolmo a Río+ 20. Latin American Journal of International Affairs, 4(3).

DEL Pilar Bueno, M. (2017). ¿ Poder material o poder social? Reflexiones sobre las negociaciones multilaterales y el poder climático de la Argentina (2003-2015). Relaciones Internacionales, 26(53), 65-86.

FEDOrovsky, J., \& Niglia, G. (2014). La protección del medio ambiente en MERCOSUR y NAFTA. In VII Congreso del IRI/I Congreso del CoFEI/II Congreso de la FLAEI (La Plata, 2014).

FrEIER, A. (2016). Integración energética regional en Mercosur. Los casos de Argentina y Brasil en el área de la energía renovable. En Guzowski, C. (comp.). Políticas de promoción de las Energias Renovables. Experiencias en América del Sur, pp. 153-192. Bahía Blanca: Ediuns.

Fuhr, H., Hickmann, T., \& KERN, K. (2018). The role of cities in multi-level climate governance: local climate policies and the 1.5 C target. Current opinion in environmental sustainability, 30, 1-6.

GILLET, S. (2014). Eco-etiquetado en el MERCOSUR. Potencialidades del Enfoque Regional en la Adopción de Modalidades de Producción y Consumo Sustentables Tesis de Maestría. Facultad de Ciencias Económicas. Universidad de Buenos Aires, Argentina.

HANGGI, H. (2003). Regionalism through interregionalism. East Asia and ASEM. En Fu-Kuo, L. y Philippe, R. (eds.). Regionalism in East Asia: 
Un clima para el cambio. Oportunidades y desafíos para la articulación interregional ASEAN-MERCOSUR en materia de cambio climático

DIEGO TOLEDO

Paradigm shifting? (197-219). Londres: Routledge.

IPCC (2001). Tercer Informe de evaluación. Cambio Climático. pp. 173-199.

HickMAnN, T. (2017). The reconfiguration of authority in global climate governance. International Studies Review, 19(3), pp. 430-451.

Keohane, R. \& Victor, D. (2010). The Regime Complex for Climate Change. Discussion Paper. Cambridge: Harvard Kennedy School.

Kiessling, C. K. (2019). Vinculación entre la política climática doméstica en países emergentes y la política internacional del cambio climático: propuesta de un marco analítico. Comillas Journal of International Relations, (15), pp. 78-98.

Lassa, J. A., \& SEMBIRING, M. (2017). Towards policy integration of disaster risk, climate adaptation, and development in ASEAN: a baseline assessment.

Letchumanan, R. (2010). Climate Change: Is Southeast Asia Up to the Challenge?: is there an ASEAN policy on climate change. En Kitchen, N. (Ed.). IDEAS reports - special reports, 50-62. LSE IDEAS, London School of Economics and Political Science.

Lo Brutto, G., \& GonzÁlez, C. H. (2015). La influencia China en la Cooperación Sur-Sur Latinoamericana, durante la segunda década del Siglo XXI. Cátedra COIBA DT cooperación y desarrollo, 2, pp. 1-15.

MANZANO Franco, K (2016). Mudanças climáticas - o desafio do século (Climate change - the challenge of the century). Konrad Adenauer Foundation.

MERCOSUR (2018) Declaración de los Ministros de Salud del Mercosur y Estados Asociados en relación a la salud y al cambio climático.

MERCOSUR (2019a). Estrategia de gestión del riesgo de desastres de los países del Mercosur.

MERCOSUR (2019b) Declaración Presidencial sobre Desarrollo Sostenible. http://www.puntofocal.gov.ar/doc/decla_eepp_sostenible-12-19.pdf

MERCOSUR (2020) La cooperación intra-MERCOSUR (2005 - 2015): Análisis de siete sectores, pp. 153-155.

ØverLand, I. (2017). Impact of Climate Change on ASEAN International Affairs: Risk and Opportunity Multiplier. Norwegian Institute of International Affairs and Myanmar Institute of International and Strategic Studies. https://www.researchgate.net/publication/320622312_Impact_of_Cl imate_

Change_on_ASEAN_International_Affairs_Risk_and_Opportunity_ Multiplier

PALACIO, G. (2013). Cambio climático, retórica política y crisis ambiental: una nueva interfase entre ciencias naturales y ciencias sociales. En Postigo, J.C. (Ed.) Cambio climático, movimientos sociales y politicas públicas. Una 
Un clima para el cambio. Oportunidades y desafíos para la articulación interregional ASEAN-MERCOSUR en materia de cambio climático

DIEGO TOLEDO

vinculación necesaria (51-74). CLACSO.

PICCONE, T. (2016). The Geopolitics of China's Rise in Latin America. Geoeconomics and global issues (2). Brookings Institution.

RAMON-BerjanO, C. (2019) Globalización con "características chinas". El creciente rol de China en América Latina y el Caribe y sus principales desafíos. Pensamiento Propio, Vol. 49-50, Año 24, pp. 31-52.

Ramoneda, E. (2013). Introducción. En Ramoneda, E. (Ed. Comp.). Concurso de Ensayos ANSEA: Compilación de Ensayos Galardonados 2013-2014. La Plata, Argentina: Instituto de Relaciones Internacionales UNLP.

Rubiolo, M. F. (2011). El Sudeste Asiático y la ASEAN en el escenario económico y político internacional contemporáneo. En Santillán, G.; Mohamed, N.; Morero, N. y Rubiolo, M.F. (Eds.). América Latina y el Este Asiático: Perspectivas desde Córdoba, Argentina: editorial CIECSCONICET-UNC.

Rubiolo, M. F. (2016). Interregionalismo Sureste Asiático-América del Sur: un complemento al bilateralismo. Revista CIDOB d'Afers Internacionals, $N^{\circ} 113$, pp. 211-234.

RÜLAND, J. Y STORZ, C. (2008). Interregionalism and interregional cooperation: the case of Asia- Europe relations. En Rüland, J.; Schucher, G. y Storz, C. (Eds.). Asian-European Relations. Building blocks for global governance (3-31). Nueva York: Routledge.

Ryan, D. (2016). Diseño de la institucionalidad climática: Aportes para el análisis. Ambiente \& Sociedad, 19(4), pp. 249-260.

SalamancA, A. Y NGUYEN, H. (2016). Climate change adaptation readiness in the ASEAN countries. Stockholm Environment Institute - Asia Centre.

Sanahuja, J. A. (2016). Regionalismo e integración en América Latina: de la fractura Atlántico-Pacífico a los retos de una globalización en crisis. Pensamiento propio, 21(44), pp. 29-76.

SANAHUjA, J. A. (2019). La crisis de la integración y el regionalismo en América Latina: giro liberal-conservador y contestación normativa. Anuario Ceipaz. 2018-2019. Ascenso del nacionalismo y el autoritarismo en el sistema internacional, pp. 107-126.

Stockholm EnVIRONMENT InstituTE - Asia (2016). Climate change adaptation readiness in the ASEAN countries. Chulalongkorn University.

STUHLDREHER, A. (2012). Construcción participativa del regionalismo estratégico: ¿hacia una agenda medioambiental externa del Mercosur? Revista Brasileira de Política Internacional, 55(1), 194-210.

Stuhldreher, A., \& Olmos, V. M. (2019). Desarrollo sostenible, cambio climático y comercio de energía en el contexto regional del MERCOSUR: consideraciones desde Uruguay. Latin American Journal 
Un clima para el cambio. Oportunidades y desafíos para la articulación interregional ASEAN-MERCOSUR en materia de cambio climático

\section{of Trade Policy, (5), 65.}

TussiE, D. (2019). La reconfiguración global: Su capítulo en vivo para América Latina. En Altmann Borbón, J. (Ed.), América Latina frente a la reconfiguración global (pp. 105-123). Buenos Aires: FLACSO.

ViglizzO, E. F. \& RiCARD, M.F (S/F). Emisiones, secuestro y balance de carbono en ambientes rurales del Mercosur: en busca del "eslabón perdido" de carbono.

Viglizzo, E. F. (2018). Cambio climático y seguridad alimentaria global: Oportunidades y amenazas para el sector rural argentino. Anales de la ANAV, 69.

ZELICOVICH, J. (2016). El MERCOSUR frente al "Regionalismo del siglo XXI". Algunas claves para la comprensión del devenir del proceso de integración. Revista Aportes Para La Integración Latinoamericana, (34), pp. 1-27. https://revistas.unlp.edu.ar/aportes/article/view/3539 


\title{
LAS DISPUTAS DEL MAR DE CHINA MERIDIONAL: UNA OPORTUNIDAD PARA FORTALECER A ASEAN
}

\author{
Max Povse \\ maxpovse@gmail.com \\ Universidad de Buenos Aires
}

\section{Introducción}

El Mar de China Meridional ha sido por siglos el punto neurálgico del comercio entre el Este Asiático y el resto del mundo. Por su condición geográfica privilegiada, aún hoy continúa siendo una vía acuática vital para el comercio global, lo que hace que su control no solo sea atractivo, sino imperativo si se pretende asumir una posición de poder global. Por ello, desde Japón durante la Guerra del Pacífico, Estados Unidos durante la Guerra Fría, hasta la República Popular China (en adelante, China) en la actualidad, las potencias con intereses hegemónicos han buscado el control -de jure o de facto- del Mar. En particular, el valor del Mar no reside solo en su rol en el comercio internacional, sino también en la capacidad geoestratégica que ofrece como punto nodal del Indo- Pacífico.

Como todo territorio valioso, sin embargo, el hecho que el Mar sea disputado por potencias no va en perjuicio de que este posea dueños jure proprio. Los países litorales del Mar hicieron uso casi irrestricto del mismo durante siglos, y a partir de él construyeron naciones prósperas. No obstante, una vez culminado el proceso colonizador en el Sudeste Asiático, con el surgimiento de los actuales Estados-nación comenzó la empresa de determinar las fronteras con la rigurosidad que exige el derecho internacional. Este proceso -aún en curso- ha visto avances y retrocesos en las décadas durante las cuales se ha prolongado, llevando a que casi la totalidad de los diferendos limítrofes -tanto terrestres como marítimos- entre los Estados del Sudeste Asiático han sido solucionados, con una importante excepción: el Mar de China Meridional.

Las razones geográficas, históricas y jurídicas que han sido postuladas por las partes interesadas constituyen un nudo gordiano que ningún arbitraje ha podido romper. Asimismo -como ocurre en casi todos los reclamos de soberanía-, la intransigencia está a la orden del día, haciendo casi imposible que se pueda hallar una solución que deje satisfechas a todas las partes. Sumado a ello, los reclamos postulan una situación particular: a diferencia de la mayoría de los diferendos territoriales, que ocurren entre dos -o a lo sumo tres- partes, el Mar de China Meridional es reclamado en partes por hasta seis países al mismo 
tiempo. Tal situación no deja otra opción más que el multilateralismo como mecanismo de manejo del conflicto, aunque, como se verá más abajo, ello no significa que sea un mecanismo exitoso, por lo menos hasta ahora. En los siguientes párrafos se hará un pequeño recorrido por los conflictos existentes, la gravedad de su situación, las alternativas propuestas en vigencia, y el rol de la Asociación de Naciones del Sudeste Asiático (en adelante, ASEAN, según sus siglas en inglés) como árbitro natural, para finalizar con determinaciones sobre las prospectivas de los mecanismos más factibles.

\section{El conflicto}

El conflicto general en el Mar de China Meridional puede dividirse en dos categorías principales: aquellos diferendos bilaterales entre un miembro de ASEAN y China, y los conflictos que involucran a dos o más miembros de ASEAN más China. Debe notarse que el reclamo de la República Popular China es compartido por la República de China, en tanto Estados que se disputan la representación conjunta de ambos. No obstante, el rol de la República de China se limita a mantener su presencia en solo dos islas en el Mar, sin demostrar capacidad ni voluntad para expandir su influencia, por lo que no constituye un actor de relevancia para el presente estudio.

Entre los conflictos de la primera categoría se hallan, a grandes rasgos: aquel entre Vietnam y China sobre las islas Paracel y las aguas adyacentes; entre Filipinas y China por el Bajo de Masinloc y la parte oriental de las islas Spratly; entre Indonesia y China por las islas nororientales del archipiélago de las Natuna; y entre Malasia y China, y Brunéi y China por las aguas contiguas a las costas septentrionales de Borneo. Estos cinco diferendos surgen de las aguas que corresponden a los reclamos de los miembros de ASEAN en base a las Convención de los Derechos del Mar, y que se superponen con el reclamo chino de las Nueve Líneas, que autoadjudica al gigante asiático casi la totalidad del Mar. Es importante destacar que, si bien estos conflictos son de carácter bilateral, los cinco ocurren como consecuencia de un factor común: el desproporcionado reclamo chino.

Los conflictos de segunda categoría también poseen como factor común el reclamo chino, pero al mismo se añade la disputa entre Vietnam y Filipinas por la mayor parte de las islas Spratly, a la que se añade el reclamo de Malasia y Brunéi sobre el extremo meridional del archipiélago. Esta situación convierte de hecho a las islas y sus aguas circundantes en un territorio quíntuplemente reclamado, erigiéndose como el caso conflictual más sensible en el Mar, sin perjuicio de que el mismo se constituya en la extensión al extremo de los conflictos de la primera categoría.

La distinción entre ambas categorías no es menor, dado que el potencial de manejo de los conflictos es radicalmente distinto entre los miembros de 
ASEAN y China que entre ellos mismos. Asimismo, constituyen situaciones diferentes aquellas en que los países intentan manejar los conflictos bilateralmente con China a aquellas en que lo hacen de manera conjunta bajo el paraguas de ASEAN. En la sección siguiente se explicará la importancia de este mecanismo de integración regional para las relaciones exteriores de los países miembros en general, y respecto a los mecanismos de manejo de conflictos, en particular.

\section{El rol de ASEAN}

ASEAN es un mecanismo de cooperación altamente efectivo para los Estados que agrupa. Dicha efectividad viene dada por compromisos -tácitos o expresos- que han asumido los Estados miembro en base a una visión utilitaria del organismo. Por utilitario, se refiere a la disposición que asumen dichos Estados para participar de la Asociación en base a problemáticas específicas que se buscan resolver, o bien, a agendas que se procuran desarrollar conjuntamente como un método agregado de progreso. No obstante, que el uso que se hace de ASEAN sea utilitario no significa que no exista un componente axiológico. Al contrario, los valores compartidos $-\mathrm{y}$ los consecuentes compromisos asumidos- son lo que mantiene el funcionamiento de la Asociación independientemente de las vicisitudes que afectan a sus miembros.

Si las problemáticas que fomentan la cooperación regional son, por definición, circunstanciales (tómense como ejemplo los incendios forestales en Sumatra y Borneo de 1997 o el proceso de independización de Timor Oriental), la construcción de agendas comunes en el seno de ASEAN ha demostrado ser un proceso, si bien paulatino, también acumulativo. La capacidad de respetar los principios fundacionales y de sostener compromisos a largo plazo son las principales razones de la constantemente creciente integración en la región.

Entre los principios mencionados, que constituyen la denominada ASEAN Way, se hallan: el de no interferencia, que funge de piedra angular para la Asociación y para los diálogos que sus miembros mantienen en su seno; el principio de musyawarah, que implica la discusión y la consulta como mecanismos operativos; y el de mufakat (o consenso), como método de toma de decisiones -y estrategia para no revelar las divisiones internas- (Swanström, 2002 , p. 134). Supeditado a dichos principios, con la ampliación de la cantidad de miembros (y de agendas), la Asociación ha ido sumando principios a su acervo: la ayuda mutua frente a desastres naturales, la defensa mutua ante agresiones extranjeras, el esfuerzo comunitario por construir un mercado común, la defensa de los derechos de los nacionales de cada país que residen o transitan por otros países de la región, entre otros.

Implicaciones del principio de no interferencia Consagrado en la 
Declaración de Bangkok de 1967 (acto fundacional de la Asociación), y subsecuentemente en la Declaración de Zona de Paz, Libertad y Neutralidad de 1971 y el Tratado de Amistad y Cooperación de 1976, el principio de no interferencia es la base de todo el ordenamiento jurídico-institucional de ASEAN, incluso de su proceso superador, la Comunidad de ASEAN, lanzado en 2015. Surgida en medio del tumultuoso período que fue para la región la Guerra Fría y, para cada país, la formación de sus Estados, naciones y regímenes políticos, la Asociación fue concebida como un foro de cooperación frente a las hegemonías de su tiempo. Con un extenso pasado de colonialismos, la soberanía adquirió un valor significativo para las elites gobernantes de los Estados del Sudeste Asiático, al mismo tiempo que estas requerían reaseguros en las relaciones exteriores para evitar apoyos foráneos a los factores internos de inestabilidad.

A medida que los aparatos estatales fueron consolidándose, la región dejó de ser víctima de intervenciones de potencias externas, y nuevos Estados se sumaron a la Asociación. Se fue configurando una mirada identitaria regional que permitió la construcción de bienes comunes. Entre estos bienes no solo se cuentan las instancias de diálogo y cooperación, sino también la integración en órganos intergubernamentales que paulatinamente han ido requiriendo mayor compromiso de parte de los Estados miembro. No obstante el continuo acercamiento entre ellos, la creación de institucionalidades supranacionales que requieran cesiones significativas de soberanía aún resulta lejana para sus idiosincrasias. Ello no solo porque la soberanía westfaliana (cf. Krasner, 2001) constituye un bien en sí para los Estados, sino porque actúa como garante -al menos de jure- contra agresiones externas, ya sea de potencias hegemónicas o de países vecinos.

La estrategia del respeto incondicional del principio de no interferencia, ha servido para mantener el funcionamiento de la Asociación, a pesar de las diferencias intrínsecas y las opiniones dispares de los miembros. El entonces Secretario General, Rodolfo Severino, aseveró en 2001 que: Al no forzar a sus miembros increíblemente diversos y mutuamente suspicaces a aceptar estándares legales vinculantes, ASEAN ha hecho el notable trabajo de mover a sus miembros de la animosidad a la cercana relación cooperativa que disfrutan hoy, una relación en la que un conflicto violento es impensable. (Severino, 3 de septiembre de 2001)

Debido a que los miembros (ni los fundadores, ni los que fueron sumándose) tuvieron que temer represalias por parte de una institución supranacional en caso de que incumplieran alguna normativa, la Asociación no suponía ningún desincentivo. Todo lo contrario, abría un juego de suma distinta a cero, haciéndose atractivo a los países de la región frente no solo a las grandes potencias del primer y segundo mundo, sino también a sus vecinos, China e India. Gracias al éxito de ASEAN Way, la misma no se ha modificado 
sustancialmente.

El principio de no interferencia es funcional a la autonomía estatal, por lo que la pertenencia a ASEAN no supone una potencial amenaza a los intereses particulares de los miembros, aun cuando los mismos entren en conflicto con los intereses regionales. Es así que ASEAN sacrifica, ya en su matriz fundadora la idea de la gobernanza regional en favor del fortalecimiento de los aparatos estatales nacionales (Ruland, 2011).

Todos los países de la región poseen tasas altísimas de crecimiento e incrementan notoriamente sus índices de desarrollo humano año a año. Tal boom socioeconómico ha sostenido la expansión de las agendas comunitarias de ASEAN, gracias al aumento en recursos económicos y humanos que ha llevado a los Estados miembro a hacer uso de la Asociación como regionalismo, y así posicionarse frente al mundo unificadamente con sus indicadores agregados, en los que representa una potencia de tamaño mediano. El particular modo en el que los países del Sudeste Asiático han sabido combinar integración de agendas sin cesión de soberanía constituye la principal innovación del abordaje que tiene esta región para con las relaciones internacionales (Chong, 2010).

Como corolario de esta sección, resta mencionar lo que algunos autores, como Hiro (2004) denominan "discusión franca y abierta", en un intento por señalar un viraje desde el principio de no interferencia. La experiencia de Myanmar es puntual para este caso, ya que es la principal referencia a la que se hace alusión al hablar de las presiones que ha ejercido ASEAN para su democratización. Si bien el debate en el caso birmano representa un claro viraje desde la política de silencio de los años setenta, se enmarca dentro de lo que Severino (3 de julio de 2000) denominó "compromiso flexible e integración mejorada", un concepto útil para señalar la existencia de una confianza suficiente entre los Estados miembro para debatir asuntos sensibles para algunos de ellos, sin que por ello peligre la integridad de la Asociación. Esto es así en tanto que cualquier salto que se intente del diálogo a la práctica precisaría, necesariamente, del apoyo del país o países en cuestión.

\section{El Alto Consejo}

En el Tratado de Amistad y Cooperación de 1976 en su artículo 14, los países miembro incorporaron la figura del Alto Consejo como mecanismo de manejo y resolución de conflictos, que funcionaría de manera sui generis ante cada caso que se presentare. En 2001, se adoptaron las reglas de procedimiento que permitirían hacer operativo al Consejo en caso de que algún miembro lo solicitara. Lamentablemente, el énfasis en los objetivos y principios que ha caracterizado al funcionamiento de ASEAN lo ha mantenido en un estado de metarégimen (Aggarwal, 1985) que no consigue materializar sus reglas y procedimientos de manejo de conflictos de manera efectiva. Esto es así porque 
las actitudes son más fáciles de consensuar que los procedimientos (Acharya, 2000) y, aunque ello haya contribuido al mantenimiento de ASEAN a través de los años, resulta insuficiente ante los desafíos actuales.

Un proceso de integración de larga data como ASEAN debería poder, al menos, ser capaz de manejar los conflictos intramurales a través de instituciones propias. Al no ocurrir esto, los países miembro recaen en instituciones internacionales como los Tribunales de Arbitraje de La Haya, o en acuerdos no vinculantes como la Declaración de Conducta sobre el Mar de China Meridional de 2002. Esta dependencia en mecanismos externos refuerza la percepción entre los Estados miembro que sus pares no son lo suficientemente confiables como para constituir mecanismos comunitarios imparciales (Swanström, 2002, p. 128), debilidad de la que algunos actores externos intentan aprovechar para promover la desunión en la Asociación.

Un regionalismo que aspire a constituirse en un régimen internacional debe superar las desconfianzas mutuas entre sus miembros, y el prejuicio de no necesitar considerar las preocupaciones de otros pares, algo que efectivamente socava el compromiso flexible e impide la integración mejorada (Fort \& Webber, 2006, p. 167). Un paso en la dirección correcta hacia la concreción de estos principios sería la convocatoria al Alto Consejo a fin de manejar el conflicto en el Mar de China Meridional, ya sea solo con los miembros de ASEAN o incluyendo a China (Amer, 2015, p. 2).

\section{Acuerdos de desarrollo conjunto}

Otra posibilidad factible para manejar los conflictos territoriales es apelar a su aspecto económico. La explotación de los recursos vivos y no vivos de las aguas en disputa es de vital importancia para las economías de la región, y el establecimiento de reglas claras para llevar adelante las actividades de pesca y exploración y extracción de recursos hidrocarburíferos resulta imperativo para comenzar un proceso de prevención de escaladas de conflictos, dado el peso de la geoeconomía en el sistema internacional.

Esta idea no es nueva, y de hecho existen varios ejemplos a nivel global que representan éxitos rotundos y, aunque no lleven a la resolución del conflicto de fondo (los reclamos territoriales), ayudan a paliar sus consecuencias no deseadas sobre la economía, a la vez que cimientan la confianza mutua. Entre estos ejemplos se encuentran: el Golfo de Fonseca, entre Nicaragua, Honduras y El Salvador; la Zona de Administración Conjunta entre Colombia y Jamaica; y el Acta de Foz de Iguazú y el Tratado de Yacyretá entre los países de la cuenca del Paraná, por nombrar algunos ejemplos en América. Pero este tipo de acuerdos de desarrollo conjunto no son únicos de Occidente: existen 19 a nivel global, y en el Sudeste Asiático se cuentan el acuerdo entre Tailandia y Malasia (MTJA, por sus siglas en inglés), que ya lleva en vigencia cuarenta años, y los 
acuerdos entre Vietnam y Malasia de 1982, y el acuerdo de las Aguas Históricas Conjuntas entre Vietnam y Camboya. Aunque los últimos dos ejemplos no resultaron exitosos, son importantes a la hora de destacar los antecedentes que permiten pensar una salida por el costado económico de los conflictos en el Mar de China Meridional.

Este es uno de los puntos del Borrador Único del Texto de Negociación (SDNT, por sus siglas en inglés) del Código de Conducta del Mar de China Meridional que introdujo China, con la condición de que las actividades económicas no fueran realizadas por compañías extranjeras, con el claro objetivo de monopolizar la explotación de recursos con compañías propias, que poseen una enorme ventaja comparativa respecto a las del resto de los países litorales (Thayer, 3 de agosto de 2018). Este caso es una de las tantas demostraciones de los detrimentos que puede conllevar la negociación asimétrica de los países por sí mismos, y no de ASEAN en su conjunto, con una potencia externa.

No obstante las posibilidades de llevar adelante proyectos de desarrollo conjuntos, tanto de manera bilateral como multilateral, en el marco de ASEAN, la aún débil cooperación económica entre los países miembro eclipsa esta opción, en favor de acuerdos más generosos con China. Como apunta Xue (2019), sin relaciones bilaterales fuertes entre todos los participantes, los proyectos conjuntos están destinados a fracasar. Es en este punto en el que se condicionan mutuamente las posiciones geopolíticas y geoeconómicas, en un círculo vicioso que supedita la integración económica a determinaciones políticas que se ven, a su vez, afectadas por los condicionamientos comerciales y financieros de China.

\section{Dificultades frente a los mecanismos de manejo de conflicto comunitarios}

De lo expuesto en los apartados anteriores surge que, si bien existen opciones viables para manejar los conflictos tanto geopolíticos (el Alto Consejo) como geoeconómicos (los acuerdos de desarrollo conjunto), su factibilidad se ve disminuida por una serie de factores tanto estructurales como actitudinales de ASEAN y sus miembros. Entre ellos, se pueden enumerar que: Existe una preferencia bien documentada de lo bilateral sobre lo multilateral en lo que respecta al manejo de conflictos entre los miembros.

Existe una tradición que establece que solo las partes involucradas pueden ser jueces de los conflictos, erosionando así la capacidad de los organismos comunitarios como mediadores. La Asociación conserva un propósito originario de priorizar el control de los conflictos sobre su solución, socavando la capacidad integral de los mecanismos de manejo de conflictos. El método no legalista de operación, que depende exclusivamente del 
posicionamiento coyuntural de los miembros, obtura las posibilidades de mantener mecanismos a largo plazo. Relacionado a ello, la persistencia de actitudes parciales inhibe a la suma de los Estados de actuar en conjunto frente a actores externos.

La falta de unidad genera una falta de poder derivado del regionalismo en sí (superador de la suma de sus partes), por lo que la Asociación depende más de lo deseable del posicionamiento estratégico de las potencias. La incapacidad de manejar los conflictos intramurales tiene un correlato directo en la debilidad para ejercer leverage en los conflictos extramurales (véase Swanström, 2002, pp. 137, 140, 148, 150; Alagappa, 1995, pp. 378, 386).

\section{Un mar de oportunidades}

A pesar de las dificultades mencionadas, los conflictos en el Mar de China Meridional representan un conjunto de oportunidades para fortalecer ASEAN en un contexto de incertidumbre global, en el que la configuración estratégica del sistema internacional se está reposicionando, acabando con la hegemonía global estadounidense y presentando nuevos hegemones en un escenario multipolar. A este respecto, el objetivo primordial de ASEAN como asociación de seguridad resurge luego de ser relegada a un segundo plano con el fin de la Guerra Fría. Si bien la agenda económica es -y debe ser- la prioridad de la Asociación en un mundo globalizado y atravesado completamente por la interdependencia compleja, la seguridad debe volver a ser prioritaria en vistas al resurgimiento de China como potencia hegemónica.

Durante el Siglo de Humillación, China se aisló y perdió el rol preponderante que ejercía sobre toda Asia en el apogeo de la dinastía Qing, situación que se prolongó durante el maoísmo. Luego, con las políticas de la Reforma y la Apertura, el gigante asiático despertó su economía, hasta constituirse hoy en la segunda a escala global, pero con un perfil político bajo, guiado por la estrategia de los 24 caracteres de Deng Xiaoping. Con la llegada de Xi Jinping, esta política -que aconsejaba no instrumentar políticas exteriores asertivas, y esperar al tiempo en que China tuviera la capacidad para hacerlo- ha sido abandonada, demostrando que ha llegado el tiempo en que el gigante también ha despertado su política exterior, con ansias de alcanzar el estatus atávico de potencia hegemónica. Así, desde 2012, cada año muestra un incremento en la actividad china en el Mar de China Meridional, en claro desafío no solo del resto de los Estados litorales, sino también de todo ASEAN, en tanto comunidad de Estados.

Frente a la amenaza que presenta China, y con Estados Unidos en retirada, ASEAN es presentada con la oportunidad única de mostrar una política de seguridad asertiva e independiente. Así, en la fuerza del conjunto, la Asociación se encuentra en posición de ejercer deterrence by denial, es decir, 
bloquear de manera activa la injerencia china en las zonas económicas exclusivas de ASEAN de manera conjunta, con patrullajes coordinados, en lo que respecta a las operaciones de campo, a la manera de la Patrulla del Estrecho de Malaca y Singapur, por tomar el ejemplo de un antecedente exitoso en la región. Por su parte, en lo que respecta al relacionamiento estratégico, el uso de mecanismos de soft balancing, como el desafío limitado en organismos regionales e internacionales, puede resultar exitoso en amainar la asertividad de la estrategia china (Anzelini, 2013; Walt, 2005), dado que esta buscar mostrarse como una potencia sin pretensiones hegemónicas, y un posicionamiento adverso unificado de diez Estados en su vecindad dañaría dicha reputación.

\section{Conclusiones}

En este ensayo se han expuesto los lineamientos de la cuestión actual sobre el Mar de China Meridional, analizando los posicionamientos de los Estados interesados y del proceso de integración que los involucra, ASEAN. En suma, la situación amerita ser considerada una tensa calma, en la que las negociaciones diplomáticas (que se han extendido por más de diecisiete años) aparentan estar desalineadas con la realidad, en lo que se puede percibir como una persistente escalada en los conflictos entre China y el resto de los Estados litorales del Mar.

La actual situación posee al menos dos desenlaces claros: por una parte, si los Estados más asertivos de ASEAN no consiguen convencer a aquellos que se sienten más próximos a China de la necesidad de hacerle frente para preservar la soberanía de la Comunidad sobre las zonas económicas exclusivas en el Mar de China Meridional, el actual borrador del Código de Conducta se verá ratificado tarde o temprano con una redacción más cercana a los intereses de Beijing que a los de Yakarta. Por otra parte, si los miembros de ASEAN deciden hacer frente al riesgo de las revanchas económicas de China en pos de mantener su soberanía comunitaria y fortalecer la solidaridad mutua, estarían en condiciones más igualitarias de negociar con el gigante asiático - de manera bilateral ASEAN-China-, pudiéndose lograr, de este modo, un acuerdo vinculante que garantice que el Mar no sea ocupado de facto por Beijing.

Si bien sendos escenarios no son más que simplificaciones formuladas ceteris paribus, representan las dos grandes constelaciones de caminos que pueden tomar las relaciones ASEAN-China en el futuro. Dependerá, finalmente, de los miembros más cercanos a esta última la decisión de vetar o no los proyectos existentes que buscan fortalecer la Asociación y darle un protagonismo en el escenario internacional, independiente de las grandes potencias, y en pie de igualdad con ellas, tanto en los aspectos económicos como políticos. 
Las disputas del Mar de China Meridional: una oportunidad para fortalecer a ASEAN

MAX POVSE

\section{Bibliografía}

ACHArya, A. (2000). Collective Identity and Conflict Management in Southeast Asia. AdDler E. \& BARnetT M. (Eds.). Security Communities. Cambridge: Cambridge University Press.

Aggarwal, V. (1985). Liberal Protectionism: The International Politics of Organized Textile Trade. Berkeley: University of California Press.

Alagappa, M. (1995). Regionalism and Conflict Management: a Framework for Analysis. En Review of International Studies, 21(4), 359-387.

AMER, R. (2015). ASEAN and Conflict Management: the Need for a High Council. Policy Brief, 178. Institute for Security and Development Policy.

ANZELINI, L., (2013), Los Estados medianos y la "autonomía heterodoxa" en el sistema internacional: algunas consideraciones sobre el caso argentine. En E. Llenderrozas (Comp.), Relaciones Internacionales: teorías y debates (pp. 303-320). Buenos Aires: EUDEBA.

ChOng, A., (2010). Southeast Asia. Theory between modernization and tradition?, en Acharya, A. y Buzan, B., Non-Western International Relations Theory. Perspectives on and Beyond Asia, pp. 117-147. Routledge.

FORT, B. \& WEBBER, D. (2006). Regional Integration in East Asia and Europe. Convergence or Divergence? Nueva York: Routledge.

HIRO, K., (2004), Why is ASEAN diplomacy changing? From "NonInterference" to "Open and Frank Discussion", Asian Survey, 44 (2), pp. 237-254, Berkeley: University of California Press.

KraSnER, S., (2001). Soberanía. Hipocresía organizada, Barcelona: Paidós.

RULAND, J., (2011). Southeast Asian regionalism and global governance: "multilateral utility" or "hedging utility"?, Contemporary Southeast Asia, 33 (1), pp. 83-112.

SEverinO, R. C., (3 de julio de 2000). Sovereignty, Intervention and the ASEAN Way, http://asean.org/?static_post=sovereignty-interventionand-the- asean-way-3-july-2000

SEVErinO, R. C., (3 de septiembre de 2001), The ASEAN Way and the Rule of Law, http://asean.org/?static_post=the-asean-way-and-the-rule-of-law SWANSTRÖM, N. (2002). Liberal Protectionism: The International Politics of Organized Textile Trade. Uppsala: Universitetstryckeriet.

ThaYer, C. (3 de agosto de 2018). A Closer Look at the ASEAN-China Single Draft South China Sea Code of Conduct. The Diplomat. $\quad$ https://thediplomat.com/2018/08/a-closer-look-atthe-asean-china-single-draft- south-china-sea-code-of-conduct/

Walt, S. (2005). Taming American Power: The Global Response to US Primacy. Norton.

XUE, S. (2019). Why Joint Development Agreements fail: implications for the Southeast Asia dispute. Contemporary Southeast Asia, 41(3), 418-446. 
MERCOSUR-ASEAN: las relaciones comerciales actuales y las oportunidades de negocio para el bloque latinoamericano en el sector de alimentos

SORAIA DANIELLE

\title{
MERCOSUR-ASEAN: LAS RELACIONES COMERCIALES ACTUALES Y LAS OPORTUNIDADES DE NEGOCIO PARA EL BLOQUE LATINOAMERICANO EN EL SECTOR DE ALIMENTOS
}

\author{
Soraia Danielle \\ Universidad Católica del Uruguay \\ Smar0804@gmail.com
}

\section{Introducción}

Ambos bloques tienen el componente del "regionalismo" como motor de inicio, a pesar de que hoy en día cada vez se aleje el pensamiento de firmar acuerdos regionales, sino que abiertos a cualquier parte del mundo. El Mercado Común del Sur (MERCOSUR) y la Asociación del de Naciones del Sudeste Asiático (ASEAN) proveyeron de un escenario de desarrollo e impacto positivo en sus respectivas regiones, provocaron un crecimiento del comercio intrarregional. Mientras que el bloque latinoamericano está enfrentando situaciones de conflicto que provocan que sus objetivos se atrasen y cambios de gobierno, ASEAN avanzó a grandes pasos en esta última década en materia económica-comercial impulsado por la firma de sus miembros en los megaacuerdos Comprehensive and Progressive Agreement for Trans-Pacific Partnership (CPATPP), Regional Comprehensive Economic Partnership (RCEP) y la cooperación Asia-Pacific Economic Cooperation (APEC).

La ASEAN fue fundada en 1967 con el ideal político y seguridad para proveer estabilidad y paz en la región, la cual siempre fue conflictiva por sus diferencias notorias, llegando a ser el escenario de uno de los conflictos más grandes de la Guerra Fría, la Guerra de Vietnam (1955-1975). Siendo así, los primeros países en firmar la Declaración de Bangkok (1984) que dio inicio al proceso de formación del bloque fueron Malasia, Tailandia, Singapur y Filipinas. Posteriormente Brunéi (1984), Vietnam (1995), Laos y Myanmar (1997) y la última adhesión fue Camboya (1999). Con ello conformaron una Asociación para la Cooperación Regional contemplando las heterogeneidades de sus miembros. Una vez logrado el objetivo de alcanzar la estabilidad, se prosiguió a una segunda etapa identificada como el impulso económicocomercial. En ella, se fundaron los cimientos para el surgimiento del nombre ASEAN en el escenario económico (Bartesaghi, 2014). Primero con la firma de la Zona de Libre Comercio en 1992, luego en el 2007 se reafirmó el pilar mencionado con la Carta de ASEAN (Bartesaghi \& Melgar, 2019). Siendo así, culmina con sus tres ejes principales que sostienen a la región: político y 
MERCOSUR-ASEAN: las relaciones comerciales actuales y las oportunidades de negocio para el bloque latinoamericano en el sector de alimentos

SORAIA DANIELLE

seguridad, económico y sociocultural (Asociación de Naciones del Sudeste Asiático, 2003).

Mientras que ASEAN formaba su Zona de Libre Comercio, en 1991 el MERCOSUR firma el Tratado de Asunción por sus miembros fundacionales: Argentina, Brasil, Paraguay y Uruguay con el ambicioso fin de formar a largo plazo un Mercado Común. El bloque fundamentalmente se formó por parte de Argentina y Brasil, quienes tenían una estrecha pero conflictiva relación comercial. Así como en la ASEAN también existía una relación de conflicto entre los miembros, a pesar de ser mucho más profunda. Llegando así a la gestación del bloque latinoamericano en conjunto con Uruguay y Paraguay, que aprovecharon para expandir sus negocios tanto intrarregionales como internacionales debido al aumento de competitividad en el escenario mundial que presentó su nueva imagen. Desde su inicio, el pilar de inserción internacional estuvo atado a sus principios de coordinación, al crear un arancel externo común y mencionándolo en el primer artículo del Tratado de Asunción como "la coordinación de posiciones en foros económico-comerciales-regionales e internacionales”. En términos de inserción internacional, volvió a retomar su pilar comercial con el nuevo Acuerdo con la Unión Europea pero no con el mismo impacto que hubiese tenido 20 años atrás, ya que existe una politización del bloque que también se reflejó en la firma de acuerdos; caso de Israel, Palestina, Egipto (María \& Pereira, 2016). Caso contrario al que sucede en el bloque del Sudeste Asiático, los Acuerdos que ha firmado sí representan los países con los cuales tienen destino sus principales exportaciones e importaciones. En el MERCOSUR solo durante la primera etapa firmó acuerdos de moderada importancia con países miembros de la ALADI.

Hoy en día la ASEAN es la sexta economía más potente del mundo ocupando el $7,3 \%$ del comercio mundial de importaciones en 2017. La economía crece a tasas del 5\% (Bartesaghi \& Melgar, 2019), convergiendo al total de una población estimada de 634 millones según el Banco Mundial. Lo que significa un amplio espectro de mercado para ingresar y grandes oportunidades de negocio a partir de las diferencias comerciales. Llegar a la ASEAN significará para el bloque su retomada de interés económico en el escenario mundial y volver a posicionarse en los estándares competitivos globales. Mirar hacia mercados externos es esencial para las regiones, contribuye a una mejora de la competitividad y un incremento del flujo de inversiones. Aun así, las diferencias entre ambos bloques en el entorno actual global del comercio son grandes, pero esto no se debe observar como un impedimento, sino como un factor a ser aprovechado y usado entre ambos para solucionar dicho obstáculo.

El objetivo del presente ensayo es analizar la situación actual en la que se encuentran ambos bloques comerciales de la región Sur-Sur, ASEAN y MERCOSUR, desarrollando la oportunidad de negocio que existe basándose 
MERCOSUR-ASEAN: las relaciones comerciales actuales y las oportunidades de negocio para el bloque latinoamericano en el sector de alimentos

en el fundamento de complementariedades. Por lo que se refiere a las oportunidades en exportación de alimentos, rubro por el cual el MERCOSUR posee ventaja competitiva (Perez, 2012). Abarcando los principales desafíos culturales que debe de superar para que las negociaciones vayan más allá de un TLC, sino que una cooperación a largo plazo.

\section{El escenario actual de las relaciones comerciales entre bloques}

En los últimos dos años las relaciones se profundizaron levemente entre ambos bloques y aumentaron los volúmenes de intercambio comercial con los miembros, principalmente con Brasil, el cual representa un gran interés para el Sudeste Asiático. Sin embargo, el primer movimiento significativo para el avance de un posible acuerdo fue durante la realización de la primera ronda de negociaciones MERCOSUR-Singapur. Por ser la primera reunión, acarreó los temas clásicos de un tratado comercial y, a su vez, algunos considerados avanzados: Bienes; Servicios e Inversiones; Reglas de Origen, Medidas Sanitarias y Fitosanitarias, Obstáculos Técnicos al Comercio, Competencia, Facilitación del Comercio, Compras Gubernamentales, Solución de Controversias, Propiedad Intelectual, y Defensa Comercial (Cancillería Argentina, 2019). Singapur es el principal bub logístico de la región, un importante factor que denota un esencial alcance a nuevos mercados inexplorados o con pocas exportaciones como el de Laos, del cual países como Uruguay y Paraguay no tienen participación. Singapur, ocupa el segundo puesto del ranking Doing Business 2018 de países con mayor facilidad de hacer negocios, tales como recepción de inversión extranjera, impuestos, trámites entre otros. Pero se ha dedicado a realizar inversiones significativas en otros países, lo cual es fundamental para que el bloque latinoamericano aumente su oferta de servicios, aumentar la generación de nuevos empleos e impulsar la mano de obra cualificada.

Brasil oficializó su interés por el bloque en el 2011, a partir de esa fecha las exportaciones aumentaron principalmente en el 2014 debido al precio de Residuos sólidos provenientes de la extracción de aceite de Soja (23.04.00) que según lo descripto en la nomenclatura, sirven para la preparación de animales. Como se puede observar en el gráfico, la balanza es favorable para el MERCOSUR. Pero se debe aclarar que el efecto en la balanza asimétrica para la ASEAN, no afecta en gran medida en su balanza comercial global. Ya que el MERCOSUR, como se puede observar en el siguiente gráfico, tiene un escaso impacto en sus importaciones y su foco principal son los intercambios comerciales con la Unión Europea y Estados Unidos. 
MERCOSUR-ASEAN: las relaciones comerciales actuales y las oportunidades de negocio para el bloque latinoamericano en el sector de alimentos

\section{Gráfico 1}

Comercio exterior entre el MERCOSUR y la ASEAN (Bienes)

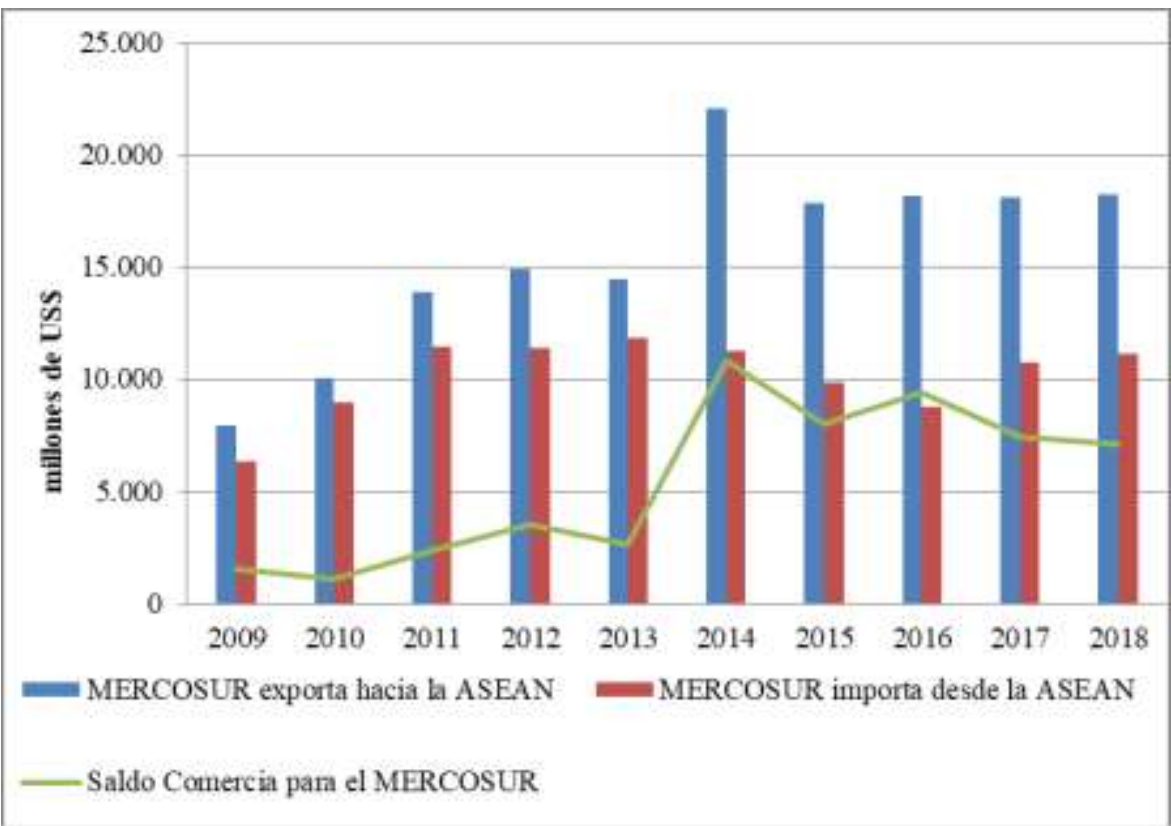

Fuente: elaboración propia en base a Trade Map

\section{Gráfico 2}

Participación de las exportaciones entre bloques

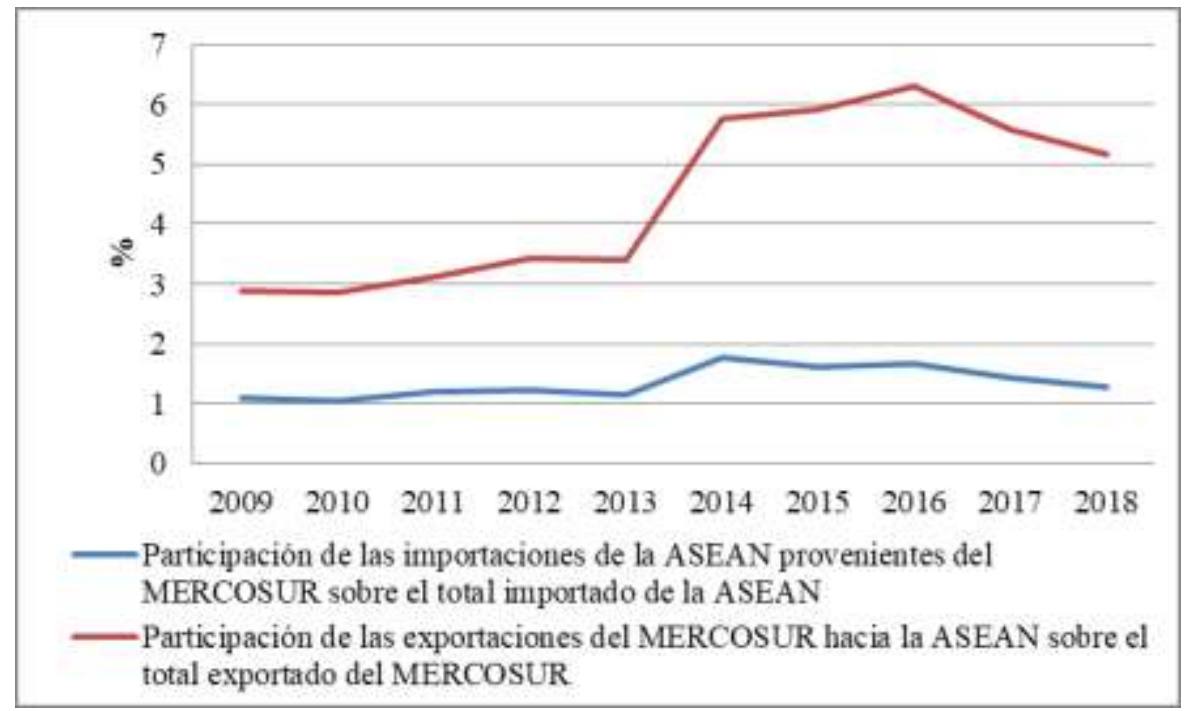

Fuente: elaboración propia en base a Trade Map 
MERCOSUR-ASEAN: las relaciones comerciales actuales y las oportunidades de negocio para el bloque latinoamericano en el sector de alimentos

El factor negativo de la balanza arraiga en la exportación de productos que son primarios y requieren poca mano de obra, en consecuencia, tienen poco valor agregado. A pesar de que en valores netos sean grandes volúmenes, no tiene gran presencia a nivel comercial, ya que son productos de fácil desvalorización en el mercado internacional. Englobadas las principales diez exportaciones del MERCOSUR como bloque, ocupan más del 80\% de las exportaciones totales, lo que significa que hay un concentrado muy grande en pocos productos. La tabla a continuación muestra la comparación de los productos exportados entre los bloques y se puede notar que los productos más exportados corresponden al sector de alimentos y derivados, con excepción del combustible y minerales. Ya en cuanto a las importaciones del MERCOSUR, se observa el agregado de valor que tienen los bienes, ubicándose en capítulos arancelarios avanzados.

\section{Tabla 1}

Comparación entre los productos exportados de la ASEAN y MERCOSUR en el marco de las relaciones entre bloque (Acumulado 2018)

\begin{tabular}{|c|c|c|c|c|c|c|}
\hline & \multicolumn{3}{|c|}{ ASEAN } & \multicolumn{3}{c|}{ MERCOSUR } \\
\hline $\begin{array}{c}\text { Ranki } \\
\text { ng }\end{array}$ & $\begin{array}{c}\text { Códi } \\
\text { go } \\
\text { SA }\end{array}$ & $\begin{array}{c}\text { Descripci } \\
\text { ón }\end{array}$ & $\begin{array}{c}\text { Participac } \\
\text { ión }\end{array}$ & $\begin{array}{c}\text { Códi } \\
\text { go } \\
\text { SA }\end{array}$ & $\begin{array}{c}\text { Descripció } \\
\text { n }\end{array}$ & $\begin{array}{c}\text { Participac } \\
\text { ión }\end{array}$ \\
\hline $\mathbf{1}$ & 85 & $\begin{array}{c}\text { Máquinas, } \\
\text { aparatos y } \\
\text { material } \\
\text { eléctrico }\end{array}$ & 32,38 & 23 & $\begin{array}{c}\text { Residuos y } \\
\text { desperdicios } \\
\text { de industrias } \\
\text { alimentarias }\end{array}$ & 28,12 \\
\hline $\mathbf{2}$ & 84 & $\begin{array}{c}\text { Máquinas, } \\
\text { aparatos y } \\
\text { artefactos } \\
\text { mecánicos }\end{array}$ & 15,75 & 10 & Cereales & 13,03 \\
\hline $\mathbf{3}$ & 87 & $\begin{array}{c}\text { Vehículos } \\
\text { automóvil } \\
\text { es, } \\
\text { tractores }\end{array}$ & 8,72 & 27 & $\begin{array}{c}\text { Combustible } \\
\text { minerales, } \\
\text { aceites } \\
\text { minerales }\end{array}$ & 12,37 \\
\hline $\mathbf{5}$ & 64 & $\begin{array}{c}\text { Cartuchos } \\
\text { y sus } \\
\text { manufact } \\
\text { uras }\end{array}$ & 7,79 & 26 & $\begin{array}{c}\text { Minerales } \\
\text { metalíferos, } \\
\text { escorias y } \\
\text { cenizas }\end{array}$ & 8,89 \\
\hline Calzado & 5,10 & 89 & Barcos & 6,82 \\
\hline
\end{tabular}


MERCOSUR-ASEAN: las relaciones comerciales actuales y las oportunidades de negocio para el bloque latinoamericano en el sector de alimentos

SORAIA DANIELLE

\begin{tabular}{|c|c|c|c|c|c|c|c|}
\hline $\begin{array}{l}\text { Asia } \\
\text { Anetica } \\
\text { Latina } \\
\end{array}$ & 6 & 15 & $\begin{array}{c}\text { Grasas y } \\
\text { sus } \\
\text { manufact } \\
\text { uras }\end{array}$ & 3,02 & 52 & Algodón & 3,89 \\
\hline 86 & 7 & 90 & $\begin{array}{c}\text { Instrumen } \\
\text { tos y } \\
\text { aparatos } \\
\text { de óptica }\end{array}$ & 2,91 & 02 & $\begin{array}{c}\text { Carne, } \\
\text { despojos } \\
\text { comestibles }\end{array}$ & 3,63 \\
\hline & 8 & 27 & $\begin{array}{l}\text { Combusti } \\
\text { bles } \\
\text { minerales, } \\
\text { aceites } \\
\text { minerales }\end{array}$ & 2,85 & 12 & $\begin{array}{l}\text { Semillas y } \\
\text { frutos } \\
\text { oleaginosos }\end{array}$ & 3,48 \\
\hline & 9 & 55 & $\begin{array}{c}\text { Fibras } \\
\text { sintéticas } \\
\text { O } \\
\text { Artificiale } \\
\text { s }\end{array}$ & 2,63 & 84 & $\begin{array}{l}\text { Máquinas } \\
\text { (turborreact } \\
\text { ores) }\end{array}$ & 2,75 \\
\hline & 10 & 39 & $\begin{array}{l}\text { Plásticos y } \\
\text { sus } \\
\text { manufact } \\
\text { uras }\end{array}$ & 2,22 & 41 & $\begin{array}{l}\text { Pieles y } \\
\text { cueros }\end{array}$ & 2,14 \\
\hline & \multicolumn{3}{|c|}{ Resto de los productos } & 16,61 & & & 14,89 \\
\hline
\end{tabular}

Fuente: elaboración propia en base a Trade Map.

La motivación para la ASEAN es Brasil por encontrarse entre los primero 30 exportadores. A continuación, se muestra una tabla en donde se puede observar la concentración existente en un único miembro del MERCOSUR, del total de las exportaciones, $67,7 \%$ son únicamente provenientes de Brasil.

Tabla 2

Participación de los Miembros del MERCOSUR en las Exportaciones hacia la ASEAN

\begin{tabular}{cccccc}
\hline País & Año & $\begin{array}{c}\text { Participación } \\
\mathbf{( \% )}\end{array}$ & Año & $\begin{array}{c}\text { Participación } \\
(\mathbf{\%})\end{array}$ & Variación \\
\hline Brasil & 2009 & 64,0 & 2017 & 67,7 & 3,7 \\
Argentina & 2009 & 33,8 & 2017 & 30,8 & $-3,0$ \\
Paraguay & 2009 & 1,0 & 2017 & 0,9 & $-0,1$
\end{tabular}


MERCOSUR-ASEAN: las relaciones comerciales actuales y las oportunidades de negocio para el bloque latinoamericano en el sector de alimentos

SORAIA DANIELLE

$\begin{array}{llllll}\text { Uruguay } & 2009 & 1,2 & 2017 & 0,6 & -0,5\end{array}$

Fuente: elaboración propia en base a Trade Map

Las inequidades existentes y la caída de las exportaciones de Argentina, significó un crecimiento en valor neto para Brasil. Por más que las exportaciones hayan tenido un aumento paulatino, siguen siendo los mismos productos. Solamente Uruguay en su vínculo bilateral con Indonesia, el 85\% está concentrado en dos productos madera y cueros (Bartesaghi, 2018). El último mencionado, está entre los productos más exportados al bloque asiático por parte del MERCOSUR.

Arraigado de la mano por las nuevas tendencias del negocio, un factor que debe considerarse como decisivo al momento de establecer una relación con el bloque ASEAN es la consideración de los nuevos temas OMC + y OMC X. Ya que el bloque del sudeste asiático es considerado avanzado y pionero en temas de negociación, porque no solo disputa sobre lo tradicional, que suelen ser puntos ya obligatorios en los acuerdos comerciales. Esto está arraigado en su mismo origen, los temas que siempre ha negociado son ene materia de cooperación, infraestructura, asuntos de carácter social, intercambio de conocimiento, entre otras. Como se mencionaba anteriormente, discuten temas que están por arriba de la Agenda del MERCOSUR, hoy en día Brasil está buscando socios que lo ayuden en materia de Transporte, Inversiones y Energías renovables, declarado por el secretario del Ministerio de Relaciones Exteriores Reinaldo José de Almeida.

En este asunto, se podría considerar a la Alianza del Pacífico como una fuerte amenaza al MERCOSUR, ya que sus miembros no solo realizan acuerdos comerciales mucho más rápido que el MERCOSUR. Sino que también realizan en base a los llamados de "nueva generación", en otras palabras, acuerdos de mayor alcance. Por ende, a pesar de que las exportaciones de Alianza Pacífico (AP) se encuentren en mejor posición, en cuanto a valor no alcanzan lo sumado entre Brasil y Argentina.

\section{Oportunidades de negocios}

Brasil es el exportador con mayor participación en el intercambio comercial con el bloque asiático. Es justo así, que en la presente sección donde se desarrollarán las oportunidades de negocio, se enfoque en los miembros: Argentina, Paraguay y Uruguay. Debido a la crisis en los países de principal exportación del MERCOSUR como China y la caída de los precios de los commodities, demostraron que la dependencia sobre escasos socios genera una inestabilidad, por eso se debe de persuadir en la diversificación de socios (Rubiolo, 2015). La diversificación de los socios comerciales es una 
MERCOSUR-ASEAN: las relaciones comerciales actuales y las oportunidades de negocio para el bloque latinoamericano en el sector de alimentos

oportunidad para ampliar el abanico de productos, así como el grado de autonomía y reducir los riesgos de limitarse en algunos países importadores. También explorar la elaboración de las Cadenas de Valor, ya que los países del bloque latinoamericano exportan en su mayoría materias primas con bajo valor de procesamiento.

Sin embargo, la primera posibilidad aparente de negocio que puede ser fructífera es la exportación de alimentos. Siendo una población de más de 650 millones, ASEAN representa una oportunidad para los exportadores de dicho rubro, como lo son los países mencionados, especialmente Uruguay que exporta fundamentalmente commodities. (Bartesaghi \& Melgar, 2019).

El enriquecimiento de la población fue dado por el aumento de la población joven, crecimiento económico de los ingresos medios, siendo que, en países como Malasia, Vietnam y Tailandia, la clase media es mayoría. Dicho hecho, cambia la configuración del consumo de bienes y servicios tanto en calidad como en cantidades. La demanda es creciente, representando una oportunidad de complementariedad que aún es inexplorada.

Cabe destacar, que a pesar de que los productos sean competitivos, ASEAN tiene una relación estrecha con Nueva Zelanda y Australia, con los cuales posee un TLC (Asean-Australia-New Zealand Free Trade Agreement o AANZFTA) que abarca la desgravación en alimentos. Ya que son exportadores de alta competencia en materia alimenticia, por consecuencia, accediendo sin aranceles o reducidos. El arancel promedio para Nación Más Favorecida, que abarca los productos primarios, tiene un promedio ponderado de 5,27\%. Los cereales, son el segundo producto más exportado por el MERCOSUR y el primero más exportado por Argentina a la ASEAN. Al momento de ingreso, tiene un arancel del 30\%. Mientras que Australia ingresa con un arancel del $0 \%$ debido a su tratado AANZFTA. En dicho rubro, existe una restricción en la oportunidad de negocio, pero se debe aprovechar que, en algunos de los productos, como los pertenecientes a los capítulos 23, 27, 59 los países del MERCOSUR ingresan con preferencia arancelaria del NMF, llegando a ser $0 \%$.

Residuos de soja y exportaciones de maíz, son los principales productos exportados por Argentina, debido a que el incremento del precio internacional de los commodities y el uso recurrente de nuevas tecnologías agrícolas proveyeron un mejor escenario a partir del 2011 (Rubiolo, 2017). Como se puede observar en el gráfico a continuación, la importación de alimento se ha más que quintuplicado desde el comienzo del siglo XXI, lo que significa que la población necesita abastecerse con insumos externos para poder cubrir los alimentos que no produce internamente. Este hecho está relacionado a motivos geográficos y climáticos que no permiten producir allí, por eso son clientes que cada vez comprarán más del resto del mundo. 
MERCOSUR-ASEAN: las relaciones comerciales actuales y las oportunidades de negocio para el bloque latinoamericano en el sector de alimentos

Gráfico 3

Importaciones de ASEAN para la categoría Alimentos (SA: 01 - 23)

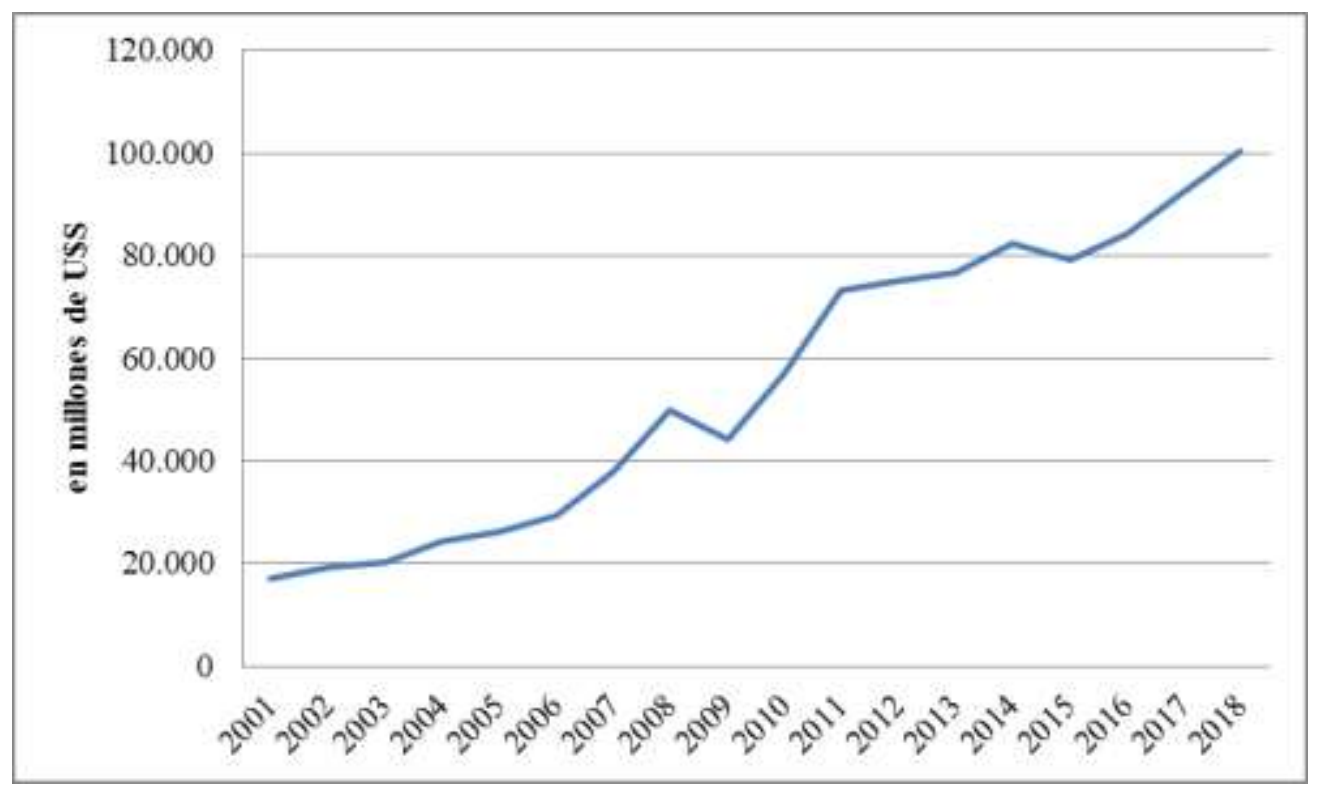

Fuente: elaboración propia en base a Trade Map

De comienzo las oportunidades deben estar enfocadas en los principales socios comerciales que tiene con el bloque del Sudeste Asiático, Singapur, Vietnam, Indonesia, Filipinas y Tailandia. Esto está manifestado de forma difusiva por parte de las recientes iniciativas que tuvo el MERCOSUR de acercarse a ellos, por un lado, las rondas de negociación para un futuro TLC con Singapur, las aperturas de embajadas de Uruguay y Paraguay en Indonesia. Llevando al caso, Indonesia se ha tornado cada vez más importante en la importación de productos que son competitivos en el MERCOSUR. Tales como la carne bovina, pescado, derivados de la leche como manteca, quesos y leche en polvo, este último que ha tenido aumento en el precio internacional. Además de los clásicos trigo, arroz, soja, azúcar, frutas y verduras. Al mismo tiempo, esto puede causar enfrentamientos en los países del bloque latinoamericano ya que intentarán todos colocar sus ofertas en los países, aprovechando las oportunidades (Bartesaghi, 2018). Para evitar estos enfrentamientos, es se podría establecer un sistema de cuotas, en donde cada país logre importar sus productos, sin perjudicar al otro.

Como se ha mencionado, hay una concentración en materia de producto, pero también en socios comerciales. Para ello se debe de diversificar la gama de socios comerciales, ya que por ejemplo en Uruguay casi el 60\% de las exportaciones se concentra en Vietnam y Tailandia (Bartesaghi \& Melgar, 
MERCOSUR-ASEAN: las relaciones comerciales actuales y las oportunidades de negocio para el bloque latinoamericano en el sector de alimentos

2019). Acotarse solo a la exportación de commodities refuerza el trabajo sobre la ventaja competitiva y no es un motor de innovación. Para ello se necesita de la cooperación entre bloques, para explorar nuevas oportunidades, que no se limiten a solamente un sector.

Más allá de las negociaciones en materias de bienes, se tiene conocimiento de que los países del Sudeste Asiático tienen una tendencia a la inversión, por lo que sería un efecto beneficioso para la balanza comercial desfavorable de la ASEAN. Reconocer el papel de la ciencia de la mano con la tecnología, es una oportunidad de intercambio de know-how y exportación mutua de servicios. Tanto Uruguay como Paraguay han desarrollado sus centros de software. Uruguay por su parte ha conseguido exportar servicios y atraer empresas internacionales para instalar outsourcing y offshoring.

\section{Desafíos culturales}

Para llegar al mercado asiático, se debe de sustentar una base sólida de intercambios culturales, información y cooperación. Las restricciones arancelarias y no arancelarias se superan luego de firmado un acuerdo, las culturales, no. Reducir la brecha cultural, que es uno de los tres pilares que sustenta el bloque del Sudeste Asiático, es uno de los principales desafíos que se encontrará a inicios de vinculación entre economías. Ya que el conocimiento mutuo y la confianza de una estabilidad son esenciales para las relaciones comerciales. A pesar de las distancias geográficas y culturales como el lingüístico, artístico, la aproximación reciente del MERCOSUR con algunos de los países miembros de la ASEAN ya acentuó un escenario favorable y pasible para las negociaciones. Aun así, falta mucho para estrechar un lazo firme, aprender los usos, costumbres y el estilo de negociación es el primer paso para llegar a un acercamiento tanto entre países como entre empresas.

Son mercados complejos de entrar y ágiles en negociación, actualmente existe una baja intensidad de acercamientos, por lo pronto no hay una meta en común de cooperación y un enlace que favorezca la formación de intereses comunes. A pesar de la ronda de negociación con Singapur, no se ha realizado un plan de acción por parte del MERCOSUR donde favorezca una estrategia o política de generación de conocimiento mutuo.

Solo en el marco de las exportaciones, hay un impacto directamente cultural que es la Certificación Halal. El 42\% de la población ASEAN es musulmana (Mufford, 2017), tener esta certificación es un requerimiento básico y de primera instancia para acceder al mercado. La compatibilización de los marcos de reglamentación surge pues, de ser una de las necesidades a concretar para el acceso en la materia de productos agrícolas y alimentos, que es en los capítulos que hay mayor compatibilidad entre los países, pero también mayores restricciones. 
MERCOSUR-ASEAN: las relaciones comerciales actuales y las oportunidades de negocio para el bloque latinoamericano en el sector de alimentos

Para realizar el acercamiento cultural, se puede entrelazar con las iniciativas de visitas comerciales, como lo hizo Argentina en el 2009 con el "Memorándum de entendimiento entra la República Argentina y el gobierno de Indonesia en materia de deportes". Acercó la asta del deporte para hacer conocer su país, en donde también incluyó el tango oriundo del Río de la Plata. También con acuerdos de cooperación, los cuales no necesariamente incluyen un nivel de profundidad alto y sirven para actuar en escenarios específicos como la Promoción de Inversión, intercambio de know-how. No sería completamente cierto, si se menciona que no hay acuerdos de cooperación, tratados y beneficios, ya que existen, pero no son explorados debido a la falta de interacción. En el ámbito del bloque solo hay uno firmado en el año de 2007 con Singapur que es el "Memorándum de entendimiento sobre Cooperación en materia de Comercio e Inversión y Plan de Acción"

Si se sigue por el ámbito bilateral, Brasil y Argentina, son los que tienen mayor cantidad de acuerdos de cooperación con los países de la ASEAN y en temáticas. Uruguay y Paraguay se encuentran por detrás, no tienen firmados en tantas materias. Pero en peor situación se encuentra Paraguay que tiene solo dos acuerdos, que son con Filipinas e Indonesia sobre la exención de visado, una temática que es básica. Brunéi, Camboya y Laos tienen una muy escasa interacción de acuerdos, solo con Argentina y Brasil que tienen algunos esporádicos durante los primeros años del siglo XXI. La cooperación más frecuente surge de la promoción y protección de inversiones recíprocas. Sólo Argentina tiene firmado bilateralmente con Filipinas, Indonesia, Tailandia y Vietnam. Ya Uruguay y Brasil tienen con Vietnam únicamente. Seguidamente surge la Cooperación Económica, Científica y Tecnológica, también en el ámbito bilateral que Uruguay se ha extendido en mayor medida con Malasia, Vietnam e Indonesia.

Uno de los que cabe destacar, es la cooperación oficial que hicieron entre dos centros de investigación de Argentina y Malasia: INTA (Instituto Nacional de Tecnología Agropecuaria) y MARDI (Malaysian Agricultural Research and Development Institute). En temas culturales, solo Argentina y Brasil tienen acuerdos con relación a la cooperación de entendimiento cultural, turístico y deportivo que se produjeron entre 2012 y 2019. Por ello, cuando se acerquen las rondas de negociaciones de ambos bloques, se encontrarán que cada país negociará los nuevos temas por su propia cuenta y no como una organización. Esto representa una seria desventaja para el contrincante asiático, que ya viene instaurando una armonización en toda la zona, y esto se debe a su pasado histórico de guerras, conflictos y su deseo por el desarrollo de las naciones en conjunto y no una disputa avasalladora. La presencia de empresas del MERCOSUR, así como las inversiones favorecerá el avance de las relaciones, también con incentivos como la reducción de costos ya sea de instalación como también aquellos decurrentes del comercio, como el flete. 
MERCOSUR-ASEAN: las relaciones comerciales actuales y las oportunidades de negocio para el bloque latinoamericano en el sector de alimentos

\section{Consideraciones finales}

Sobre el paso de los años, ambos bloques tuvieron un proceso invertido de desarrollo y profundización. Mientras que el bloque del Sudeste Asiático alcanzó su pilar de comercio exterior, el MERCOSUR se transformó en aquello que ASEAN usó en su provecho. El uso excesivo de la política en el bloque latinoamericano le significó grandes pérdidas de estabilidad en el escenario mundial sobre las cuestiones económicas y status. Llegar al ASEAN significará para el MERCOSUR no solo su retomada de interés del pilar económico en el contexto mundial, y seguir prosiguiendo con los principios que se establecieron desde su fundación y volver a posicionarse en los estándares competitivos. Mirar hacia mercados externos es esencial para las regiones, contribuye a una mejora de la competitividad, mejorando el precio de importación, incremento del flujo de inversiones, la diversificación de socios y el beneficio de diferentes actores sociales. Específicamente, la cooperación SurSur ha favorecido a países en desarrollo en materias de innovación y desarrollo en conjunto, con especial énfasis en América Latina y el Sudeste Asiático.

Para llegar al objetivo tan añorado, será necesario desarrollar un ambiente amigable de inversión en la región, así como también realizar promoción comercial, tales como las participaciones en ferias, visitas comerciales y misiones exploratorias, tornarlo atractivo, para así atraer inversores al territorio MERCOSUR. La apertura de Embajadas y Consulados también es una demostración de interés en la región, así como lo hicieron Uruguay y Paraguay.

Un hecho para tomar en cuenta, en favor al MERCOSUR, es que recientemente comenzó a realizar negociaciones con países que integran el foro ASEAN +3, lo cual representa cierta armonía entre un bloque y el otro. De igual forma, se declaró a finales de 2017 el interés de un posible TLC con Japón, las negociaciones no han sido retomadas, pero hay una declaración de inicio. Siguiendo por una misma línea de acción, durante el 2018 Uruguay, bilateralmente, hizo público un memorándum en el cual resaltaba el interés de comenzar las negociaciones para un TLC con China.

También se debe de tomar en cuenta que las próximas reuniones del MERCOSUR, en cuanto a su agenda externa, serán con Vietnam e Indonesia, los cuales son miembros de la ASEAN y acerca más aún un futuro encuentro entre bloques. Es una oportunidad, pero también un desafío, las negociaciones son diferentes por los estilos de cada país miembro pero también hay más beneficios a ser aprovechados. El próximo año de 2020, es un año crucial ya que culminará su ciclo establecido en el “ASEAN 2020” y abrirá uno nuevo con más proyectos de integración, posicionamiento de mercado y los ojos del mundo estarán allí. 
MERCOSUR-ASEAN: las relaciones comerciales actuales y las oportunidades de negocio para el bloque latinoamericano en el sector de alimentos

Este es un momento esencial para que el MERCOSUR diversifique sus socios comerciales en materia de comercio exterior, para disminuir el grado de dependencia que tiene de países como China que ocupan gran parte tanto de sus exportaciones como importaciones. No caer en la discontinuidad al estrechar lazos y fomentar un Plan de Acción a largo plazo tanto en el ámbito

multilateral como bilateral, para entrelazar los vínculos Sur-Sur fomentando los flujos de inversión y comercio.

\section{Referencias bibliográficas}

Association of Southeast Asian NAtions (2003). Declaration of ASEAN (Bali Concord II). https://asean.org/?static_post=declaration-ofasean-concord-ii-bali-concord-ii

BARTESAGHI, I. (2014). La ASEAN y el MERCOSUR. Similitudes, Diferencias y Potencialidades. Temas de Derecho Económico. Enfoque Nacional e

Internacional, $\mathrm{N}^{\circ} 2$.

https://ucu.edu.uy/sites/default/files/facultad/fce/dnii/La_ASEAN_ y_el_MERCOSUR_similit udes_diferencias_y_potencialidades.pdf

BARTESAGHI, I. (2018). Las relaciones comerciales entre Uruguay e Indonesia. Informe elaborado en el marco de la Cátedra Mercosur-ASEAN.

Bartesaghi, I., \& Melgar, N. (2019). Oportunidades de Uruguay en Asia: el caso de la Asociación de Naciones del Sudeste Asiático. Revista Diplomática 2 a Época. Vol. 1, pp. 83-92.

CAnCillería Argentina (26 de abril de 2019). Primera Ronda de Negociaciones MERCOSUR-Singapur.

https://www.cancilleria.gob.ar/es/actualidad/noticias/primera-rondade-negociaciones- mercosur-singapur

MARÍA, N. D., \& PEREIRA, M. E. (2016). Estrategias de inserción internacional del MERCOSUR y la ASEAN. Revista PUCE. Num. 103, pp. 273-297.

MufFord, T. L. (2017). A right for All: Freedom of religion or belief in Asian. United States Commission on International Religious Freedom. Washington, D.C.

PEREZ, M. (2012). Cooperación y Regionalismo entre MERCOSUR y la ASEAN Pacific. Buenos Aires: Universidad di Bologna - Representación en Buenos Aires.

Rubiolo, F. (2015). Argentina-Indonesia: Frotalecimiento de las relaciones comerciales y despertar del interés político en el marco de una estrategia Sur-Sur. Revista Ad-Minister, pp. 34-50.

Rubiolo, F. (2017). Argentina y el Sudeste de Asia en los noventa: análisis de una vinculación central para la actual estrategia Sur-Sur. Buenos Aires: Eduntref. 


\title{
INTERVENIR O NO INTERVENIR: EL DESAFÍO DE CREAR UN SISTEMA REGIONAL DE DERECHOS HUMANOS EN LA ASEAN
}

\author{
Alejandro Lamarque \\ Universidad de Buenos Aires \\ alejandro.lamarque@gmail.com
}

\section{Introducción}

El himno oficial de la Asociación de Naciones del Sudeste Asiático (ASEAN por sus siglas en inglés) sintetiza en pocas estrofas el espíritu de un proyecto de integración regional de más de cinco décadas. Unidad, prosperidad y paz son las metas compartidas por un conjunto de naciones ante el desafío de posicionarse en un sistema de relaciones internacionales poblado de viejas y nuevas potencias. Es así como la ASEAN devino el medio a través del cual la región adquiere identidad propia, vertebrando su proyección e inserción en el escenario global.

Con el tiempo, el interés internacional por el bloque ASEAN ha destacado su capacidad de sentar bases firmes para la cooperación entre los países de una región marcada por su diversidad política, geográfica, religiosa, étnica y económica. Ante todo, los admirables desempeños económicos de la región han predominado en las discusiones sobre esta iniciativa regional. Sin embargo, tal como indica la quinta estrofa de su himno oficial - For peace, our goal from the very start"-, los primeros avances y éxitos de la ASEAN no fueron en cuestiones económicas sino en cuestiones securitarias.

Este ensayo propone tomar en consideraciones los alcances y limitaciones de este nuevo sistema regional de derechos humanos. Para ello, la primera parte detalla el desarrollo de la ASEAN como respuesta a imperativos de seguridad en una región inestable. La atención se centra en contextualizar la importancia del principio de no intervención, mostrando su incidencia en cada desarrollo o iniciativa de la asociación. Luego se procede a describir el desarrollo del incipiente sistema de derechos humanos en un período de profundo cambio institucional. Por último, la tercera parte puntualiza las limitaciones del sistema regional de derechos humanos como cristalización de dos perspectivas en disputa. 
Intervenir o no intervenir: el desafío de crear un sistema regional de derechos

humanos en la ASEAN

ALEJANDRO LAMARQUE

\section{Orígenes de ASEAN: el principio de no intervención como fundamento de la seguridad regional}

Tras su creación en 1967, las prioridades de la ASEAN no podían ser otras que no fueran la seguridad regional. ${ }^{1}$ El contexto de inestabilidad política nacional y regional en las primeras décadas de posguerra fue uno de los problemas compartidos por cada uno de los Estados del Sudeste Asiático (SEA), y fue anterior al comienzo del proceso de integración. Así las jóvenes naciones de la región emprendieron la formación de una organización regional capaz de aliviar tensiones y facilitar la discusión, contención y resolución pacífica de los conflictos entre Estados.

A lo largo de cinco décadas de existencia, la ASEAN se constituyó en una instancia articuladora de la seguridad regional en el SEA. Esto no es una cuestión menor, dado el pasado de desconfianza y enfrentamientos entre los países de la región. En igual medida, la incertidumbre respecto a la paz y seguridad sigue siendo hasta hoy de suma importancia, no solo para los Estados, sino también para sus poblaciones que han vivido procesos de violencia extrema.

Como indica Bellamy (2014), durante la Guerra Fría la región fue un epicentro de los dos grandes conflictos: por una parte, la lucha entre ideologías comunistas y anticomunistas y por otra, entre la descolonización y la construcción de los Estados nacionales. En el contexto de estos conflictos, la violencia extrema contra civiles llegó a ser considerada una herramienta para asegurar los objetivos planteados a un costo "razonable".

La región vivió picos de violencia en las décadas de los años 60 y 70 con el asesinato de opositores -presuntos comunistas- en Indonesia y Filipinas, la intensificación de la guerra en Indochina, la invasión Indonesia a Timor Leste, las campañas contra milicias étnicas en Myanmar, el régimen de Kampuchea Democrática en Camboya y una multiplicidad de conflictos étnicoreligiosos e independentistas en regiones como Aceh, Papúa Occidental, Sulawesi y Molucas, Mindanao, sur de Tailandia, Rakhine, Sabah y Sarawak (Bellamy, 2014; Cribb, 2013; Urgell, 2007).

Con el tiempo y bajo el influjo de las circunstancias, la ASEAN se reformó para adaptarse a los nuevos desafíos que se abrían con los cambios geopolíticos y sus influencias en la región. Simultáneamente, a la puesta en marcha de una Comunidad ASEAN, la Asociación dio pasos firmes y rápidos en la creación de un sistema regional de derechos humanos. Esto fue tomado con sorpresa e incluso escepticismo por parte de la comunidad internacional.

1 Para profundizar en el tema ver Rubiolo, 2006; Tang, Wilhelmy von Wolff \& Fajardo Vallejo, 2007; Kelin, Som, Saludin, Shuib \& Ajis, 2011; Davies, 2013; Bartesaghi, 2014 y Emmers, 2016. 
Intervenir o no intervenir: el desafío de crear un sistema regional de derechos

humanos en la ASEAN

ALEJANDRO LAMARQUE

Los instrumentos y dispositivos desarrollados hasta la fecha se han desarrollado no sin dificultades, ya que cristalizan las tensiones entre dos principios: por una parte, el de no intervención que estructura cada documento, práctica e institución de ASEAN. Por otra, la responsabilidad de proteger que se ha afianzado como norma internacional y genera expectativas sobre cómo responder ante el genocidio y los crímenes masivos (Bellamy, 2015). El resultado de ésta "síntesis", como la denomina Davies (2013), resulta en un sistema de derechos humanos diferente al de otras regiones; condicionado por las tensiones entre esos dos principios distintos.

La ASEAN fue el último en una serie de intentos infructuosos de crear instancias regionales de cooperación para los Estados del Sudeste Asiático. Entre fines de los 50s y 60s, se sucedieron distintas iniciativas que variaron en su composición y prioridades. Tal es el caso la Association of Southeast Asia (ASA), creada el 31 de julio de 1961 e integrada por Malasia, Filipinas y Tailandia. Esta asociación pensada para alcanzar paz y estabilidad regional, al igual que cooperación cultural y económica, llegó a su fin por las disputas territoriales de sus miembros en torno a la región de Sabah.

Posteriormente, ASA fue sucedida por MAPHILINDO sigla que hace referencia al acuerdo alcanzado por Malasia, Filipinas (Philippines) e Indonesia en julio de 1963. Esta experiencia regional también llegaría a su fin de la mano de la Konfrontasi entre Malasia e Indonesia respecto a Borneo. No fue hasta la caída del gobierno de Sukarno en Indonesia, en 1967, que el peligro de la confrontación quedó aplacado y se dio una convergencia sobre los beneficios de una organización regional. Esto se materializó en la Declaración de Bangkok que creó la Asociación de Naciones del Sudeste Asiático (ASEAN) con la firma de Malasia, Singapur, Indonesia, Filipinas y Tailandia el 8 de agosto de $1967 .^{2}$

Al surgir en un contexto de grandes tensiones regionales, la ASEAN fue ante todo un foro para forjar confianza entre sus miembros y establecer normas de convivencia. Así, del modo en que los asuntos eran discutidos, las diferencias negociadas y las decisiones tomadas surgió la cultura diplomática del Sudeste Asiático conocida como "ASEAN Way". Como indican Chua y Lim (2018), el rasgo primario de esta cultura es la informalidad de las interacciones entre países, facilitando flexibilidad en las formas de tramitar problemas y tensiones. Esta impronta informal caracterizó el desarrollo institucional de ASEAN durante varias décadas, hasta que la ampliación de sus integrantes y de sus objetivos exigieron una institucionalidad formal firme.

Las características predominantes del estilo ASEAN son la centralidad de las decisiones por consenso y el principio de no intervención en los asuntos de otros Estados tanto de potencias extrarregionales como de países de la

2 Para profundizar ver Tang, Wilhelmy von Wolff \& Fajardo Vallejo, 2007 y Kelin, Som, Saludin, Shuib \& Ajis, 2011. 
Intervenir o no intervenir: el desafío de crear un sistema regional de derechos

humanos en la ASEAN

ALEJANDRO LAMARQUE

región. Dichos asuntos permanecen rigurosamente excluidos en la medida que no tengan incidencia en la estabilidad regional. Este principio se consolidó como el fundamento de la ASEAN con la firma, en 1971, de la Declaración de Kuala Lumpur que establece la Zona de Paz, Libertad y Neutralidad (ZOPFAN). Esta Declaración muestra la voluntad de las cinco naciones de ASEAN de asegurar la región frente a intervenciones de potencias extranjeras a medida que la Doctrina Guam del Presidente Nixon anunciaba la retirada de los Estados Unidos del SEA y la influencia sino- soviética se afirmaba en Indochina (Rubiolo, 2006).

Como sugiere Rubiolo, desde una perspectiva constructivista, el principio de no intervención es un aspecto de la estructura de conocimiento compartido sobre el que se establecen relaciones de cooperación y se define el rol de cada actor. Así, es "el consenso en torno a la primacía de este principio el que permite un nuevo avance hacia el abandono de la conflictividad, y la búsqueda de soluciones de manera conjunta” (Rubiolo, 2006, pp. 23).

Posteriormente, este principio sería reforzado con la firma del Tratado de Amistad y Cooperación (TAC) en la Cumbre de Bali de 1976. Este es un pacto de no agresión entre sus miembros que institucionaliza pautas de conducta como el respeto por la independencia, la soberanía y la integridad territorial, la no intervención en los asuntos internos y la solución pacífica de las controversias (Tang, Wilhelmy von Wolff \& Fajardo Vallejo, 2007). Retomando a Chua y Lim (2018), el TAC hasta el día de hoy es un documento esencial en las relaciones de ASEAN con socios extrarregionales y por ello, las naciones que busquen entablar vínculos de cooperación con ASEAN deben respetar los principios delineados por ese tratado.

La firma del TAC coincide con la intensificación del conflicto en Indochina, que con el tiempo se convertiría en la prueba de fuego de la ASEAN. La frágil estabilidad de la región se vio sacudida en el año 1975 cuando Vietnam avanzó sobre el resto del país tras la retirada de EE.UU. Ese mismo año, el movimiento comunista camboyano liderado por Pol Pot derrotó a las fuerzas del mariscal Lon Nol e inició un proyecto de transformación radical que tendría devastadoras consecuencias para su población.

En el mismo año en que se firmó el TAC, los países de ASEAN firmaron la Declaración de la "Concordia ASEAN". Ambos documentos son un llamado a la resolución pacífica de controversias bajo la sombra amenazante de una expansión del conflicto en Indochina (Rubiolo, 2006). El momento crítico llegó con la invasión de Vietnam a Camboya en diciembre de 1978 tras dos años de enfrentamientos fronterizos. Tal como lo indica la declaración conjunta de la reunión especial de representantes emitida el 12 de enero de 1979, esta invasión violó normas básicas del TAC, como el principio de no intervención, la renuncia al uso de la fuerza y la resolución pacífica de conflictos. Simultáneamente, China invadió Vietnam para salir derrotada poco 
Intervenir o no intervenir: el desafío de crear un sistema regional de derechos

humanos en la ASEAN

ALEJANDRO LAMARQUE

tiempo después sin siquiera comprometer la presencia vietnamita en Camboya. Se inició de este modo un conflicto que marcaría la dinámica regional durante una década y posicionaría a la ASEAN como articulador de la política del SEA ante a los ojos de la comunidad internacional (Chua \& Lim, 2018).

En junio de 1980, Vietnam atacó el pueblo tailandés de Ban Non Mak Moon cerca de la frontera camboyana hasta que la Fuerza Aérea y el Ejército tailandés expulsaron a las fuerzas vietnamitas. Así se concretaban los temores de la ASEAN de un spillover del conflicto en toda la región. Ante la concreción de la amenaza, ASEAN desarrolló una respuesta concertada para la crisis camboyana que como indican Chua y Lim (2018) consistió en tres pilares: primero, el apoyo a las fuerzas nacionalistas de Camboya -como las lideradas por el Príncipe Sihanouk- en contra de la ocupación vietnamita. En segundo lugar, aislar a Vietnam y ejercer presiones diplomáticas, económicas y políticas para entablar negociaciones y alcanzar una solución política que incluyera la retirada total de las fuerzas vietnamitas y la realización de elección libres bajo supervisión internacional. Por último, la búsqueda de una solución política que devolviera a Camboya su soberanía e independencia pero que también atendiera las preocupaciones legítimas de sus vecinos, incluyendo a Vietnam, sobre cuestiones de seguridad.

Más allá de sus divergencias, los cinco países de la ASEAN actuaron concertadamente, presentando con éxito resoluciones de la Asamblea General de Naciones Unidas e impidiendo el reconocimiento del gobierno provietnamita establecido en Camboya. Posteriormente, ASEAN auspició las reuniones informales de Yakarta (Jakarta Informal Meeting I y II) de 1989 que contribuyeron al desarrollo de la Conferencia de París sobre Camboya.

Ese mismo año, ante los efectos de las sanciones económicas y la asistencia menguante de la URSS, Vietnam se vio forzada a retirar sus fuerzas del país vecino. El conflicto culminó con la firma de los Acuerdos de París en 1991 y la ASEAN ganó reconocimiento internacional por sus contribuciones al poner la cuestión camboyana en la agenda internacional y buscando una salida política (Rubiolo, 2006).

Tras la firma de los Acuerdos de Paz, Naciones Unidas asumió la responsabilidad de asegurar una transición pacífica. La Autoridad Provisional de las Naciones Unidas en Camboya asumió las responsabilidades de gobierno y la organización de las primeras elecciones nacionales. También en este proceso, las naciones de ASEAN contribuyeron con personal militar y policial al igual que asesores diplomáticos para asistir al Consejo Supremo Nacional de Camboya liderado por su presidente, el Príncipe Sihanouk (Merican, 2007).

Retomando a Rubiolo (2006), la ASEAN encontró en la gestión del conflicto de Camboya la necesidad de alcanzar unidad, demostrando que el estilo $A S E A N$ de intervenir en conflictos podía brindar respuestas efectivas y decisivas a pesar de las diferencias internas entre cada uno de sus países. Hechos 
Intervenir o no intervenir: el desafío de crear un sistema regional de derechos

humanos en la ASEAN

ALEJANDRO LAMARQUE

concretos como la amenaza vietnamita para Tailandia movilizaron esa posición común por parte de la ASEAN a la vez que los Estados miembros demostraron voluntad de actuar más allá de sus intereses particulares en defensa de la estabilidad regional.

Las mismas funciones de mediación tuvieron lugar en la crisis política de 1997 iniciada por el desplazamiento del Primer Ministro Norodom Ranariddh de la coalición de gobierno por el entonces Co-Primer Ministro Hun Sen. Esta crisis demoró el ingreso de Camboya a la ASEAN, llevando a la creación de la llamada Troika ASEAN (instancia ad-hoc compuesta por tres presidentes del Comité Permanente) para preservar los logros de la UNTAC.

Asimismo, en el año 2011 ASEAN intervino en la disputa fronteriza entre Camboya y Tailandia por la posesión del templo Preah Vihear que incluyó la movilización de tropas y el desplazamiento de miles de habitantes que escaparon de los enfrentamientos. El conflicto comenzó en 2008 pero la ASEAN se abstuvo de intervenir a instancias de los países en disputa que quisieron evitar la internacionalización del conflicto. Sin embargo, a medida que los mecanismos bilaterales fracasaban y el conflicto se agudizaba, el Consejo de Seguridad de Naciones Unidas decidió ceder la responsabilidad de resolver el conflicto a la ASEAN (UN Security Council, 2011). Tras mantener reuniones con las partes, ASEAN decidió enviar observadores de la asociación para supervisar las negociaciones. Si bien la reticencia de Tailandia frustró esta iniciativa, la delegación de responsabilidad de Naciones Unidas a la ASEAN no tenía precedentes en la historia de la organización (Amador \& Teodoro, 2016).

Los instrumentos firmados por los países miembros al igual que su intervención conjunta en momentos de inestabilidad regional evidencian que la función primaria de ASEAN como organización regional es la preservación de la seguridad en el SEA. Como indican Amador y Teodoro (2016), las organizaciones regionales tienen un rol en cuestiones de seguridad internacional porque las regiones son el punto de encuentro entre seguridad nacional y seguridad global.

Los conflictos al interior de los Estados no pueden ser disociados de su ambiente externo y la seguridad de un Estado en particular es inseparable de la seguridad de sus vecinos. La formación de arreglos regionales mediante organizaciones como ASEAN confirma este consenso.

\section{Institucionalización de la ASEAN: hacia una comunidad y el desarrollo de un sistema de derechos humanos}

Como se indicó en la introducción, este ensayo se centra en cuestiones de seguridad y derechos humanos en el marco de la ASEAN por sobre las cuestiones económicas que, a menudo, han sido las más tratadas. Teniendo en 
Intervenir o no intervenir: el desafío de crear un sistema regional de derechos

humanos en la ASEAN

ALEJANDRO LAMARQUE

cuenta esto, bastará mencionar que la paz iniciada luego de la crisis camboyana permitió retomar las metas económicas postergadas durante varias décadas. Así en 1992 los países de la ASEAN se comprometieron a establecer y participar del Área Exclusiva de Libre Comercio (AFTA) y el Acuerdo Marco para el fortalecimiento de la Cooperación Económica en ASEAN. Estos pasos son precursores de los objetivos económicos definidos en la Segunda Declaración de la Concordia que significó la creación de una Comunidad Económica de ASEAN. También se crearon instancias de cooperación con las grandes economías de la región como el llamado ASEAN Más Tres (APT) (Rubiolo, 2006).

La solución del conflicto camboyano abrió una etapa de expansión de la ASEAN hasta incluir a todos los Estados del SEA. Como indican Chua y Lim (2018), la ASEAN fue pensada desde su concepción como una instancia regional inclusiva que incorporara a todos los países del SEA. Hasta no conseguirlo, la ASEAN sería considerada una organización subregional. La ampliación habilitaría que todos los miembros compartieran instancias de diálogo y códigos de conducta comunes para alcanzar sus metas de prosperidad económica y seguridad política. Por eso, a la previa incorporación de Brunéi Darussalam en 1984 siguieron Vietnam (1995), Laos, Myanmar (1997) y Camboya (1999). Timor Leste participó como invitado en varias reuniones especiales de ASEAN, solicitando formalmente convertirse en el onceavo miembro en 2013, aunque todavía no lo ha logrado.

En este período ASEAN no solo expandió su número de miembros sino también su número de socios extrarregionales. La creciente presencia China en la región impulsó la formación de instancias de cooperación multilateral para minimizar posibles enfrentamientos como las tensiones surgidas respecto a la propiedad de las islas del Mar de China Meridional y la península coreana, entre otros.

En función de lo antedicho, en 1994 se creó el Foro Regional de ASEAN (ARF) cuyo programa contempla tres fases: construcción de confianza, diplomacia preventiva y solución de conflictos. ${ }^{3}$ El foro también analiza problemas de seguridad no convencionales como el terrorismo y el crimen internacional. Además, aspirando a conseguir interdependencia en materia de seguridad, el foro promovió el Tratado de Amistad y Cooperación y el código de conducta estándar para las relaciones interestatales (Tang, Wilhelmy von Wolff \& Fajardo Vallejo, 2007).

${ }^{3}$ En la actualidad, los miembros extrarregionales que participan del foro son Australia, Bangladesh, Canadá, China, República Popular Democrática de Corea, Unión Europea, India, Japón, Mongolia, Nueva Zelanda, Pakistán, Papúa Nueva Guinea, República de Corea, Rusia, Sri Lanka y Estados Unidos. 
Intervenir o no intervenir: el desafío de crear un sistema regional de derechos

humanos en la ASEAN

ALEJANDRO LAMARQUE

Hasta entonces, el desarrollo de las funciones de la ASEAN se dio sobre el entramado informal y flexible de relaciones que caracteriza al estilo $A S E A N$. Sin embargo, los eventos que marcaron los últimos años del siglo sacudieron los consensos básicos de esta cultura diplomática e incentivaron procesos de reforma.

Hacia fines de 1997, la crisis asiática evidenció la persistente vulnerabilidad de la región a influencias externas. La capacidad de ASEAN de lidiar conjuntamente con problemas de tal envergadura como los resultantes de la globalización fue puesta en tela de juicio. Asimismo, la asociación fue criticada por no atender eficazmente cuestiones relativas a los derechos humanos y problemas transnacionales como desastres naturales.

En ese ambiente de cuestionamientos, surgieron debates sobre los alcances del principio de no intervención y la institucionalización de la Asociación. Se alzaron voces que los consideraron inadecuados para fundamentar las bases de un orden regional Indo-Pacífico (Acharya, 2009; Davies, 2013, 2014).

El consenso sobre la necesidad de reformas se empezó a manifestar en diciembre de 1997, cuando los representantes de los países miembros firmaron el documento de la Visión de ASEAN 2020. Esta visión plasma un renovado esfuerzo por fortalecer los lazos de integración de la región y por construir una identidad compartida sobre la cual fundar una comunidad. En 2003, se firmó la Declaración de Concordia en Bali, donde se detalla formalmente el establecimiento de la Comunidad ASEAN. Dicha comunidad descansa sobre tres pilares: la cooperación política y de seguridad, la cooperación económica, y la cooperación socio cultura.

Por último, la transición de un modo informal de cooperación hacia un marco institucionalizado se dio mediante una constitución que diera entidad legal a la Asociación para entablar acuerdos vinculantes con sus socios y otras organizaciones internacionales. Con la entrada en vigencia de la Carta en 2008 comienza una nueva etapa de la ASEAN. Se dejan atrás los vínculos flexibles e informales en favor de relaciones institucionalizadas respaldadas por instrumentos codificados vinculantes.

Es durante este clima de discusión de objetivos y procedimientos institucionales, que la ASEAN comienza a desarrollar un sistema regional de derechos humanos como los de Europa, África y las Américas. Es claro, que los derechos humanos no han sido una preocupación prioritaria de ASEAN, sin embargo, en las últimas dos décadas, la Asociación ha desarrollado instrumentos y dispositivos, culminando en una Declaración de Derechos Humanos, sobre la que se fundamenta un incipiente sistema de derechos humanos en el SEA.

Los antecedentes de la Declaración se remontan a la Conferencia Mundial de Derechos Humanos de 1993 realizada en Viena. Allí la ASEAN 
Intervenir o no intervenir: el desafío de crear un sistema regional de derechos

humanos en la ASEAN

ALEJANDRO LAMARQUE

produjo un comunicado conjunto en el que los países miembros se comprometían a considerar el establecimiento de un mecanismo regional de derechos humanos. Posteriormente, la crisis financiera de 1997 y sus graves consecuencias sociales reposiciona a los derechos humanos en las discusiones respecto a reformas institucionales dentro de la asociación.

Como indica Davies (2013), los miembros de ASEAN se dividieron en dos extremos en un espectro progresista-tradicionalista. El extremo progresista atribuyó el fracaso de lidiar con las causas y consecuencias de la crisis a la reticencia de comentar los asuntos internos de los demás Estados. Por otra parte, si bien los tradicionalistas no rechazaron de cuajo todo cambio, mantuvieron una firme decisión de alterar los compromisos con la soberanía estatal y la seguridad vigentes hasta la crisis.

Esta división explica en parte la ausencia de referencias a los derechos humanos en las declaraciones y tratados de la organización. La Visión 2020, el Grupo de Personas Eminentes (EPG) y los Acuerdos de Bali hacen referencias genéricas al bienestar de las sociedades del SEA. Es recién con la continuación de los Acuerdos de Bali, el Programa de Acción de Vientiane, que los derechos humanos comienzan a tener una presencia constante en las discusiones sobre reforma institucional.

En este programa los Estados de ASEAN acuerdan compartir información sobre derechos humanos, poner en marcha programas de trabajo al respecto, articular los mecanismos ya existentes sobre la materia y formar comisiones en defensa de los derechos de las mujeres, los niños y los migrantes (Davies, 2013 y 2014).

Algo determinante en todo este proceso fue enmarcar todas estas discusiones e iniciativas dentro del área de trabajo de la Comunidad de Política y Seguridad. Como indica Davies: "Dentro del pilar de Seguridad los derechos humanos fueron "vendidos" con éxito como algo no radicalmente nuevo, sino como una continuación lógica del compromiso tradicional de la ASEAN con asuntos de seguridad estatal" (Davies, 2013: 53). ${ }^{4}$ Así se llegó a la concreción de los elementos centrales del sistema de derechos humanos: la Declaración de Derechos Humanos ASEAN (AHRD) en 2012 y la Comisión Intergubernamental de Derechos Humanos de la ASEAN (AICHR) en 2009.

\section{Equilibrio entre intervención y no intervención: las limitaciones de los elementos del sistema de derechos humanos de ASEAN}

La "síntesis" descrita por Davies, entre perspectivas progresistas y tradicionalistas, en la creación del sistema regional de derechos humanos

\footnotetext{
${ }^{4} \mathrm{La}$ traducción del inglés al español es del autor.
} 
Intervenir o no intervenir: el desafío de crear un sistema regional de derechos

humanos en la ASEAN

ALEJANDRO LAMARQUE

resultó en la conformación de instrumentos y dispositivos con capacidades limitadas de intervenir en defensa de los derechos humanos de los habitantes del SEA. Como indica Bui (2016) en su análisis de la AHRD y la AICHR, esas restricciones son tanto de índole sustantiva como procedimental.

La principal limitación sustantiva radica en elementos que ponen en cuestión el principio de universalidad de los derechos humanos. A pesar que varios Estados de la región adoptaron tratados y declaraciones de derechos humanos fundados en el principio de universalidad, los gobiernos sostienen ideas particularistas y relativistas.

La AHRD queda condicionada en la medida que no se comprometa el contexto político, económico, religioso y cultural del Estado nacional. Esto en parte ha revivido el viejo debate sobre "valores asiáticos", utilizando argumentos culturalistas y particularistas para eximir a la región de estándares internacionales en distintos rubros (Bui, 2016; Davies, 2013 y 2014).

Por otra parte, los derechos individuales consagrados en estos instrumentos se encuentran balanceados por deberes sociales lo que supone límites claros a la posibilidad de exigir su realización y al deber de protegerlos. Esto quiebra un tema subyacente en los principios universales de derechos humanos ya que los individuos son poseedores de derechos y los Estados son los responsables de garantizarlos. En línea con los argumentos culturalistas, Bui (2016) identifica la contraposición de un presunto "comunitarismo" de las sociedades asiáticos por sobre un "individualismo" de las sociedades occidentales donde deberes no especificados hacia la comunidad condicionarían la defensa de derechos individuales.

Por último, la AHRD condiciona los derechos y libertades ante los imperativos de preservar el estado de derecho, la seguridad nacional y el orden público de los países en cuestión. De este modo, y como sugieren Bui (2016) y Davies (2013 y 2014), los derechos contenidos en la declaración de una entidad regional quedan supeditados a los mandatos y necesidades de las leyes domésticas.

Estas limitaciones serias al potencial del sistema regional de derechos humanos se ven agravadas por las limitaciones a los mecanismos diseñados para su protección. Bui (2016) describe el caso de la AICHR destacando, en primer lugar, su carácter de órgano de consulta intergubernamental lo que dificulta las posibilidades de ejercer accountability en materia de derechos humanos ya que su labor tendría que realizarse con los mismos Estados que debe controlar. Si bien no se puede decir que la Comisión carece de herramientas, estas están condicionadas por la falta de independencia respecto de los gobiernos de ASEAN.

En resumen, la "síntesis" descrita por Davies ha sumido al sistema regional de derechos humanos en un equilibrio entre la seguridad nacional y la seguridad de las personas donde la primera impera sobre la segunda. El 
Intervenir o no intervenir: el desafío de crear un sistema regional de derechos

humanos en la ASEAN

ALEJANDRO LAMARQUE

principio de no intervención continúa estructurando el desarrollo de la Asociación por sobre otras iniciativas de reforma.

\section{Conclusiones}

La historia de ASEAN es la historia de una región que intenta dejar atrás su pasado de inestabilidad política, conflictos interestatales y violencia extrema. Estos desafíos han vertebrado la formación de una empresa destinada a cambiar la lógica imperante en las relaciones internacionales de la región. En dicho camino, el principio de no intervención garantizó la unidad de los miembros en tiempos de crisis, sustituyendo los enfrentamientos por la resolución pacífica y consensuada de los conflictos.

Desde la solución del conflicto de Camboya no ha habido conflictos interestatales graves, confirmando la transformación de la región en un espacio de paz. Sin embargo, un distanciamiento del escenario regional permite ver los desafíos securitarios al interior de las fronteras, donde conflictos viejos y nuevos comprometen los derechos humanos más básicos de los pueblos del SEA. Así como la seguridad estatal no puede separarse de la seguridad regional, la seguridad de los pueblos al interior de las fronteras no debe ser ignorada. La dinámica de los acontecimientos traumáticos guio los impulsos de formación y reforma de la ASEAN.

Queda por ver si un sistema de derechos humanos incapaz de atender las demandas de los pueblos, no será obsoleto ante violaciones de derechos humanos. Violaciones que, de no ser tomadas en cuenta, puedan derivar en conflictos de alcance regional.

\section{Referencias bibliográficas:}

Acharya, A. (2009). Constructing a Security Community in Southeast Asia. ASEAN and the problem of regional order. Routledge, Londres.

AjIS, M.N.; Keling, M.F.; SAludin, M.H.; SHuib, S. y SOM, H. (2011). The Development of ASEAN from Historical Approach, Asian Social Science, Vol.7, No.7, pp. 169-189. Canadian Center of Science and Education.

BARTESAGHI, I. (2014). La ASEAN y el MERCOSUR: similitudes, diferencias y potencialidades, Revista Temas de Derecho Económico. Enfoque Nacional e Internacional, $N^{\circ} 2$, pp. 1-20. Tribunales Ediciones, Buenos Aires, Argentina.

Bellamy, A.J. (2014). The other Asian miracle? The decline of mass atrocities in East Asia, Global Change, Peace \& Security, Vol. 26, No.1, pp. 1-19. Recuperado 
Intervenir o no intervenir: el desafío de crear un sistema regional de derechos humanos en la ASEAN

ALEJANDRO LAMARQUE

https://www.tandfonline.com/doi/abs/10.1080/14781158.2014.86560 0

Bellamy, A.J. (2015). The responsibility to protect turns ten, Ethics \& International Affairs, Vol.29, No.2, pp. 161-185. Carnegie Council for Ethics in International Affairs. Recuperado de: https://www.cambridge.org/core/journals/ethics-and-internationalaffairs/article/responsibility-to-protect-turnsten/ACF97A60B5553FA72E5C4E015FBDB8E7

Bui, H. (2016). The ASEAN Human Rights System: A Critical Analysis, Asian Journal of Comparative Law, II, p. 111-140. National University of Singapore. Recuperado de: https://www.cambridge.org/core/journals/asian-journal-ofcomparative-law/article/asean- human-rights-system-a-criticalanalysis/095F2F8A32A544F1AEEB6A2D89328F1E

CHUA, D. y LIM, E. (2018). ASEAN 50. Regional Security Cooperation though selected documents. S. Rajaratnam School of International Studies. Recuperado de: https://www.worldscientific.com/worldscibooks/10.1142/1047 8

CribB, R. (2013). Political Genocide in Postcolonial Asia, en Bloxham, D. y Dirk Moses, A. (Eds.), The Oxford Handbook of Genocide Studies, pp. 445465. Oxford University Press.

DAvies, M. (2013). The ASEAN Synthesis: Human rights, Nonintervention, and the ASEAN Human Rights Declaration, Georgetown Journal of International Affairs, Vol. 14, No. 2, pp. 51-58. Recuperado de: https://www.georgetownjournalofinternationalaffairs.org/onlineedition/the-asean-synthesis- human-rights-non-intervention-andthe-asean-human-rights-declaration-by-matthew-davies

Davies, M. (2014). An Agreement to Disagree: The ASEAN Human Rights Declaration and the Absence of Regional Identity in Southeast Asia, Journal of Current Southeast Asian Affairs, Vol.33, No.3, pp. 107-129. Recuperado de: http://nbnresolving.org/urn/resolver.pl?urn:nbn:de:gbv:18-4-8086

Emmers, R. (2016). Enduring Mistrust and Conflict Management in Southeast Asia: An Assessment of ASEAN as a Security Community. Institute for East Asian Studies, Sogang University. Recuperado de: https://www.rsis.edu.sg/staff-publication/enduring-mistrust-andconflict-management-in-southeast-asia-an-assessment-of-asean-as-asecurity- community/\#.XkmY-GhKiM8

Fajardo VAllejo, L.M; TANG, P.S. Y Wilhelmy VON WolfF, M. (2007). El Sudeste asiático: estructura y cambio de sus relaciones 
Intervenir o no intervenir: el desafío de crear un sistema regional de derechos humanos en la ASEAN

ALEJANDRO LAMARQUE

internacionales, Estudios Internacionales, 157, pp. 9-26. Instituto de Estudios Internacionales, Universidad de Chile.

JOYCEE, A.T. Y AMADOR, J.S. III (2016). The role of the Association of Southeast Asian Nations in Post-Conflict Reconstruction and Democracy Support. International Institute for Democracy and Electoral Assistance. Recuperado de: https://www.idea.int/es/publications/catalogue/role-associationsoutheast-asian-nations-post- conflict-reconstruction-and

MERICAN, D. (2007). Cambodia "es Engagement with ASEAN: Lessons for Timor Leste, CICP Working Paper, No.14, pp. 1-23. Cambodian Institute for Cooperation and Peace. Recuperado de: http://www.cicp.org.kh/userfiles/file/Working\%20Paper/CICP\%20w orking $\% 20$ paper $\% 2014-$

$\% 20$ Cambodia's $\% 20$ Engagement $\% 20$ in $\% 20$ ASEAN $\% 20$ by $\% 20$ Din $\% 2$ 0Merican.pdf

Rubiolo, M.F. (2006). Asociación de Naciones del Sudeste Asiático: Construcción de una identidad común. Centro Argentino de Estudios Internacionales. Recuperado de: https:/ / racimo.usal.edu.ar/5838/1/P\%C3\%A1ginas $\% 20$ desde'Tesis. $\mathrm{UNI} \% 270045452$.Asociaci $\%$ C3 $\%$ B3n $\% 20 \mathrm{de} \% 20$ naciones $\% 20 \mathrm{del} \% 20$ sudeste $\% 20$ asi $\%$ C3\%A1 tico.pdf

United Nations Security Council, (2011) „Security Council Press Statement on Cambodia- Thailand Border Situation ${ }^{e}$, Press Release SC/10174, 14 February 2011.

Urgell, J. (2007). Guerra y Paz en el Sudeste Asiático, Papeles de cuestiones internacionales, $\quad N^{\circ} 97, \quad$ pp. 125-138. Recuperado de: https://escolapau.uab.cat/img/programas/alerta/articulos/07articulo 056.pdf 

Comité de ASEAN en Buenos Aires

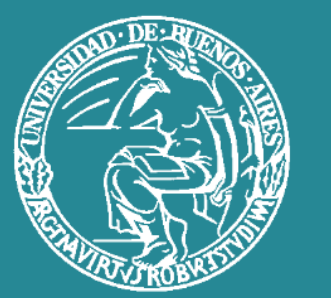

Grupo de Estudios sobre Asia y América Latina Instituto de Estudios de América Latina y el Caribe Universidad de Buenos Aires 